\title{
Novel approaches for developing new antiarrythmic agents
}

PhD Thesis

Claudia Corici, DPharm

Department of Pharmacology and Pharmacotherapy

Faculty of Medicine

University of Szeged

Szeged

Hungary 
TABLE OF CONTENTS

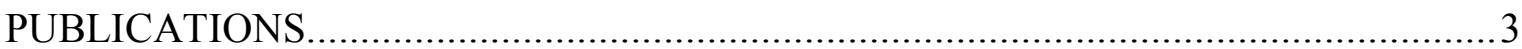

ACRONYMS AND ABREVIATIONS

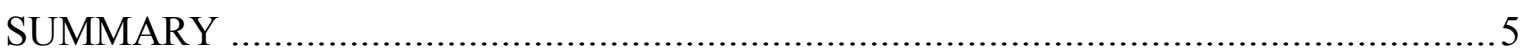

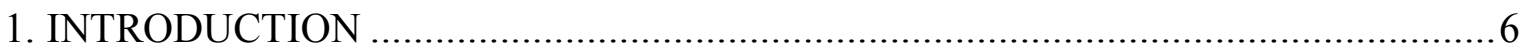

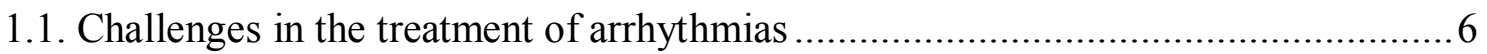

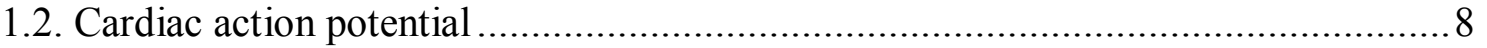

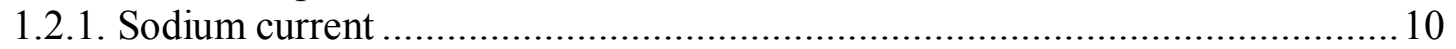

1.2.2. Potassium currents - Delayed rectifier current …...................................... 10

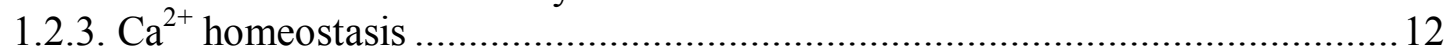

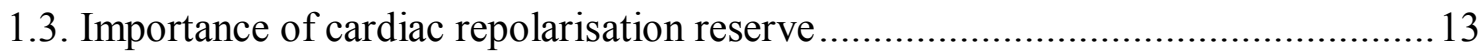

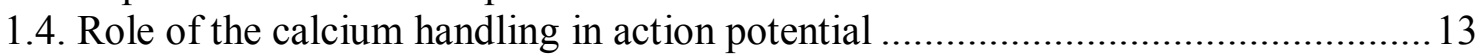

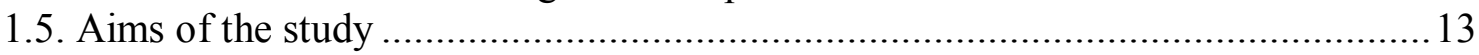

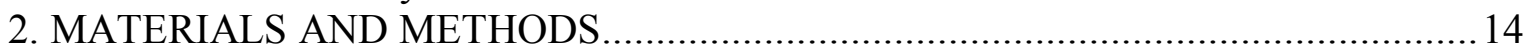

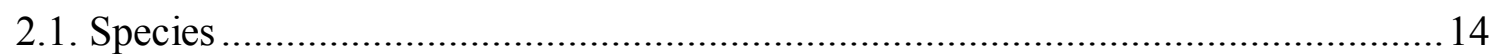

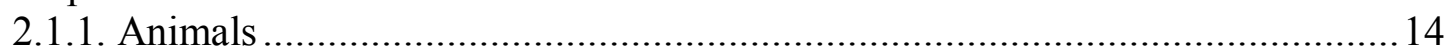

2.1.1.a. Preparation of rabbit ventricular myocytes ....................................... 14

2.1.1.b. Preparation of dog ventricular myocytes ........................................... 15

2.1.1.c. Preparation of guinea pig papillary muscles and ventricular myocytes.... 16

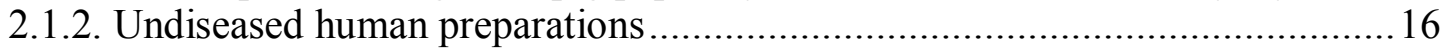

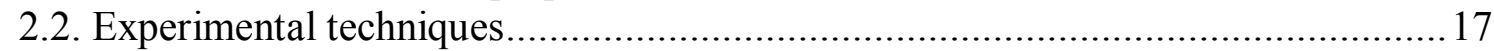

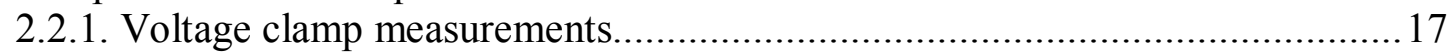

2.2.2. Action potential measurements ............................................................. 20

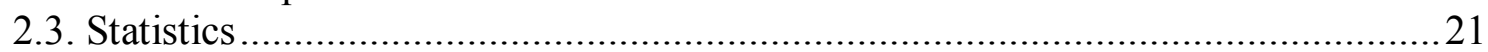

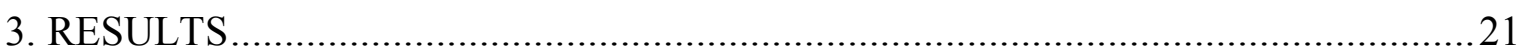

3.1. Effects of the optical enantiomers of R-L3 on $\mathrm{I}_{\mathrm{Ks}}$ in rabbit ventricular myocytes... 21

3.1.1. Chemical structure of R-L3 enantiomers .................................................... 21

3.1.2. The investigation of the effect of R-L3 enantiomers on $\mathrm{I}_{\mathrm{Ks}}$ current ................22

3.1.3. Effect of selective $\mathrm{I}_{\mathrm{Ks}}$ blockade and activation on the APD ..........................2. 24

3.2. The investigation of the properties of the rapid and slow delayed rectifier currents in undiseased human, dog, rabbit and guinea pig ventricular myocytes ...............26

3.2.1. The current-voltage (I-V) relationship of the $\mathrm{I}_{\mathrm{Kr}}$ and $\mathrm{I}_{\mathrm{Ks}}$ currents .................26

3.2.2. The activation and deactivation kinetics of the $\mathrm{I}_{\mathrm{Kr}}$ and $\mathrm{I}_{\mathrm{Ks}}$ currents .................27

3.3. Effects of ORM - 10103 on the NCX current, $\mathrm{I}_{\mathrm{CaL}}, \mathrm{I}_{\mathrm{Na}}$, and $\mathrm{K}^{+}$currents and on the formation of EAD and DAD in the canine hearts ................................................ 31

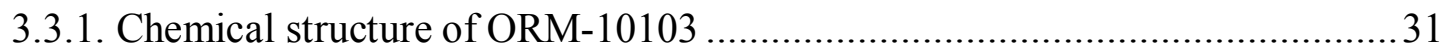

3.3.2. Effects of ORM-10103 on the outward and inward NCX current .................. 32

3.3.3. The effect of ORM-10103 on the L-type inward calcium, inward sodium and outward potassium currents.................................................................. 34

3.3.4. Effects of ORM-10103 on the early and delayed afterdepolarizations ............ 37

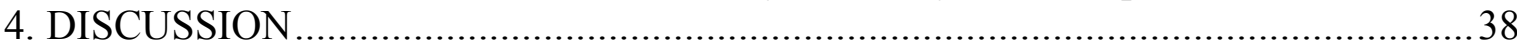

4.1. The effects of the two optical enatiomers of R-L3 ............................................. 38

4.2. Comparison of the properties of the $\mathrm{I}_{\mathrm{Kr}}$ and $\mathrm{I}_{\mathrm{Ks}}$ in human, dog, rabbit and guinea pig

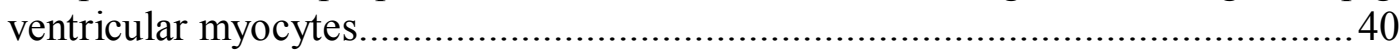

4.3. Effects of the ORM-10103 on the NCX, delayed rectifier potassium current and on

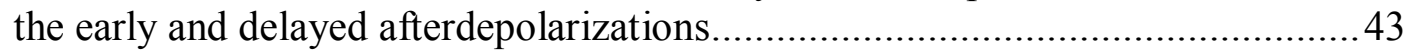

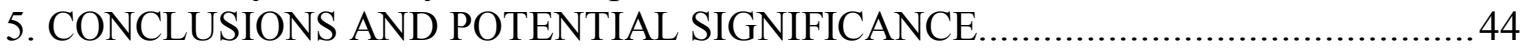

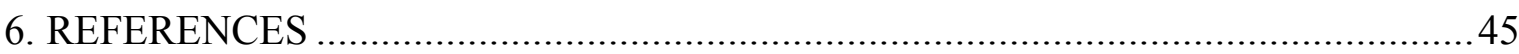

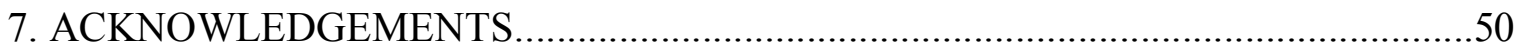




\section{PUBLICATIONS}

\section{LIST OF PUBLICATIONS RELATED TO THE SUBJECT OF THE THESIS}

\section{Full length papers}

I. Corici C, Kohajda Z, Kristóf A, Horvath A, Virág L, Szél T, Nagy N, Szakonyi Zs, Fülöp $F$, Muntean DM, Varró A, Jost N. R-L3 enantiomers have adverse modulating effects on $\mathrm{I}_{\mathrm{Ks}}$ in rabbit ventricular myocytes.

Canadian Journal of Physiology and Pharmacology, 91(8), 648-656, 2013.

IF.: 1,556

II. Jost N, Nagy N, Corici C, Kohajda Zs, Horváth A, Acsai K, Biliczki P, Levijoki J, Pollesello P, Koskelainen T, Otsomaa L, Tóth A, Papp JGy, Varró A, Virág L. ORM10103, a novel specific inhibitor of the $\mathrm{Na}^{+} / \mathrm{Ca}^{2+}$ exchanger, decreases early and delayed afterdepolarizations in the canine heart.

British Journal of Pharmacology, epub, doi: 10.1111/bph.12228, 2013.

IF.: 5,067

\section{Published abstracts}

III/A. Kohajda Zs, Kristóf A, Corici C, Horváth A, Virág L, Fülöp F, Varró A, Papp JGy, Jost $N$. R-L3 enantiomers have adverse modulating effects on $\mathrm{I}_{\mathrm{Ks}}$ in rabbit ventricular myocytes

Cardiologia Hungarica, 42:(Suppl..A), A27, 2012.

III/B. Kohajda Zs, Kristóf A, Corici C, Virág L, Fülöp F, Varró A, Jost N. R-L.3 enantiomers have adverse modulating effects on $\mathrm{I}_{\mathrm{Ks}}$ in rabbit ventricular myocytes.

Cardiovascular Research, 93:(Suppl.1), S23, 2012.

IV. Corici C, Kohajda Zs, Horváth A, Bitay M, Bogáts G, Papp JGy, Virág L, Varró A, Muntean DM, Jost $N$. The investigation of the kinetics of rapid and slow delayed rectifier currents in undiseased human, dog, rabbit and guinea pig ventricular myocytes by applying modern electrophysiological techniques

Abstract of the $21^{\text {st }}$ Meeting of the Alpe Adria Association of Cardiology, Trieste, Italy, June, 7-8, 2013.

\section{OTHER PAPERS NOT RELATED TO THE THESIS}

1. Kohajda Z, Kristóf A, Corici C, Virág L, Muntean DM, Varró A, Jost N. Novel pharmacological strategies for antiarrhythmic therapy in atrial fibrillation. In Treatment Strategies in Cardiology (ed. Laura Hajba; ebook), Volume 3, Issue 2, pp. 50-55, 2011, Publisher: Cambridge Research Centre, London, UK. 
2. Kohajda Zs, Kristóf A, Kovács PP, Corici C, Virág L, Juhász V, Husti Z, Baczkó I, Varró A, Jost $N$. Properties of the transient outward, ultra-rapid delayed rectifier and acetylcholine-sensitive potassium currents in isolated atrial myocytes from dogs: sinus rhythm and tachypaced model of permanent atrial fibrillation.

BMC Pharmacology, 11:(Suppl.2), A60, 2011.

\title{
ACRONYMS AND ABREVIATIONS
}

\author{
AF: atrial fibrillation \\ AP: action potential \\ APA: action potential amplitude \\ APD: action potential duration \\ $\mathbf{A P D}_{\mathbf{5 0}}$ and $\mathbf{A P D}_{\mathbf{9 0}}$ : action potential durations at $50 \%$ and $90 \%$ of repolarization \\ CAST: Cardiac Arrhythmia Suppression Trial \\ CaM: calmodulin \\ CaMKII: Ca2+ -dependent calmodulin-kinase II \\ cAMP: cyclic adenosine-monophosphate \\ CaT: $\mathrm{Ca} 2+$ transient \\ $\mathbf{d V} / \mathbf{d t}_{\text {max }}$ : maximum rate of depolarization \\ DAD: delayed afterdepolarisations \\ DM: dog myocytes \\ EAD: early afterdepolarisations \\ ERP: effective refractory period \\ GM: guinea pig myocytes \\ HM: human donor myocytes \\ HP: holding potential \\ $\left[\mathrm{Ca}^{2+}\right]_{\mathrm{i}}$ : intracellular $\mathrm{Ca}^{2+}$ \\ $\mathbf{I}_{\mathrm{Ca}}: \mathrm{Ca}^{2+}$ current \\ $\mathbf{I}_{\mathbf{K} 1}$ : inward rectifier $\mathrm{K}^{+}$current \\ $\mathbf{I}_{\mathbf{K r}}$ : rapid component of the delayed rectifier $\mathrm{K}^{+}$current \\ $\mathbf{I}_{\mathbf{K s}}$ : slow component of the delayed rectifier $\mathrm{K}^{+}$current \\ $\mathbf{I}_{\mathbf{K}(\mathbf{A T P})}$ : ATP-sensitive potassium current \\ $\mathbf{I}_{\mathrm{Na}}: \mathrm{Na}^{+}$current \\ $\mathbf{I}_{\text {NaK }}: \mathrm{Na}^{+} / \mathrm{K}^{+}$pump current \\ $\mathbf{I}_{\mathbf{t o}}$ : transient outward $\mathrm{K}^{+}$current \\ LQT1: long-QT syndrome \\ NCX: $\mathrm{Na}^{+}-\mathrm{Ca}^{2+}$ exchanger \\ ORM-10103 : NCX inhibitor \\ R-L3: benzodiazepine derivative L-364,373, $\mathrm{I}_{\mathrm{Ks}}$ current activator ( $d$-enantiomer) \\ RM: rabbit myocytes \\ RP: resting membrane potential \\ SR: sarcoplasmic reticulum \\ SWORD: Survival With Oral D-sotalol \\ $\mathbf{V}_{\text {max }}$ : maximum rate of depolarization \\ VF: ventricular fibrillation \\ VT: ventricular tachycardia
}




\section{SUMMARY}

Arrhythmias are a major public health concern. The most common forms of arrhythmias leading to a high risk of cardiac morbidity and mortality are atrial fibrillation (AF) and ventricular tachycardia/ventricular fibrillation (VT/VF). We focus on ionchannel activation and blockade and the role of intracellular $\mathrm{Ca}^{2+}$ as key elements in generating arrhythmias.

The aims of the present study were:

To analyze the effect of the two optical enantiomers of the benzodiazepine R-L3 (ZS_1270B and ZS_1271B) on $\mathrm{I}_{\mathrm{Ks}}$ current in rabbit isolated ventricular myocytes.

To investigate and to compare the properties (including amplitudes, current-voltage relationships, activation and deactivation kinetics) of the rapid and slow components of the delayed rectifier potassium current $\left(\mathrm{I}_{\mathrm{Kr}}\right.$ and $\left.\mathrm{I}_{\mathrm{Ks}}\right)$ in ventricular preparations isolated from dog, rabbit and guinea pig hearts and from undiseased human cardiac muscle.

To investigate the electrophysiological effects of ORM-10103, a newly synthetised specific sodium/calcium exchanger (NCX) inhibitor, on the NCX and L-type $\mathrm{Ca}^{2+}$ currents and on the triggered arrhythmias (formation of early and delayed afterdepolarizations).

\section{Our results demonstrate:}

$\checkmark$ The two optical enantiomers of R-L3 (ZS_1270B and ZS_1271B) have adverse modulating effects on $\mathrm{I}_{\mathrm{Ks}}$ in the same concentration range. ZS_1270B is a potent activator of $\mathrm{I}_{\mathrm{Ks}}$, therefore, this substance is adequate to test whether $\mathrm{I}_{\mathrm{Ks}}$ activators are indeed ideal tools to suppress ventricular arrhythmias originating from prolongation of action potentials.

$\checkmark$ The human cardiac delayed rectifier potassium currents best resemble those measured in the dog ventricle and rabbit heart, but are dissimilar to the kinetic properties of $\mathrm{I}_{\mathrm{Kr}}$ and $\mathrm{I}_{\mathrm{Ks}}$ found in guinea pig. Based also on our studies the $\mathrm{I}_{\mathrm{Kr}}$ current plays the most important role in cardiac repolarization, and our findings suggest that the dog and the rabbit are suitable species for preclinical evaluation of new drugs believed to affect cardiac repolarisation.

ORM-10103 possesses strong NCX-inhibitory activity and it is able to suppress elementary arrhythmogenic phenomena, such as EAD and DAD. 


\section{INTRODUCTION}

Arrhythmias are a major public health concern. The most common forms of arrhythmias leading to a high risk of cardiac morbidity and mortality are atrial fibrillation (AF) and ventricular tachycardia/ventricular fibrillation (VT/VF). "Arrhythmia" refers to any change in the normal sequence and/or shape of electrical impulses during the cardiac cycle. We focus on ion-channel activation and blockade and the role of intracellular $\mathrm{Ca}^{2+}$ as key elements in generating arrhythmias (1).

\subsection{Challenges in the treatment of arrhythmias}

The available antiarrhythmic drugs (AA) can be classified by the Vaughan Williams 4 - level schema or by the mechanistic and clinically relevant Sicilian Gambit. The Vaughan Williams schema is somewhat outdated because antiarrhythmic drugs have complex actions that do not easily fit into 1 of the 4 specified classes of drug effects (2). The Sicilian Gambit, introduced in 1991, was an attempt to provide a classification of antiarrhythmic drugs based on their mechanism of action and on arrhythmogenic mechanism $(3,4)$.

\begin{tabular}{|c|c|c|c|}
\hline $\begin{array}{l}\text { Class I } \\
\text { Drugs that delay fast sodium } \\
\text { channel mediated conduction }\end{array}$ & $\begin{array}{l}\text { Class II } \\
\text { Sympathetic } \\
\text { antagonists }\end{array}$ & $\begin{array}{l}\text { Class III } \\
\text { Drugs that } \\
\text { prolong } \\
\text { repolarisation }\end{array}$ & $\begin{array}{l}\text { Class IV } \\
\text { Calcium } \\
\text { antagonists }\end{array}$ \\
\hline $\begin{array}{l}\text { IA } \\
\text { Depress phase } 0 \\
\text { Delay conduction } \\
\text { Prolong repolarisation } \\
\text { Disopyramide, Procainamide, Quinidine } \\
\text { IB } \\
\text { Little effect on phase } 0 \text { in normal tissue } \\
\text { Depress phase } 0 \text { in abnormal tissue } \\
\text { Shorten repolarisation or little effect } \\
\text { Diphenylhydantoin, Lidocaine, } \\
\text { Mexiletine, } \\
\text { Tocainide } \\
\text { IC } \\
\text { Markedly depress phase } 0 \\
\text { Markedly slow conduction } \\
\text { Slight effect on repolarisation } \\
\text { Flecainide, Moricizine, Propafenone }\end{array}$ & $\begin{array}{l}\text { Acebutolol } \\
\text { Betaxolol } \\
\text { Bisoprolol } \\
\text { Bucindolol } \\
\text { Carvedilol } \\
\text { Esmolol } \\
\text { Metoprolol } \\
\text { Nadolol } \\
\text { Propranolol } \\
\text { Timolol } \\
\text { Others }\end{array}$ & $\begin{array}{l}\text { Amiodarone } \\
\text { Azimilide } \\
\text { Bretylium } \\
\text { Dofetilide } \\
\text { Ibutilide } \\
\text { Sotalol } \\
\text { Tedisamil }\end{array}$ & $\begin{array}{l}\text { Diltiazem } \\
\text { Nifedipine } \\
\text { Nisoldipine } \\
\text { Verapamil }\end{array}$ \\
\hline
\end{tabular}

Figure 1. The Vaughan Williams classification of antiarrhythmic drugs (adapted from 5). 
In the past, drug treatment of cardiac arrhythmias has proven difficult, both because of inadequate effectiveness and a risk of serious complications. In spite of the important advances in cardiology, the pharmacological treatment of cardiac arrhythmias remained empiric to a large extent because of our incomplete understanding of either physiological and pathophysiological processes underlying the cardiac rhythm disturbances and the mechanisms by which antiarrhythmic drugs prevent, suppress, and in some cases also induce, arrhythmias. Therefore, in order to develop new more effective agents with less proarrhythmic potency, it is important to understand the mechanism of action of antiarrhythmic drugs at the organ, tissue, cellular and also subcellular levels $(\mathbf{1 , 6 , 7 )}$.

Pharmacological treatment of arrhythmias still raises a number of problems, there have been dramatic examples in the past, and studies of the effectiveness of antiarrhythmic drugs at ventricular levels have shown an increase in mortality directly related to drug side-effects. The Cardiac Arrhythmia Suppression Trial (CAST) evaluated the effect of antiarrhythmic therapy (encainide, flecainide, or moricizine) in patients with asymptomatic or mildly symptomatic ventricular arrhythmia (six or more ventricular premature beats per hour) after myocardial infarction in order to see whether antiarrhythmic therapy reduces the risk factor for sudden death in survivors of myocardial infarction with occurence of ventricular premature depolarizations. During an average of 10 months of follow-up, the patients treated with active drug had a higher rate of death from arrhythmia than the patients assigned to placebo. Because of these results, the part of the trial involving encainide and flecainide has been discontinued. It was concluded that neither encainide nor flecainide should be used in the treatment of patients with asymptomatic or minimally symptomatic ventricular arrhythmia after myocardial infarction, even though these drugs may be effective initially in suppressing ventricular arrhythmia (8,9).

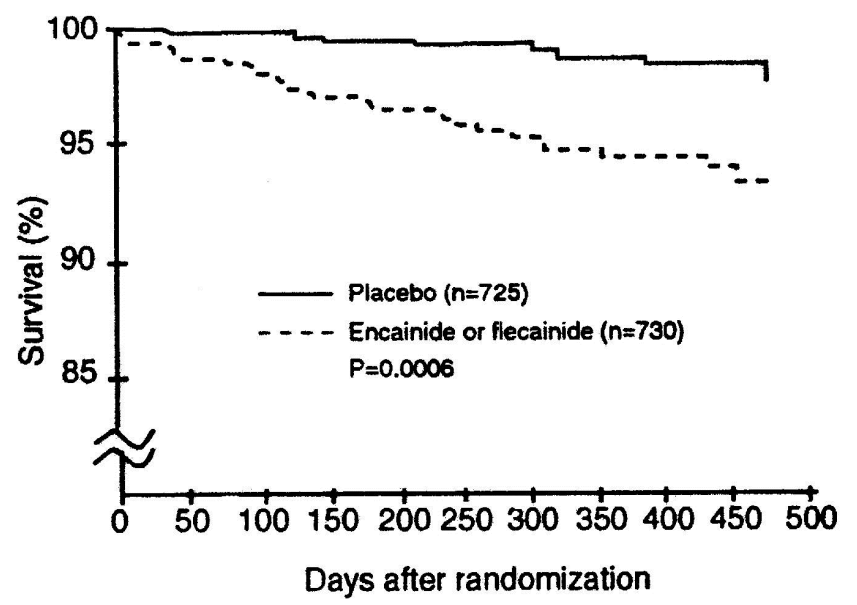

Figure 2. Higher rate of survival with placebo compared with patients taking encainide or flecainide in the Cardiac Arrhythmia Suppression Trial (CAST, adapted from $\mathbf{8}$ ) 
The SWORD (Survival With Oral D-sotalol) study investigated, whether d-sotalol, a pure potassium-channel blocker with no clinically significant beta-blocking activity, could reduce all-cause mortality in high-risk patients, because other studies have suggested that potassium-channel blockers might reduce the this risk. Among the recruited patients, administration of d-sotalol was associated with increased mortality, which was presumed primarily to be due to arrhythmias. The prophylactic use of the potassium-channel blocker d-sotalol did not reduce mortality, and was associated with increased mortality in high-risk patients after myocardial infarction (10).

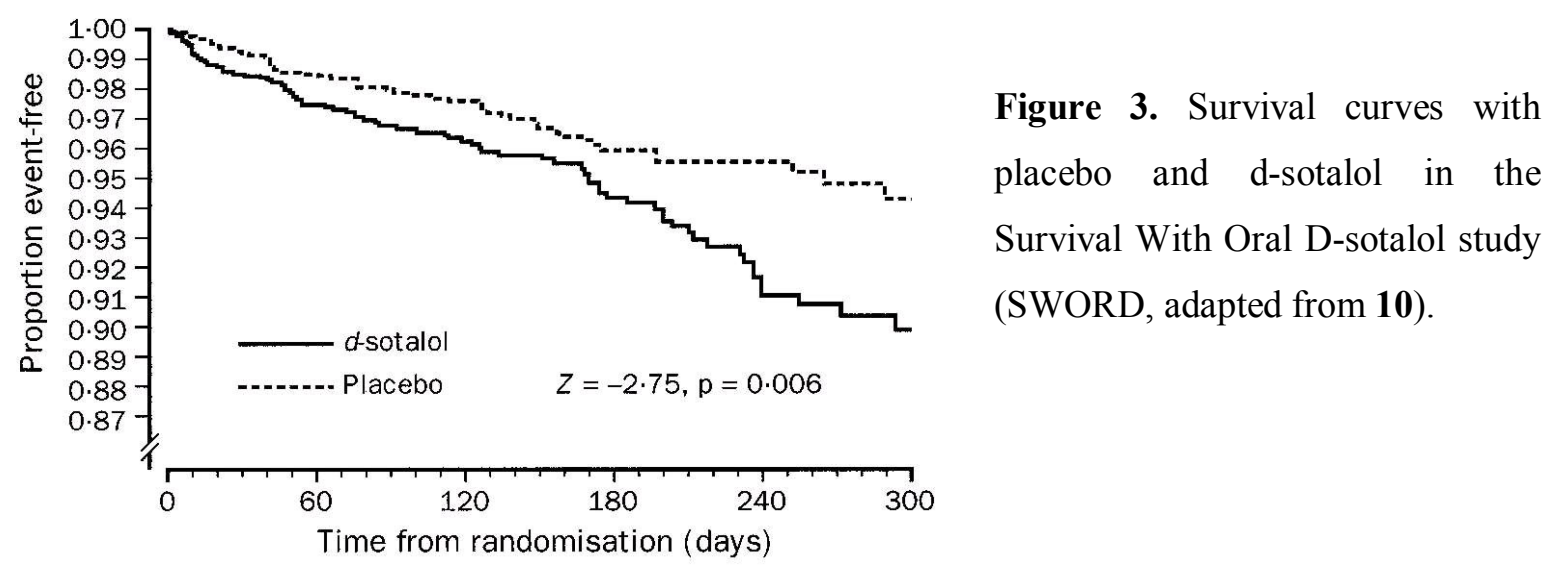

At the cellular level, arrhythmias are generated by multifaceted interplay between different types of ion channels and/or disordered $\mathrm{Ca}^{2+}$ signalling.

\subsection{Cardiac action potential}

The shape and the duration of cardiac action potential are determined by a balance, (i.e. activation and inactivation) of inward and outward currents. The cardiac electrical cycle has been schematically divided in five "phases", four of them describing the AP contour and one the diastolic interval (Figure 4). Phase 0 occurs when the excitation threshold is exceeded, being supported by activation of two inward (depolarizing) currents, fast $\mathrm{Na}^{+}\left(\mathrm{I}_{\mathrm{Na}}\right)$ current and $\mathrm{Ca}^{2+}$ current. $\mathrm{I}_{\mathrm{Na}}$ is large and provides most of the charge influx required for propagation. $\mathrm{I}_{\mathrm{CaL}}$ mediates most of $\mathrm{Ca}^{2+}$ influx required to trigger myocyte contraction and may support propagation when $\mathrm{I}_{\mathrm{Na}}$ is not expressed or functional (e.g. in the nodes). Phase 0 depolarization also activates $\mathrm{K}^{+}$currents, which contribute to termination of this phase and to subsequent repolarization. Among these, the transient outward current $\left(I_{t o}\right)$ is sufficiently fast to limit depolarization rate during phase 0 . Phase 1 is the initial phase of repolarization, mainly supported by $\mathrm{I}_{\mathrm{to}}$, which is activated and quickly inactivated by depolarization. Thus, $\mathrm{I}_{\text {to }}$ supports fast repolarization (11). 


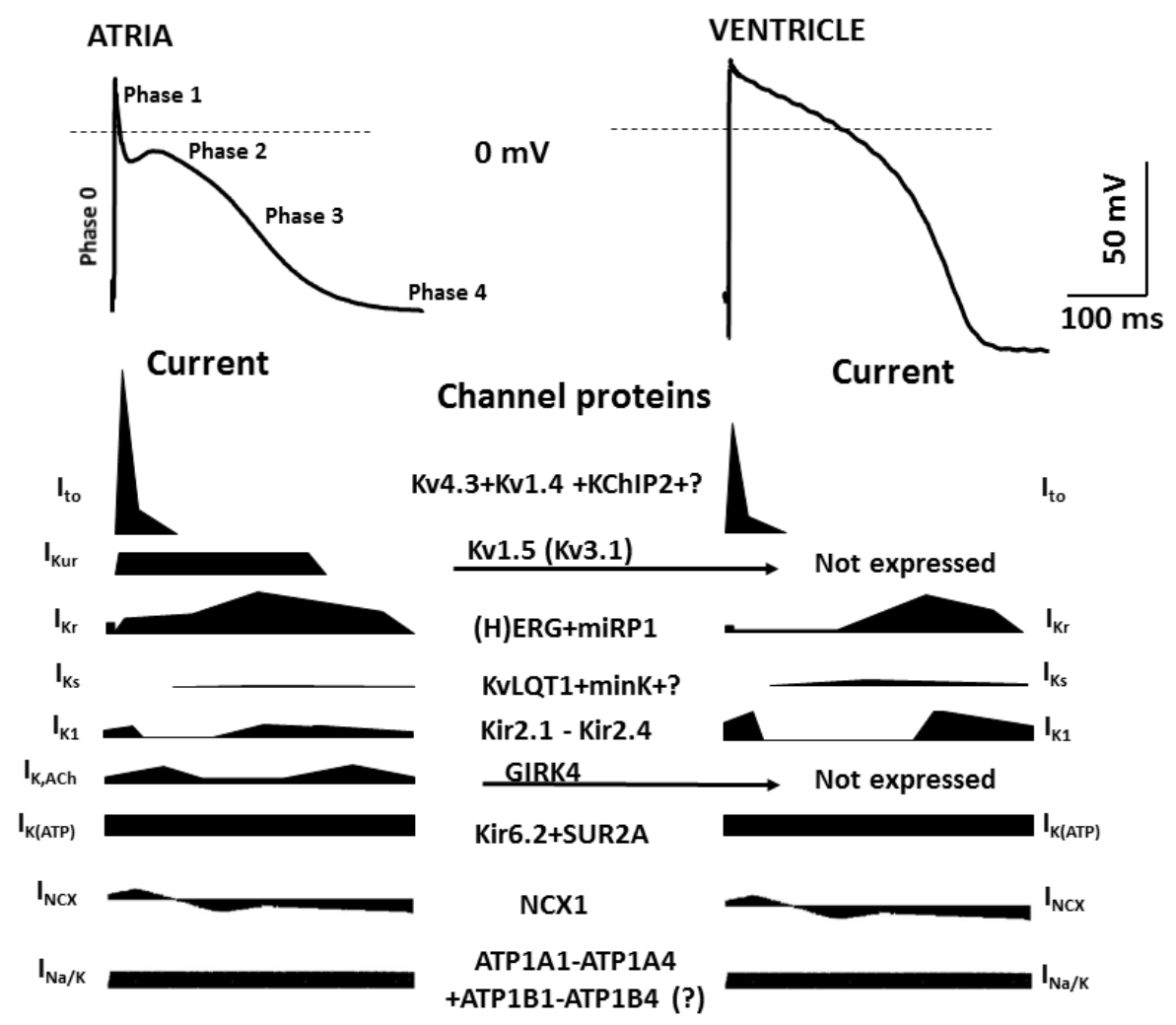

Figure 4. Phases of a prototypical atrial and ventricular action potentials (AP) and underlying ion currents. The numbers refer to the five phases of the action potential. In each current profile the horizontal line represents the zero current level; inward currents are below the line and outward ones are above it (modified from 12).

Phase 2, also named AP "plateau", is the slow repolarization phase, the late components of inward currents (late $\mathrm{I}_{\mathrm{Na}}$, late $\mathrm{I}_{\mathrm{Ca}}$ ) oppose the outward repolarizing currents i.e. the rapid and slow components $\left(\mathrm{I}_{\mathrm{Kr}}\right.$ and $\mathrm{I}_{\mathrm{Ks}}$ ) of the delayed rectifier $\mathrm{K}^{+}$current and the inward rectifier $\mathrm{K}^{+}$current $\left(\mathrm{I}_{\mathrm{K} 1}\right)$ (13). The current generated by operation of the $\mathrm{Na}^{+} / \mathrm{Ca}^{2+}$ exchanger $\left(\mathrm{I}_{\mathrm{NCX}}\right)$ can variably contribute to phase 2, according to the magnitude and course of the cytosolic $\mathrm{Ca}^{2+}$ transient and to the subsarcolemmal $\mathrm{Na}^{+}$levels (14). Phase 3 is the terminal phase of repolarization, which differs from phase 2 for its faster repolarization rate. Phase 3 is dominated by $\mathrm{I}_{\mathrm{Kr}}$ and $\mathrm{I}_{\mathrm{K} 1}$, both characterized by a kinetic property, named "inward rectification" $(\mathbf{1 5 , 1 6 , 1 7 )}$. The loss of one repolarizing current may not lead to excessive AP lengthening, since other unimpaired $\mathrm{K}^{+}$channels may provide sufficient repolarizing capacity, i.e. there is a redundancy of the repolarization process ('repolarization reserve'). The key players of the reserve are $\mathrm{I}_{\mathrm{Kr}}, \mathrm{I}_{\mathrm{Ks}}, \mathrm{I}_{\mathrm{K} 1}$, and presumably $\mathrm{I}_{\text {to }}(\mathbf{1 8 , 1 9 )}$. Phase 4 describes membrane potential during diastole. Besides the time-dependent currents, specific for each AP phase, time-independent (or "background") currents may also contribute to the whole AP course. These mainly include the $\mathrm{Na}^{+} / \mathrm{K}^{+}$ 
pump current $\left(\mathrm{I}_{\mathrm{Na} / \mathrm{K}}\right)$, the $\mathrm{Na}^{+} / \mathrm{Ca}^{2+}$ exchanger current $\left(\mathrm{I}_{\mathrm{NCX}}\right)$ and the ATP-sensitive potassium current $\left(\mathrm{I}_{\mathrm{K}(\mathrm{ATP})}\right)$.

\subsubsection{Sodium current}

The $\mathrm{Na}^{+}$current $\left(\mathrm{I}_{\mathrm{Na}}\right)$ activates and inactivates within a few milliseconds. In the limited range of membrane potentials where activation and inactivation curves of the $\mathrm{I}_{\mathrm{Na}}$ overlap, a small persistent $\mathrm{Na}^{+}$current could be observed (late sodium current, $\mathrm{I}_{\mathrm{NaL}}$ ). The slow inactivation or 'window current' may still provide a significant amout of $\mathrm{Na}^{+}$ions, which can modulate $\mathrm{Ca}^{2+}$ handling via the reverse activity of $\mathrm{NCX}$. The gating of $\mathrm{I}_{\mathrm{Na}}$ may also be modulated by intracellular calcium $\left[\mathrm{Ca}^{2+}\right]_{\mathrm{i}}$, however, the exact mechanism (i.e. via direct $\mathrm{Ca}^{2+}$ binding to the channel or via the CaM/CaMKII pathway) is not yet fully clarified. Maltsev (20) reported that all proposed modulatory pathways might be responsible for the modulation of the $\mathrm{Na}^{+}$- channel: CaMKII slows the decay of $\mathrm{I}_{\mathrm{NaL}}$, while $\left[\mathrm{Ca}^{2+}\right]_{\mathrm{i}}$ shifts the steady-state inactivation level towards more positive potentials $(1,21,22)$.

The blockade of the $\mathrm{Na}^{+}$current slows conduction, which could help prevent arrhythmias by transforming an unidirectional block into a bidirectional one. But this slowing conduction can also promote reentry by decreasing wavelength. This could be the reason for the failure of Class IC drugs in the CAST (1989) (8).

\subsubsection{Potassium currents - Delayed rectifier current}

The delayed rectifier potassium current $\left(\mathrm{I}_{\mathrm{K}}\right)$ is considered to be one of the most important transmembrane ionic current controlling repolarisation in mammalian ventricular muscle $(\mathbf{2 3 , 2 4 , 2 5 )}$. The majority of antiarrhythmic drugs, which exert their effect by lengthening cardiac repolarisation (Class I/A and III) are usually blockers of this current. This current was first described by Noble and Tsien in sheep cardiac Purkinje fibre (26) and has since been identified in various species and cardiac tissue types $\left(\mathbf{2 7 , 2 8 , 2 9 )}\right.$. In most species $I_{K}$ consists of two components, $I_{K r}$ (rapid) and $I_{K s}$ (slow). These two components differ from each other with respect to their drug sensitivity, rectification and kinetical properties $(\mathbf{3 0}, 31,32)$. The characteristics of these currents have been extensively studied using the patch-clamp technique in ventricular myocytes obtained from several mammalian species. These studies have revealed important species differences in the existence and properties of $\mathrm{I}_{\mathrm{K}}(\mathbf{3 3}, \mathbf{3 4}, \mathbf{3 5})$.

$\mathrm{I}_{\mathrm{Ks}}$ and $\mathrm{I}_{\mathrm{Kr}}$ have been both generally accepted as having important roles during normal cardiac action potential repolarisation (36,37). Specific blockers of $\mathrm{I}_{\mathrm{Kr}}$ (d-sotalol, 
dofetilide, E-4031) have been widely shown to lengthen cardiac APD and this is consistent with their strong antiarrhythmic potency $(\mathbf{3 8 , 3 9 , 4 0 )}$. Despite their favourable antiarrhythmic effect, however, a large international study (SWORD study) revealed an increased mortality in patients treated with the pure Class III, selective $\mathrm{I}_{\mathrm{Kr}}$ blocker antiarrhythmic drug, d-sotalol (10). Pure Class III drugs (i.e. those that block $\mathrm{I}_{\mathrm{Kr}}$ selectively) increase the inhomogeneity of repolarisation and consequently that of the refractoriness $(\mathbf{4 1 , 4 2 )}$. The reverse use-dependent effect of these drugs is also disadvantageous because at slow heart rate it may cause early afterdepolarisations (EAD), which may lead to torsade de pointes type ventricular arrhythmias (43). Great expectations were raised about the antiarrhythmic potential of the pure $\mathrm{I}_{\mathrm{Ks}}$ blockers, which were expected to lengthen the action potential duration (APD) in a frequency-independent manner, therefore, without the unfavourable reverse use-dependent properties, which seems characteristics of the $\mathrm{I}_{\mathrm{Kr}}$ blockers.

The role of $\mathrm{I}_{\mathrm{Ks}}$ current in human ventricular muscle action potential repolarization, on the other hand, has been debated. As with $\mathrm{I}_{\mathrm{Kr}}$, $\mathrm{I}_{\mathrm{Ks}}$ has been identified in several mammalian species, including humans $(\mathbf{4 4}, \mathbf{4 5}, \mathbf{4 6})$ which are associated with specific form of the inherited long-QT syndrome, LQT1 (47). Jost et al. (48) previously demonstrated that complete pharmacological block of $\mathrm{I}_{\mathrm{Ks}}$ by either chromanol 293B or L735,821 has little effect on APD in isolated dog and rabbit ventricular muscle over a wide range of physiological pacing frequencies. They also explained that $\mathrm{I}_{\mathrm{Ks}}$ is the key player of the repolarization reserve, because when APD is abnormally long, $\mathrm{I}_{\mathrm{Ks}}$ likely provides an important safety mechanism that, when removed, increases arrhythmic risk. The high proarrhythmic risk associated with these conditions could be markedly diminished by activation of $\mathrm{I}_{\mathrm{Ks}}$ current, providing thus a promising strategy to increase the repolarization reserve without significantly lengthening of action potential duration. This was long time hampered by lacking of selective $\mathrm{I}_{\mathrm{Ks}}$ agonists. The recently synthesized benzodiazepine derivative L-364,373 (R-L3) has been reported to activate $\mathrm{I}_{\mathrm{Ks}}$ at micromolar concentrations in ventricular myocytes of guinea pig (49) and rabbit (50), as well as in genes encoding the Iks current, KCNQ1 expressed in Xenopus oocytes (51). In a later study RL-3 failed to activate $\mathrm{I}_{\mathrm{Ks}}$ current in dog ventricular myocytes (52); it was shown that $1 \mu \mathrm{M}$ R-L3 did not affect at all $\mathrm{I}_{\mathrm{Ks}}$ current amplitude, while at higher concentration as $3 \mu \mathrm{M}$, the compound even blocked the current. One later study suggested a possible explanation for this discrepancy: the two enantiomers of the racemic R-L3 have different activities, namely that the $d$ enantiomer activates, while the $l$ enantiomer potently blocks 
$\mathrm{I}_{\mathrm{Ks}}(\mathbf{5 3})$.

For preclinical evaluation of new drugs believed to affect cardiac action potential repolarisation it would be useful to find the most "human-like" species. In our study we demonstrate the existence of the $\mathrm{I}_{\mathrm{Kr}}$ and $\mathrm{I}_{\mathrm{Ks}}$ in undiseased human heart, and determine their properties by comparing them to those measured in other mammalians. The study gave also the opportunity to perform an extensive study to reveal the exact mechanism and role of $\mathrm{I}_{\mathrm{Kr}}$ and $\mathrm{I}_{\mathrm{Ks}}$ in controlling cardiac action potential configuration, and therefore, to determine the main source for initiating final cardiac repolarisation.

\subsection{3. $\mathrm{Ca}^{2+}$ homeostasis}

$\mathrm{Ca}^{2+}$ has a central role in excitation-contraction coupling (ECC), since $\mathrm{Ca}^{2+}$ ions entering the cell from the extracellular space $\left(\mathrm{Ca}^{2+}\right.$ - influx $)$ trigger a substantially larger $\mathrm{Ca}^{2+}$ release from the sarcoplasmic reticulum (SR). The transient $\left[\mathrm{Ca}^{2+}\right]_{\mathrm{i}}$ increase $\left(\mathrm{Ca}^{2+}\right.$ transient, $\mathrm{CaT}$ ) is terminated by both $\mathrm{Ca}^{2+}$ reuptake to the $\mathrm{SR}$ (via the activity of the SR $\mathrm{Ca}^{2+}$ pump, SERCA2a), and $\mathrm{Ca}^{2+}$ extrusion (efflux from the cell). Two classes of $\mathrm{Ca}^{2+}$ channels ( $\mathrm{T}$ and $\mathrm{L}$ types) exist in cardiac myocytes, but especially the L-type is well expressed. During depolarization L- type voltage dependent $\mathrm{Ca}^{2+}$ channels exhibit large conductance $\mathbf{( 5 4 , 5 5 )}$.

The sodium/calcium exchanger (NCX) (56) is considered to be a major regulator maintaining the $\mathrm{Ca}^{2+}$ homeostasis in the myocardium $\mathbf{( 5 7 , 5 8 )}$. In the forward mode, NCX is known to extrude $\mathrm{Ca}^{2+}$ from the cell to the extracellular space during the diastole, at relatively low free cytoplasmic $\mathrm{Ca}^{2+}$ concentration and negative transmembrane potential. Since the extrusion of one $\mathrm{Ca}^{2+}$ is coupled with the entry of $3 \mathrm{Na}^{+}$into the cell, the forward mode of the NCX is accompanied by a net inward current; when the intracellular $\mathrm{Ca}^{2+}$ level is elevated, this can cause substantial depolarization, leading to early (EAD) and delayed (DAD) afterdepolarizations (59). EAD and DAD are generally thought to play important roles in arrhythmogenesis $\left(\mathbf{6 0 , 6 1 )}\right.$, especially under conditions when the $\mathrm{K}^{+}$ conductance is decreased, as in heart failure (62). It might be be speculated, therefore, that specific blockers of NCX are potentially antiarrhythmic in dysrhythmias related to a $\mathrm{Ca}^{2+}$ overload $\left(\mathbf{6 3 , 6 4 )}\right.$. The available NCX inhibitors also decreased the L-type $\mathrm{Ca}^{2+}$ current $\left(\mathrm{I}_{\mathrm{CaL}}\right)$ which in turn is known to decrease the intracellular $\mathrm{Ca}^{2+}$ load, thereby indirectly changing the magnitude of NCX. It has previously been demonstrated that KB-R7943 and SEA-0400, effective inhibitors of NCX, reduced the incidence of ischaemia/reperfusion- 
related arrhythmias induced by a $\mathrm{Ca}^{2+}$ overload (65) and decreased the pharmacologically induced $\mathrm{EAD}$ and $\mathrm{DAD}$ in canine ventricular preparations (66).

\subsection{Importance of cardiac repolarisation reserve}

The concept of the repolarization reserve was introduced by Roden in 1998, based mainly on clinical observations (67). The principle of the repolarization reserve is a redundancy of the repolarization process, i.e. loss of one repolarizing current may not lead to excessive AP lengthening, since other unimpaired $\mathrm{K}+$ channels may provide sufficient repolarizing capacity. Therefore, it has critical importance in stabilizing the APD, refractoriness and conduction of the electric impulses. Furthermore, it restricts excessive AP lengthening caused by impaired channel function, e.g. in LQT's, extreme bradycardia, hypokalaemia, hypothyroidism, diabetes mellitus, drug exposure, etc. The repolarization reserve has also important role in decreasing the transmural dispersion of the repolarization, thus preventing cardiac arrhythmias. The key players of the reserve are $\mathrm{I}_{\mathrm{Kr}}$, $\mathrm{I}_{\mathrm{Ks}}, \mathrm{I}_{\mathrm{K} 1}$, and presumably $\mathrm{I}_{\mathrm{to}}$. The majority of life-threatening arrhythmias are known to derive from repolarization abnormalities. Therefore, better understanding of the development of novel strategies to treat arrhythmias requires much more detailed knowledge of the repolarization mechanisms, including all its determinants $(\mathbf{4 5 , 6 8 , 4 8 , 6 9 )}$.

\subsection{Role of the calcium handling in action potential}

By generating net current associated with $\mathrm{Ca}^{2+}$ movement, channels and transporters involved in $\mathrm{Ca}^{2+}$ handling may significantly contribute to the shaping of the action potential. At the beginning of the AP and during the plateau phase, activation of $\mathrm{I}_{\mathrm{CaL}}$ plays a significant role in maintaining the AP plateau, which is essential for the appropriate AP duration. Similarly, because of the $1 \mathrm{Ca}^{2+} / 3 \mathrm{Na}^{+}$stoichiometry of the $\mathrm{Na}^{+} / \mathrm{Ca}^{2+}$-exchange, removal of $\mathrm{Ca}^{2+}$ from the cell via NCX also generates an inward current, which could theoretically slow the repolarization phase of the AP. On the other hand, being an important regulator of many intracellular processes, $\mathrm{Ca}^{2+}$ ions can also regulate/modulate the gating of other channels. Prominent examples are modulation of $\mathrm{I}_{\mathrm{Ks}}, \mathrm{I}_{\mathrm{Kr}}$ and $\mathrm{I}_{\mathrm{K} 1}$ currents (70,71).

\subsection{Aims of the study}

(1) To analyse the effect of the two optical enantiomers of R-L3 (ZS_1270B and ZS_1271B) on $\mathrm{I}_{\mathrm{Ks}}$ current in rabbit isolated ventricular myocytes, by applying the wholecell patch clamp and standard microelectrode techniques. 
(2) To investigate and to compare the electrophysiological properties (including amplitudes, current-voltage relationships, activation and deactivation kinetics) of $\mathrm{I}_{\mathrm{Kr}}$ and $\mathrm{I}_{\mathrm{Ks}}$ currents in ventricular preparations isolated from dog, rabbit and guinea pig hearts and from undiseased human cardiac muscle.

(3) To investigate the electrophysiological effects of ORM-10103, a newly synthetised specific NCX inhibitor, on the NCX and L-type $\mathrm{Ca}^{2+}$ currents and on the triggered arrhythmias (formation of early and delayed afterdepolarizations).

\section{MATERIALS AND METHODS}

\subsection{Species}

Experiments were carried out in ventricular preparations isolated from dog, rabbit and guinea pig hearts and from undiseased human cardiac muscle.

\subsubsection{Animals}

Untreated New-Zealand white rabbits, guinea pig and adult mongrel dogs of either sex (body weights 8 to $16 \mathrm{~kg}$ ) were used for the study. All experiments were conducted in compliance with the Guide for the Care and Use of Laboratory Animals (USA NIH publication No 85-23, revised 1996). The protocols were approved by the Review Board of the Department of Animal Health and Food Control of the Ministry of Agriculture and Rural Development, Hungary (XII./01031/000/2008 and XIII./1211/2012) and Ethical Committee for the Protection of Animals in Research at the University of Szeged, Szeged, Hungary (approval number: I-74-9-2009) and conformed to Directive 2010/63/EU of the European Parliament.

\subsection{1.a. Preparation of rabbit ventricular myocytes}

Untreated New-Zealand white rabbits (body weights $1.5-2 \mathrm{~kg}$ ) of either sex were used for the study. Single ventricular myocytes were obtained by enzymatic dissociation. The animals were sacrificed by cervical dislocation after receiving $400 \mathrm{IU} / \mathrm{kg}$ heparin intravenously. The chest was opened and the heart was quickly removed and placed into cold $\left(4^{\circ} \mathrm{C}\right)$ solution with the following composition $(\mathrm{mM}): \mathrm{NaCl} \mathrm{135,} \mathrm{KCl} 4.7, \mathrm{KH}_{2} \mathrm{PO}_{4}$ 1.2, $\mathrm{MgSO}_{4}$ 1.2, HEPES 10, $\mathrm{NaHCO}_{3} 4.4$, Glucose 10, $\mathrm{CaCl}_{2}$ 1.8, (pH 7.2). The heart was mounted on a modified, $60 \mathrm{~cm}$ high Langendorff column and perfused with oxygenated and prewarmed $\left(37^{\circ} \mathrm{C}\right)$ solution mentioned above. After washing out of blood (3-5 $\left.\mathrm{min}\right)$ it was perfused with nominally Ca-free solution until the heart stopped beating (approx. 3-4 minutes). The digestion was performed by perfusion with the same solution supplemented 
with $0.33 \mathrm{mg} / \mathrm{ml}(90 \mathrm{U} / \mathrm{ml})$ collagenase (Type I, SIGMA Chemical, St. Louis, MO, USA,) and $0.02 \mathrm{mg} / \mathrm{ml}$ Pronase E (SIGMA) with $0.1 \%$ albumin using a perfusion pump (flow rate approx. $15 \mathrm{ml} / \mathrm{min}$ ). In the $15^{\text {th }}$ minute of the enzyme perfusion the calcium concentration was elevated by $200 \mu \mathrm{M}$. After 30-35 minute the heart was removed from the canula and was placed into enzyme free solution containing $1.8 \mathrm{mM} \mathrm{CaCl}_{2}$ and $1 \%$ albumin and equilibrated at $37^{\circ} \mathrm{C}$ for 10 minutes. Then the tissue was cut into small fragments. After gentle agitation, the cells were separated from the chunks by filtering through nylon mesh. Sedimentation was used for harvesting cells; as soon as most myocytes reached the bottom of the vessel the supernatant was removed and replaced by HEPES buffered Tyrode's solution. This solution contained (mM): $\mathrm{NaCl} 144, \mathrm{NaH}_{2} \mathrm{PO}_{4}$ 0.33, $\mathrm{KCl} 4.0, \mathrm{CaCl}_{2}$ 1.8, $\mathrm{MgCl}_{2}$ 0.53, Glucose 5.5, and HEPES 5.0 at $\mathrm{pH}$ of 7.4 containing $1.8 \mathrm{mM} \mathrm{CaCl}_{2}$. This procedure was repeated two times. The cells were stored at room temperature in the Tyrode's solution (72).

\subsection{1.b. Preparation of dog ventricular myocytes}

For voltage clamp and conventional microelectrode experiments, adult mongrel dogs of either sex weighing 8 to $16 \mathrm{~kg}$ were used. Following sedation (xylazine, $1 \mathrm{mg} / \mathrm{kg}$, i.v.) and thiopental (30 mg/kg i.v.)-induced anaesthesia, each heart was rapidly removed through a right lateral thoracotomy and immediately rinsed in oxygenated modified Locke's solution containing (in $\mathrm{mM}$ ): $\mathrm{Na}^{+} 140, \mathrm{~K}^{+} 4, \mathrm{Ca}^{2+} 1.0, \mathrm{Mg}^{2+} 1, \mathrm{Cl}^{-} 126, \mathrm{HCO}_{3}{ }^{-} 25$ and glucose 11 . The $\mathrm{pH}$ of the solution, when gassed with $95 \% \mathrm{O}_{2}$ and $5 \% \mathrm{CO}_{2}$ at $37{ }^{\circ} \mathrm{C}$, ranged from 7.35 to 7.45 .

Ventricular myocytes were enzymatically dissociated from the canine hearts. A portion of the left ventricular wall containing an arterial branch large enough to cannulate was then perfused in a modified Langendorff apparatus, at a pressure of $60 \mathrm{~cm} \mathrm{H}_{2} \mathrm{O}$, with solutions in the following sequence: 1$)$ isolation solution supplemented with $\mathrm{CaCl}_{2}(1.25$ $\mathrm{mM}$ ) for $10 \mathrm{~min}$; 2) isolation solution for another $10 \mathrm{~min}$; 3) isolation solution (150 ml) containing collagenase (type I, $0.33 \mathrm{mg} / \mathrm{ml}$; Sigma Chemical, St. Louis, MO, USA) (10 min). Protease (type XIV, $0.04 \mathrm{mg} / \mathrm{ml}$; Sigma Chemical) was added to the final perfusate and another 15-20 min of digestion was allowed. The isolation solution $\left(\mathrm{Ca}^{2+}\right.$-free) was Eagle, Minimum Essential Medium, Joklik modification (Sigma Chemical), supplemented with (in mM) HEPES 10 and $\mathrm{NaHCO}_{3} 4.4$ (pH 7.2, adjusted with $\mathrm{NaOH}$ ). Portions of the left ventricular wall judged to be well digested were diced into small pieces in isolation solution supplemented with $\mathrm{CaCl}_{2}(1.25 \mathrm{mM})$ for $15 \mathrm{~min}$. These tissue samples were then 
gently agitated in a small beaker to dislodge single myocytes from the extracellular matrix. The resulting cell suspension contained a mixture of subepicardial, midmyocardial and subendocardial myocytes. Throughout the entire isolation procedure, solutions were gassed with $100 \% \mathrm{O}_{2}$, while their temperature was maintained at $37{ }^{\circ} \mathrm{C}$. Myocytes were allowed to settle to the bottom of the beaker for $10 \mathrm{~min}$, after which half of the supernatant was replaced with fresh solution. This procedure was repeated three times. Myocytes placed in isolation solution supplemented with $\mathrm{CaCl}_{2}(1.25 \mathrm{mM})$ were maintained at 12-14 ${ }^{\circ} \mathrm{C}$ prior to the experimentation.(45)

\subsection{1.c. Preparation of guinea pig papillary muscles and ventricular myocytes}

Guinea pigs (300-500 grams) of either sex were used. The animals were sacrificed by cervical dislocation after receiving $400 \mathrm{IU} / \mathrm{kg}$ heparin intravenously. The chest was opened and the heart was quickly removed and immediately rinsed in oxygenated Locke's solution containing (in $\mathrm{mM}$ ): $\mathrm{NaCl}, 120 ; \mathrm{KCl}, 4 ; \mathrm{CaCl}_{2}, 2 ; \mathrm{MgCl}_{2}, 1 ; \mathrm{NaHCO}_{3}, 22$; and glucose, 11. The $\mathrm{pH}$ of this solution was 7.35 to 7.45 when gassed with $95 \% \mathrm{O}_{2}$ and $5 \%$ $\mathrm{CO}_{2}$ at $37^{\circ} \mathrm{C}$. Papillary muscles were obtained from the right ventricle of the hearts. The preparations were placed in a tissue bath and allowed to equilibrate for at least $1 \mathrm{~h}$ while superfused with oxygenated Locke's solution (flow rate 4-5 $\mathrm{ml} \mathrm{min}^{-1}$ ) warmed to $37{ }^{\circ} \mathrm{C}$. For patch-clamp experiments isolated myocytes were prepared by a method quite similar as for rabbit. After the hearts were excised and mounted on a Langendorff apparatus and retrogradely perfused with oxygenated isolation solution at $37^{\circ} \mathrm{C}$. When hearts were clear of blood, the perfusate was changed to a nominally $\mathrm{Ca}^{2+}$-free isolation solution until contraction ceased. Perfusion was continued with the same solution containing collagenase (120 U/ml, Type II, Worthington) and 1\% bovine serum albumin (Sigma Chemical, St. Louis, MO) until left ventricular tissue softened. Small pieces of tissue were removed, mechanically dissociated by trituration, and isolated cells kept in the storage solution at room temperature (73).

\subsubsection{Undiseased human preparations}

\section{Patients:}

Hearts were obtained from organ donors whose hearts were explanted to obtain pulmonary and aortic valves for transplant surgery. Before cardiac explantation, organ donor patients did not receive medication, except dobutamine, furosemide, and plasma expanders. The investigations conform to the principles outlined in the Declaration of Helsinki (Cardiovascular Research 1997; 35:2-4) and all experimental protocols were 
approved by the University of Szeged and National Scientific and Research Ethical Review Boards (No. 51-57/1997 OEj and 4991-0/2010-1018EKU (339/PI/010.)). Proper consent was obtained for use of each individual's tissue for experimentation. After explantation, each heart was perfused with cardioplegic solution and kept cold $\left(4-6{ }^{\circ} \mathrm{C}\right)$ for 2-4 hours prior to dissection.

\subsection{Experimental techniques}

\subsubsection{Voltage clamp measurements}

One drop of cell suspension was placed within a transparent recording chamber mounted on the stage of an inverted microscope (Olympus IX51, Tokyo, Japan), and individual myocytes were allowed to settle and adhere to the chamber bottom for at least 5 minutes before superfusion was initiated. Only rod shape cells with clear striations were used. HEPES buffered Tyrode's solution served as the normal superfusate. Patch-clamp micropipettes were fabricated from glass capillaries (Clark, UK) using a using a microprocessor controlled horizontal puller (Sutter P-97, Sutter Co, Novato, CA, USA). These electrodes had resistances between 1.5 and 2.5 Mohms. During these experiments we used different types of external and internal solutions as follows:

\section{(1) For measuring R-L3 enantiomers:}

Compositions of solutions used (in $m M$ ):

Pipette solution: $\mathrm{KCl} 140, \mathrm{MgCl}_{2} 4, \mathrm{~K}_{2} \mathrm{ATP}$ 5, HEPES 10, EGTA 1; pH adjusted to 7.2 by $\mathrm{KOH}$.

External solution: Tyrode solution $\left(\mathrm{NaCl} 135, \mathrm{KCl} 4.7, \mathrm{KH}_{2} \mathrm{PO}_{4} 1.2, \mathrm{MgSO}_{4} 1.2\right.$, HEPES 10, $\mathrm{NaHCO}_{3} 4.4$, glucose $10, \mathrm{CaCl}_{2} 1.8 ; \mathrm{pH}$ adjusted to 7.2 by $\mathrm{NaOH}$ ) containing $1 \mu \mathrm{M}$ nisoldipine (gift from the Bayer $\mathrm{AG}$, Leverkusen, Germany) was placed in the external solution to eliminate inward $\mathrm{Ca}^{2+}$ current $\left(\mathrm{I}_{\mathrm{Ca}}\right)$. The rapid $\mathrm{I}_{\mathrm{Kr}}$ and slow $\mathrm{I}_{\mathrm{Ks}}$ components of the delayed rectifier potassium current were separated by using $1 \mu \mathrm{M}$ dofetilide (Sequoia Research Products, Ltd, UK), a selective $\mathrm{I}_{\mathrm{Kr}}$ blocker. Cell capacitance (114.23 $\pm 8.12 \mathrm{pF}, \mathrm{n}=20$ for rabbit cell) was measured by applying a $10 \mathrm{mV}$ hyperpolarising pulse from $-10 \mathrm{mV}$. The holding potential was $-90 \mathrm{mV}$. The capacity was measured by integration of the capacitive transient divided by the amplitude of the voltage step (10 $\mathrm{mV})$. When measuring $\mathrm{I}_{\mathrm{Ks}}$, sodium current $\left(\mathrm{I}_{\mathrm{Na}}\right)$, was inactivated by applying a short $20 \mathrm{~ms}$ prepulse to $-40 \mathrm{mV}$, which also largely inactivated transient outward current $\left(\mathrm{I}_{\text {to }}\right)$. 


\section{(2) For measuring delayed rectifier potassium currents in the comparative study}

Compositions of solutions used (in $m M$ ):

Pipette solution: K-aspartate 100, $\mathrm{KCl} 45, \mathrm{~K}_{2} \mathrm{ATP} 3, \mathrm{MgCl}_{2}$ 1, EGTA 10, HEPES 5; $\mathrm{pH}$ adjusted to 7.2 by $\mathrm{KOH}$.

External solution: Tyrode solution $\left(\mathrm{NaCl} 135, \mathrm{KCl} 4.7, \mathrm{KH}_{2} \mathrm{PO}_{4} 1.2, \mathrm{MgSO}_{4} 1.2\right.$, HEPES $10, \mathrm{NaHCO}_{3} 4.4$, glucose $10, \mathrm{CaCl}_{2} 1.8$; $\mathrm{pH}$ adjusted to 7.2 by $\mathrm{NaOH}$ ) containing $1 \mu \mathrm{M}$ nisoldipine (gift from the Bayer AG, Leverkusen, Germany) was placed in the external solution to eliminate inward $\mathrm{Ca}^{2+}$ current $\left(\mathrm{I}_{\mathrm{Ca}}\right)$. L-738,821, a selective $\mathrm{I}_{\mathrm{Ks}}$ blocker (100 nM, Merck-Sharpe \& Dohme, West Point, USA) was added to the control solution when we measured $I_{K r}$ current (74). While measuring $I_{K s}$ current, a selective $I_{K r}$ blocker (1$5 \mu \mathrm{M}$ E-4031, Drug Research Institute, Budapest) was added to the control solution (30). Cell capacitance was measured by applying a $10 \mathrm{mV}$ hyperpolarising pulse from $-10 \mathrm{mV}$. The holding potential was $-90 \mathrm{mV}$. The capacity was measured by integration of the capacitive transient divided by the amplitude of the voltage step $(10 \mathrm{mV})$. When measuring $\mathrm{I}_{\mathrm{Ks}}$, sodium current $\left(\mathrm{I}_{\mathrm{Na}}\right)$, was inactivated by applying a short $20 \mathrm{~ms}$ prepulse to $-40 \mathrm{mV}$, which also largely inactivated transient outward current $\left(\mathrm{I}_{\mathrm{to}}\right)$.

\section{(3) For the measurement of the $\mathrm{Na}^{+} / \mathrm{Ca}^{2+}$ exchanger current (NCX) using ORM- 10103}

Compositions of solutions used (in $m M$ ):

Pipette solution: CsOH 140, aspartic acid 75, TEACl 20, MgATP 5, HEPES 10, NaCl 20, EGTA 20 and $\mathrm{CaCl}_{2} 10$ (pH adjusted to 7.2 with $\mathrm{CsOH}$ ).

External solution: $\mathrm{K}^{+}$-free bath solution $-\mathrm{NaCl} 135, \mathrm{CsCl} 10, \mathrm{CaCl}_{2} 1, \mathrm{MgCl}_{2} 1$, $\mathrm{BaCl}_{2}$ 0.2, $\mathrm{NaH}_{2} \mathrm{PO}_{4}$ 0.33, TEACl 10, HEPES 10, glucose 10 and ouabain $20 \mu \mathrm{M}$, nisoldipine $1 \mu \mathrm{M}$, and lidocaine $50 \mu \mathrm{M}$, at $\mathrm{pH} 7.4$ (the method of Hobai et al (75) was applied, in which special $\mathrm{K}^{+}$-free bath and pipette solutions were used in order to block the $\mathrm{Na}^{+}-, \mathrm{Ca}^{2+}-, \mathrm{K}^{+}$-currents and the $\mathrm{Na}^{+} / \mathrm{K}^{+}$pump current.)

The I-V (current-voltage) relationship of $\mathrm{Na}^{+} / \mathrm{Ca}^{2+}$ exchanger current was measured through the use of ramp pulses at $20 \mathrm{~s}$ intervals. The ramp pulse initially led to depolarization from the holding potential of $-40 \mathrm{mV}$ to $60 \mathrm{mV}$ with a rate of $100 \mathrm{mV} / \mathrm{s}$, then to hyperpolarization to $-100 \mathrm{mV}$, and depolarization back to the holding potential. The descending limb of the ramp was utilized to plot the I-V curve.

The experimental protocol was as follows:

1) the whole cell configuration was established in HEPES-buffered Tyrode's solution; 
2) the control I-V curve was recorded in the special $\mathrm{K}^{+}$-free bath solution after $8-10 \mathrm{~min}$ from establishing whole cell configuration;

3) after 6-10 $\mathrm{min}$ incubation the I-V relation was recorded in the presence of ORM-10103;

4) at the end of the experiments the $\mathrm{Ni}^{2+}$ - insensitive current was measured by the application of $10 \mathrm{mM} \mathrm{NiCl}_{2}$.

The NCX current was defined as the $\mathrm{Ni}^{2+}$ - sensitive current i.e. the trace recorded in the presence of $10 \mathrm{mM} \mathrm{NiCl}$ subtracted from that measured in the absence of $\mathrm{NiCl}_{2}$. In separate experiments, the effect of ORM-10103 on the $\mathrm{Ni}^{2+}$ - insensitive current was also tested.

\section{(4) For the measurement of L-type calcium current using ORM-10103}

Compositions of solutions used (in $m M$ ):

Pipette solution: CsOH 110, CsCl 20, TEACl 10, MgATP 5, EGTA 5, HEPES 10 and GTP 0.1 (pH was adjusted to 7.2 by aspartic acid).

External solution: Tyrode solution supplemented with $3 \mathrm{mM}$ 4-aminopyridine

$\mathrm{I}_{\mathrm{CaL}}$ current was evoked by $400 \mathrm{~ms}$ long depolarizing voltage pulses to various test potentials ranging from $-35 \mathrm{mV}$ to $+55 \mathrm{mV}$. The holding potential was $-80 \mathrm{mV}$. A short prepulse to $-40 \mathrm{mV}$ served to inactivate $\mathrm{Na}^{+}$current. The amplitude of $\mathrm{I}_{\mathrm{CaL}}$ was defined as the difference between the peak inward current at the beginning of the pulse and the current at the end of the pulse.

(5) For the measurement of $K^{+}$currents - inward rectifier $\left(I_{K 1}\right)$, transient outward $\left(I_{t o}\right)$, rapid $\left(I_{K r}\right)$ and slow $\left(I_{K s}\right)$ delayed rectifier - using ORM-10103

Compositions of solutions used (in $\mathrm{mM}$ ):

Pipette solution: $\mathrm{KOH} 110, \mathrm{KCl} 40, \mathrm{~K}_{2} \mathrm{ATP} 5, \mathrm{MgCl}_{2}$ 5, EGTA 5, and HEPES 10 (pH was adjusted to 7.2 by aspartic acid).

External solution: $1 \mu \mathrm{M}$ nisoldipine was added to the Tyrode solution to eliminate $\mathrm{I}_{\mathrm{CaL}}$. When $\mathrm{I}_{\mathrm{Kr}}$ was recorded $\mathrm{I}_{\mathrm{Ks}}$ was inhibited by using the selective $\mathrm{I}_{\mathrm{Ks}}$ blocker HMR 1556 $(0.5 \mu \mathrm{M})$. During $\mathrm{I}_{\mathrm{Ks}}$ measurements, $\mathrm{I}_{\mathrm{Kr}}$ was blocked by $0.1 \mu \mathrm{M}$ dofetilide. The currents were activated by applying depolarizing voltage pulses.

With the exception of ORM-10103 (from Orion Pharma, Espoo, Finland), nisoldipine (gift from Bayer AG, Leverkusen, Germany) and strophanthin-G (from BDH Chemicals 
Ltd, Poole, England) all chemicals were purchased from Sigma-Aldrich Fine Chemicals (St. Louis, MO, USA).

Membrane currents were recorded with an Axopatch 200B amplifier (Molecular Devices-Axon Instruments, Union City, CA, USA) using the whole-cell configuration of the patch-clamp technique. After establishing a high (1-10 Gohm) resistance seal by gentle suction, the cell membrane beneath the tip of the electrode was disrupted by suction or by application of $1.5 \mathrm{~V}$ electrical pulses for $1-5 \mathrm{~ms}$. The series resistance was typically $4-8$ Mohm before compensation (50 - 80\%, depending on the voltage protocols). Experiments where the series resistance was high, or substantially increased during measurement, were terminated and the results were excluded from analyses. Membrane currents were digitized using a $333 \mathrm{kHz}$ analog-to-digital converter (Digidata 1320 and 1440, Molecular Devices-Axon Instruments) under softwares control (pClamp 8.0 and pClmap10, Axon Instruments). Analyses were performed using Axon (pClamp 8.0 and pClamp 10) softwares after low-pass filtering at $1 \mathrm{kHz}$. All patch-clamp data were collected at $37^{\circ} \mathrm{C}$.

\subsubsection{Action potential measurements}

Initially, each preparation was stimulated at a basic cycle length of $1000 \mathrm{~ms}$ (frequency $=1 \mathrm{~Hz}$ ), using $2 \mathrm{~ms}$ long rectangular constant voltage pulses isolated from ground and delivered via bipolar platinum electrodes in contact with the preparation using an EMG 4767 type stimulator (Medicor Ltd, Budapest, H-1147, Hungary). One hour or more was allowed for each preparation to equilibrate while continuously superfused with Tyrode's solution warmed to $37{ }^{\circ} \mathrm{C}$. Transmembrane potentials were recorded using a conventional glass microelectrode filled with $3 \mathrm{M} \mathrm{KCl}$ with a tip resistance of 5-20 Mohms connected to an high impedance electrometer (Bio-Logic VF102, CLAIX, F38640 , France) referenced to ground. The first derivative of transmembrane potential $\left(\mathrm{V}_{\max }\right)$ was electronically obtained, derived using a Bio-Logic DV-140 (Claix, F-38640, France) differentiator designed and calibrated to have a linear response over the range of 10 to $1000 \mathrm{~V} / \mathrm{s}$. Amplifier outputs were digitized using an ADA 3300 analog-to-digital converter (Real Time Devices Inc, State College, PA 16804, USA) with a maximum sampling frequency rate of $50 \mathrm{kHz}$ connected to an IBM compatible personal computer. Data was stored and analyzed on a personal computer (PC) while also monitored on a dual beam memory oscilloscope (Tektronix 2230, Beaverton, OR 97077, USA). Resting membrane potential (RP), action potential amplitude (APA), and action potential durations (APD), determined at $50 \%$ and $90 \%$ repolarization $\left(\mathrm{APD}_{50}\right.$ and $\left.\mathrm{APD}_{90}\right)$, were 
automatically measured with software developed in our laboratory (APES, Hugo Sachs Elektronik, March-Hugstetten, D-79229, Germany). Stimulation pulses were also controlled by PC software providing constant current pulses with programmed timing and amplitudes to the preparation via an EMG 47671 type signal isolator (Medicor Ltd, Budapest, H-1147, Hungary).

In each experiment, baseline action potential characteristics were first obtained during superfusion with normal $37{ }^{\circ} \mathrm{C}$ Tyrode's solution during while continuous pacing was maintained at a basic cycle length of $1000 \mathrm{~ms}$. Recordings were continuously monitored to confirm one-to-one activation throughout the procedure. After baseline measurements were obtained, each preparation was superfused with Tyrode's solution containing a single test drug diluted to the proper concentration for 40 to 60 minutes before measurements were repeated at 3 min intervals in the continued presence of the test drug until less than a $5 \%$ change occurred in action potential characteristics between subsequent samples. When microelectrode impalement was lost, reimpalement was attempted. If action potential characteristics recorded with the new impalement deviated by more than 5\% from the preceding ones, the experiment was terminated, and results were excluded from evaluation.

\subsection{Statistics}

All data are expressed as means \pm SEM. Statistical analysis was performed with Student's $t$-test for paired data. The results were considered statistically significant when $p$ was $<0.05$.

\section{RESULTS}

\subsection{Effects of the optical enantiomers of $R-L 3$ on $I_{K s}$ in rabbit ventricular myocytes}

\subsubsection{Chemical structure of R-L3 enantiomers}

The applied R-L3 enantiomers were $(R)$ - and (S)-5-(2-Fluorophenyl)-1,3-dihydro-3(1H-indol-3-ylmethyl)-1-methyl-2H-1,4-benzodiazepin-2-one) (ZS_1270B) and (ZS_1271B) synthetized by Fülöp and his colleagues at the Department of Medicinal Chemistry, University of Szeged, utilizing the method of Evans et al. (76) (Figure 5). 


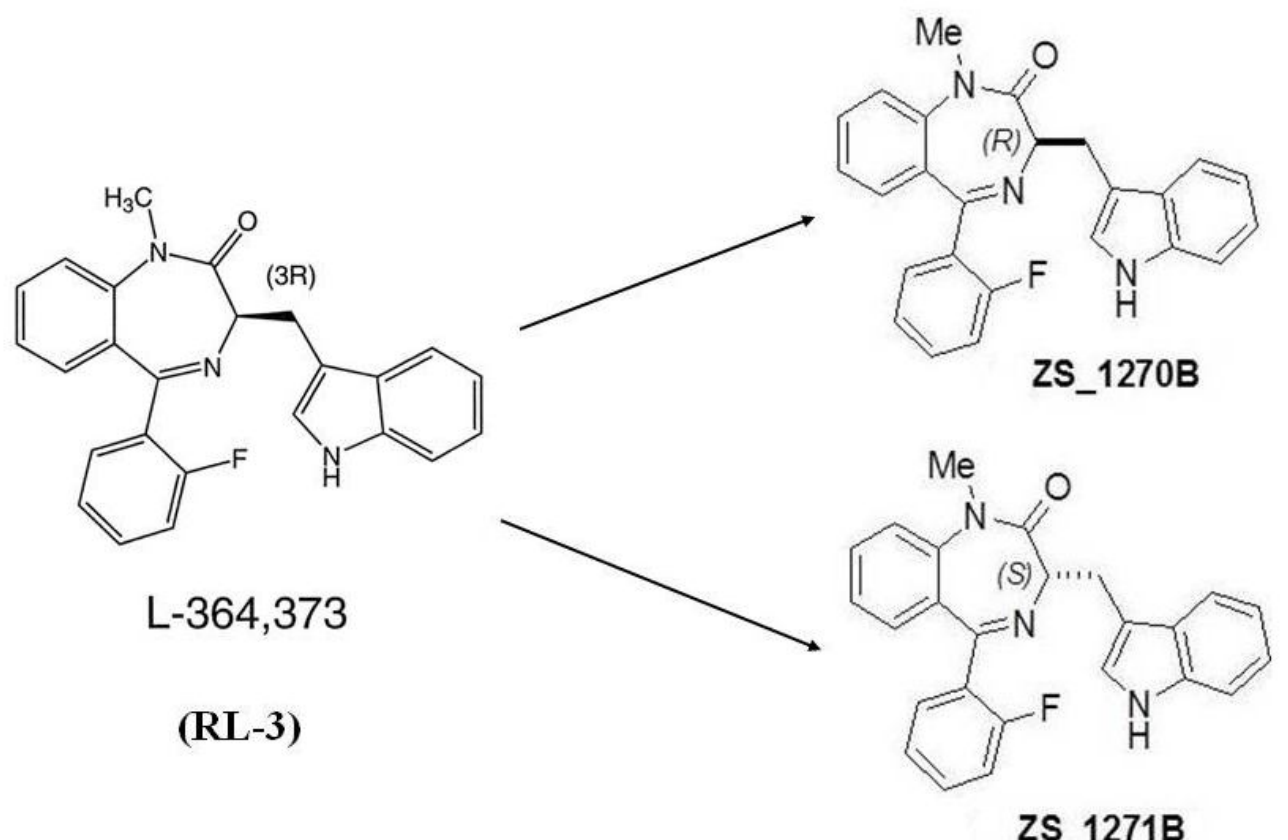

Figure 5. Chemical structure of the R-L3 (L-364,373) enantiomers

\subsubsection{The investigation of the effect of $R-L 3$ enantiomers on $I_{K s}$ current}

The effect of RL-3 enantiomers on $\mathrm{I}_{\mathrm{Ks}}$ was tested on rabbit ventricular myocytes because relatively large and easily measured $\mathrm{I}_{\mathrm{Ks}}$ currents have been described particularly in this species (72).

The left panels of Figure 6 show original recordings of the $\mathrm{I}_{\mathrm{Ks}}$ current obtained from rabbit ventricular myocyte. Test pulses of $5000 \mathrm{~ms}\left(\mathrm{I}_{\mathrm{Ks}}\right)$ in duration between $-10 \mathrm{mV}$ and $+50 \mathrm{mV}$ from the holding potential of $-80 \mathrm{mV}$, were used to examine $\mathrm{I}_{\mathrm{Ks}}$ current in this species. The pulse frequency was $0.05 \mathrm{~Hz}\left(\mathrm{I}_{\mathrm{Kr}}\right)$ or $0.1 \mathrm{~Hz}\left(\mathrm{I}_{\mathrm{Ks}}\right)$. Figure 6A shows the decaying tail of $\mathrm{I}_{\mathrm{Ks}}$ current at $-40 \mathrm{mV}$ after the test pulse. We determined the amplitudes of the $\mathrm{I}_{\mathrm{Ks}}$ tail currents as the difference between the peak tail current and the holding current level at $-40 \mathrm{mV}$. To obtain a complete block of $\mathrm{I}_{\mathrm{Kr}}$ dofetilide $(1 \mu \mathrm{M})$ was added to the nutrient solution. The bottom panel of the same Figure 6A show that $1 \mu \mathrm{M}$ ZS_1270B largely increased both outward depolarizing and deactivating tail currents. The corresponding current-voltage relationships of $\mathrm{I}_{\mathrm{Ks}}$, before and after the superfusion with ZS_1270B measured on an average of 6 cells are shown in the right panel of Figure 6 . We can conclude that at $40 \mathrm{mV}, \mathrm{I}_{\mathrm{Ks}}$ tail current amplitude increased by about $26 \%$ in a statistically significant extent from $45.9 \pm 4.97 \mathrm{pA}$ to $66.1 \pm 4.54 \mathrm{pA}$, after drug superfusion (Figure 6B). 

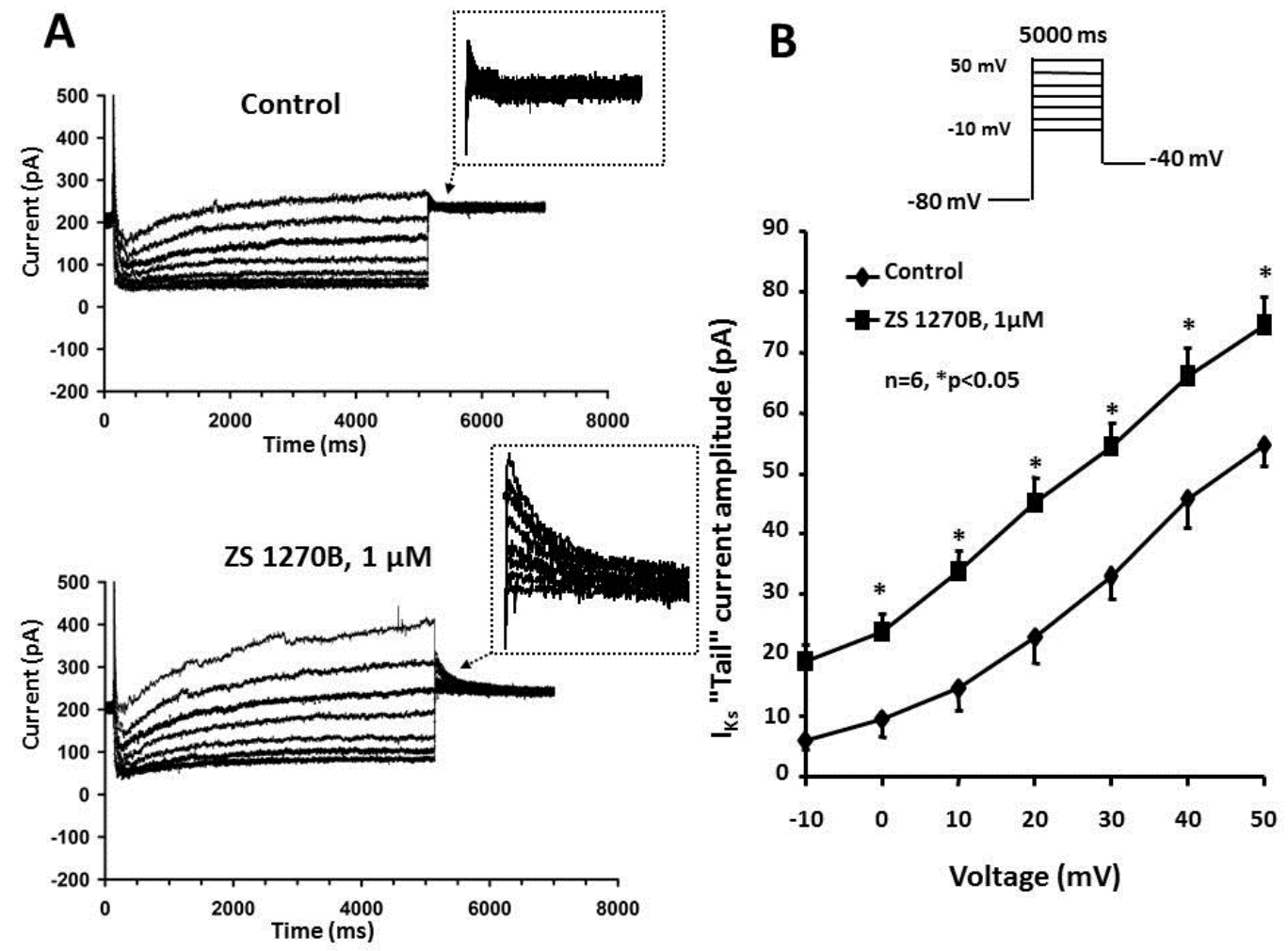

Figure 6. Panel A. Effect of ZS_1270B on the slow delayed rectifier $\mathrm{K}^{+}$current $\left(\mathrm{I}_{\mathrm{Ks}}\right)$. $\mathrm{I}_{\mathrm{Ks}}$ current traces recorded from rabbit ventricular myocyte under control conditions (top) and in the presence of $1 \mu \mathrm{M}$ ZS_1270B (bottom). Experiments were performed in the presence of the selective $\mathrm{I}_{\mathrm{Kr}}$ blocker dofetilide $(1 \mu \mathrm{M})$, added to the bath solution. Panel B. Corresponding $\mathrm{I}_{\mathrm{Ks}}$-tail currentvoltage relationship before and after application of $1 \mu \mathrm{M}$ ZS_1270B. The inset in the top of the figure shows the voltage protocol applied during measurements. Values represent mean \pm SEM, $\mathrm{n}=7,{ }^{*} \mathrm{p}<0.05$.

The left panels of Figure 7 show original recordings of the current where we can see the effect of the left enantiomer ZS_1271B on the $\mathrm{I}_{\mathrm{Ks}}$ current recorded in rabbit ventricular myocytes (Figure 7A). In Figure 7B the corresponding current-voltage relationships of $\mathrm{I}_{\mathrm{Ks}}$ before and after the superfusion with ZS_1271B $(1 \mu \mathrm{M})$ measured on an average of 7 cells clearly show that the left enantiomer is a potent inhibitor of the $\mathrm{I}_{\mathrm{Ks}}$ current. At $40 \mathrm{mV}, \mathrm{I}_{\mathrm{Ks}}$ tail current amplitude decreased in a statistically significant extent to about $47 \%$ from $97.1 \pm 9.7 \mathrm{pA}$ to $45.86 \pm 11.6 \mathrm{pA}$, after drug superfusion (Figure $7 \mathrm{~B}$ ). 

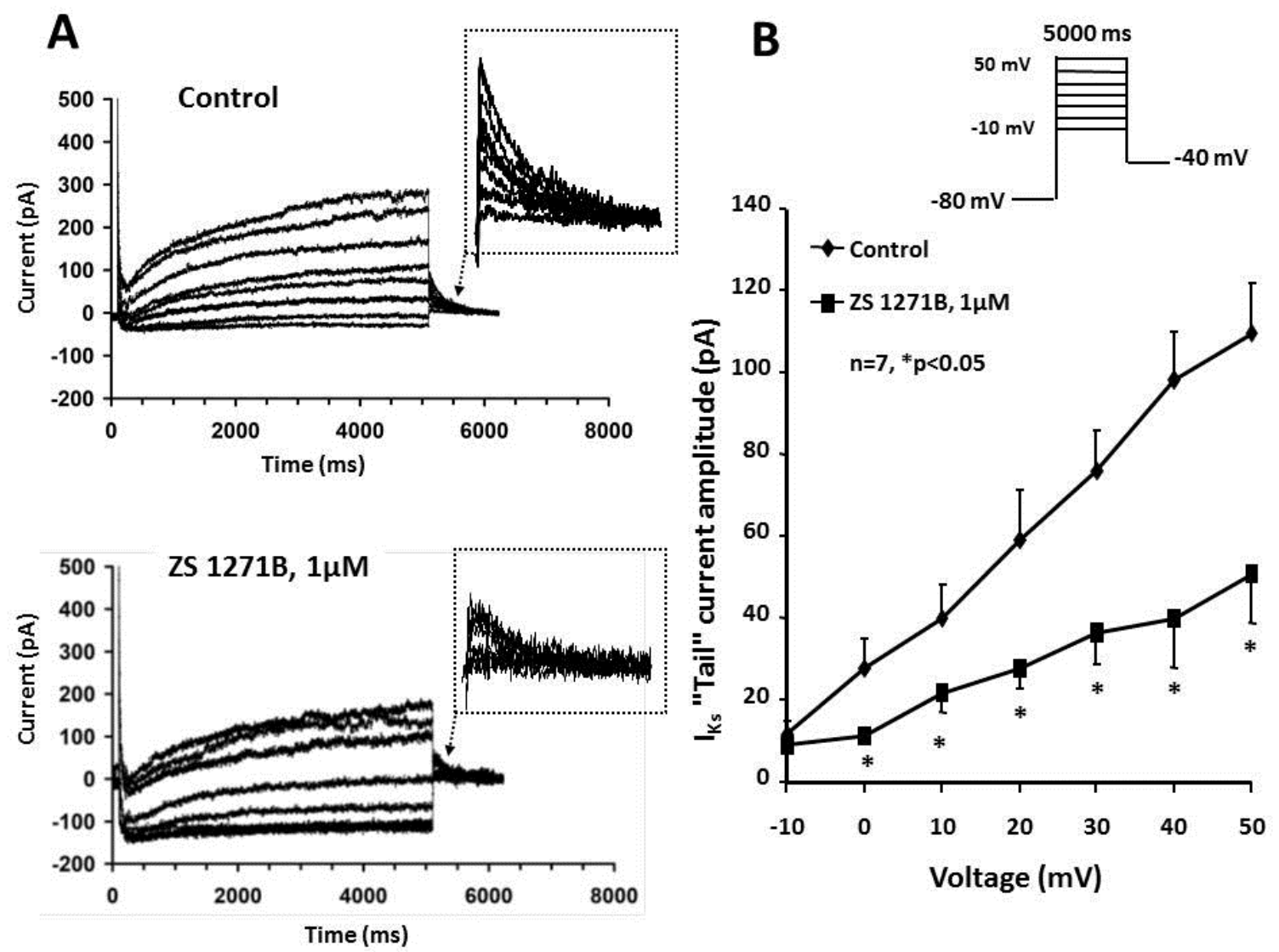

Figure 7. Panel A. Effect of ZS_1271B on the slow delayed rectifier $\mathrm{K}^{+}$current $\left(\mathrm{I}_{\mathrm{KS}}\right)$. $\mathrm{I}_{\mathrm{Ks}}$ current traces recorded from rabbit ventricular myocyte under control conditions (top) and in the presence of $1 \mu \mathrm{M}$ ZS_1271B (bottom). Experiments were performed in the presence of the selective $\mathrm{I}_{\mathrm{Kr}}$ blocker dofetilide $(1 \mu \mathrm{M})$, added to the bath solution. Panel B. Corresponding $\mathrm{I}_{\mathrm{Ks}}$-tail currentvoltage relationship before and after application of $1 \mu \mathrm{M}$ ZS_1271B. The inset in the top of the figure shows the voltage protocol applied during measurements. Values represent mean \pm SEM, $\mathrm{n}=7,{ }^{*} \mathrm{p}<0.05$.

\subsubsection{Effect of selective $I_{K s}$ blockade and activation on the APD}

In our above results we demonstrated that the two R-L3 enantiomers have indeed adversely modulating effects on the $\mathrm{I}_{\mathrm{Ks}}$ current, and are suitable to test the effect of both selective blockade and activation of the $\mathrm{I}_{\mathrm{Ks}}$ current on the ventricular action potential repolarization.

To test this hypothesis we investigated the effect of the two R-L3 enantiomers in guinea pig ventricular papillary muscle preparations. Guinea pig is the species known to have significant larger $I_{K s}$ current than in myocytes originated from other species including human (77). It is known that $\mathrm{I}_{\mathrm{Ks}}$ is relatively small current in most mammalians, and it was shown that blockade of $\mathrm{I}_{\mathrm{Ks}}$ current did not lengthen action potential duration in normal condition (without sympathetic stimulation) in most species including rabbits $(\mathbf{2 4 , 4 8 , 7 2 )}$.

In a previous study we have reported that guinea pig is the only widely investigated 
species where $\mathrm{I}_{\mathrm{Ks}}$ is large enough so that even without sympathetic stimulation selective $\mathrm{I}_{\mathrm{Ks}}$ blockade lengthened APD in noticeable manner (77).

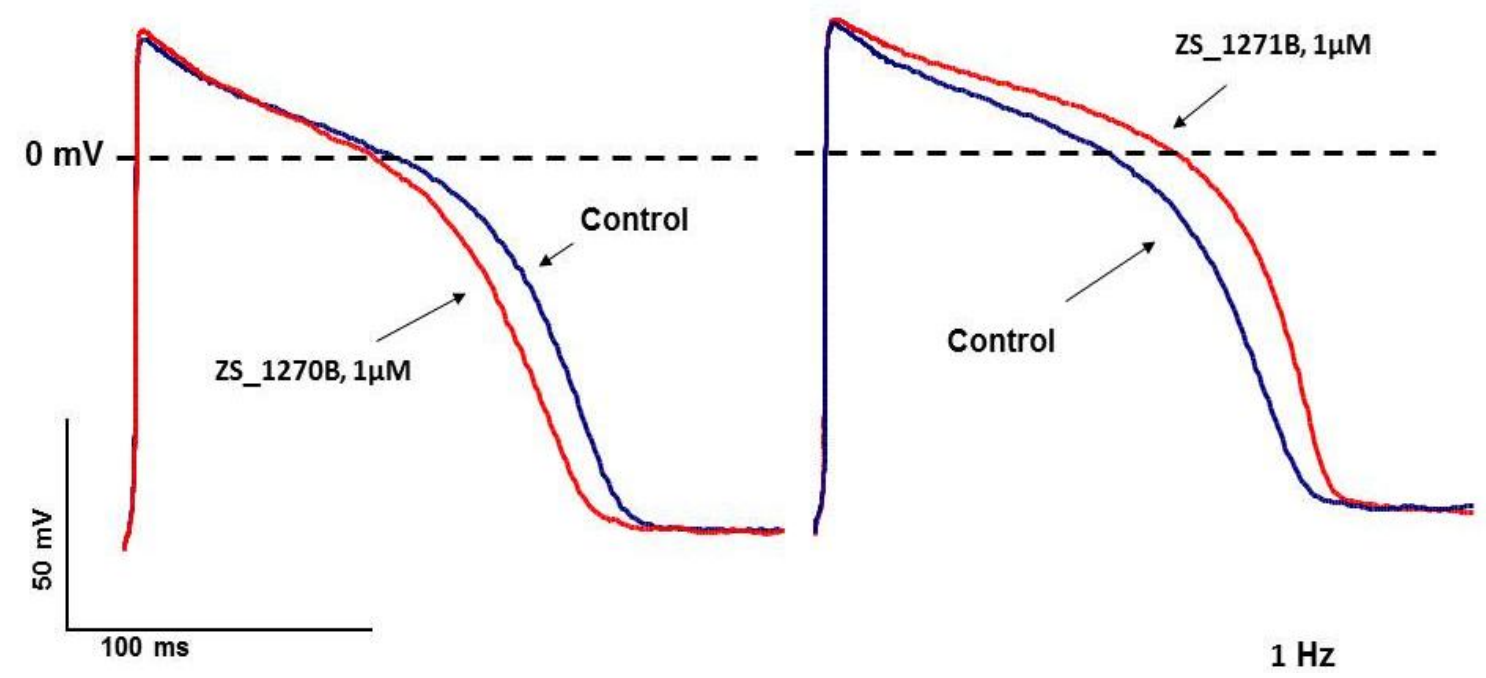

Figure 8. Guinea pig ventricular papillary muscle action potential recordings in the absence of any sympathetic agonist before and after 40 minutes of superfusion with the RL-3 enantiomers $1 \mu \mathrm{M}$ ZS_1270B (left panel) and $1 \mu \mathrm{M}$ ZS_1271B (right panel), respectively. Stimulation frequency was $1 \mathrm{~Hz}$.

Therefore, we chose for these experiments guinea pig ventricular myocytes since in this species is expected to noticeably measure both lengthening and shortening of the ventricular APD. As Figure 8 shows in guinea pig right ventricular preparations the activator right enantiomer ZS_1270B $(1 \mu \mathrm{M})$ shortened $\mathrm{APD}_{90}$ by about $12.2 \pm 0.9 \%$ $(\mathrm{n}=4), * \mathrm{p}<0.05)$, while the $\mathrm{I}_{\mathrm{Ks}}$ blocker left enantiomer ZS_1271B $(1 \mu \mathrm{M})$ lengthened it by about $14.2 \pm 1.3 \%(n=4, * p<0.05)$ in the average of $4-4$ cells.

Table 1 summarizes all action potential data recorded in guinea pig ventricular preparations.

\begin{tabular}{|c|c|c|c|c|c|}
\hline Parameters & $\mathrm{RP}(\mathrm{mV})$ & APA $(m V)$ & $\mathrm{APD}_{50}(\mathrm{~ms})$ & $\mathrm{APD}_{90}(\mathrm{~ms})$ & $\mathrm{V}_{\max }(\mathrm{V} / \mathrm{s})$ \\
\hline $\begin{array}{c}\text { Control } \\
(n=4)\end{array}$ & $-84.2 \pm 0.6$ & $106.2 \pm 2.2$ & $149.0 \pm 6.2$ & $182.1 \pm 10.1$ & $238.0 \pm 9.2$ \\
\hline $\begin{array}{c}{ }^{1}{ }^{1 \mu M} \\
(n=4)\end{array}$ & $-84.3 \pm 0.5$ & $107.7 \pm 2.4$ & $159.2 \pm 6.2^{*}$ & $209.2 \pm 8.0^{*}$ & $233.9 \pm 9.4^{*}$ \\
\hline
\end{tabular}




\begin{tabular}{|c|c|c|c|c|c|}
\hline Parameters & RP $(\mathbf{m V})$ & APA $(\mathbf{m V})$ & APD $_{50}(\mathrm{~ms})$ & APD $_{90}(\mathbf{m s})$ & V $_{\max }(\mathrm{V} / \mathbf{s})$ \\
\hline $\begin{array}{c}\text { Control } \\
(\mathbf{n}=\mathbf{4})\end{array}$ & $-85.2 \pm 0.3$ & $109.4 \pm 0.3$ & $149.4 \pm 5.1$ & $184.7 \pm 8.1$ & $231.0 \pm 6.2$ \\
\hline $\begin{array}{c}\mathbf{1} \boldsymbol{\mathbf { 1 }} \mathbf{\mathrm { M }} \\
\mathbf{( \mathbf { n } = 4 )}\end{array}$ & $-84.6 \pm 1.6$ & $108.6 \pm 1.7$ & $141.0 \pm 15.4^{*}$ & $165.7 \pm 11.3^{*}$ & $229.9 \pm 8.4$ \\
\hline
\end{tabular}

Table 1. The electrophysiological effects of the RL-3 enantiomers ZS_1271B and ZS_1270B in guinea pig right papillary muscle recorded at the basic cycle length of $1000 \mathrm{~ms}$.

\subsection{The investigation of the properties of the rapid and slow delayed rectifier currents in undiseased human, dog, rabbit and guinea pig ventricular myocytes}

\subsubsection{The current-voltage (I-V) relationship of the $I_{K r}$ and $I_{K s}$ currents}

$\mathrm{I}_{\mathrm{Kr}}$ and $\mathrm{I}_{\mathrm{Ks}}$ currents were present in all studied species (Figure 9). $1 \mu \mathrm{M}$ nisoldipine was added to the external solution to eliminate inward $\mathrm{Ca}^{2+}$ current $\left(\mathrm{I}_{\mathrm{Ca}}\right)$. We used L738,821 selective $\mathrm{I}_{\mathrm{Ks}}$ blocker when we measured $\mathrm{I}_{\mathrm{Kr}}$ current, while measuring $\mathrm{I}_{\mathrm{Ks}}$ current, a selective $\mathrm{I}_{\mathrm{Kr}}$ blocker (1-5 $\mu \mathrm{M}$ E-4031) was added to the control solution. The rapid delayed rectifier current $\left(\mathrm{I}_{\mathrm{Kr}}\right)$ in human $(\mathrm{HM})$, dog $(\mathrm{DM})$, rabbit $(\mathrm{RM})$ and guinea pig $(\mathrm{GM})$ myocytes was measured by $1 \mathrm{~s}$ test voltage pulses from -20 to $50 \mathrm{mV}$ with pulse frequency of $0.05 \mathrm{~Hz}$. The holding potential in these experiments was $-40 \mathrm{mV}$. The deactivating socalled tail current was measured as $\mathrm{I}_{\mathrm{Kr}}$ after returning the voltage from the test potential to $-40 \mathrm{mV}$. The amplitude of the $\mathrm{I}_{\mathrm{Kr}}$ tail current was determined as the difference between the peak tail current and the holding current level at $-40 \mathrm{mV}$.

The amplitude of the E-4031 sensitive $\mathrm{I}_{\mathrm{Kr}}$ tail current was very similar in HM and DM $(0.35 \pm 0.07$ and $0.38 \pm 0.02 \mathrm{pA} / \mathrm{pF}$, respectively, $\mathrm{n}=12-15)$ but larger in $\mathrm{RM}$ and $\mathrm{GM}$ $(0.66 \pm 0.05 \mathrm{pA} / \mathrm{pF}$ and $1.0 \pm 0.08 \mathrm{pA} / \mathrm{pF}$, respectively, $\mathrm{n}=10)$. The slow delayed rectifier $\left(\mathrm{I}_{\mathrm{Ks}}\right)$ was measured by $5 \mathrm{~s}$ test voltage pulses from -20 to $+50 \mathrm{mV}$ with the pulse frequency of $0.1 \mathrm{~Hz}$. The holding potential in these experiments was $-40 \mathrm{mV}$. $\mathrm{I}_{\mathrm{Kr}}$ was completely blocked by 1-5 $\mu \mathrm{M}$ E-4031. The deactivating $\mathrm{I}_{\mathrm{Ks}}$ tail current was measured after returning the voltage from $+50 \mathrm{mV}$ to $-40 \mathrm{mV}$. The $\mathrm{I}_{\mathrm{Ks}}$ tail current was considerably larger in $\mathrm{GM}$ (amplitude at $-40 \mathrm{mV}$, after a $5 \mathrm{~s}$ long test pulse to $50 \mathrm{mV}$ was $3.3 \pm 0.6 \mathrm{pA} / \mathrm{pF}, \mathrm{n}=10$ ) than in $\mathrm{RM}(1.22 \pm 0.7 \mathrm{pA} / \mathrm{pF}, \mathrm{n}=7)$ and $\mathrm{DM}(0.9 \pm 0.05 \mathrm{pA} / \mathrm{pF}, \mathrm{n}=24)$. In HM I $\mathrm{K}_{\mathrm{Ks}}$ tail was even smaller than in $\mathrm{DM}(0.2 \pm 0.05 \mathrm{pA} / \mathrm{pF}, \mathrm{n}=14)$. 


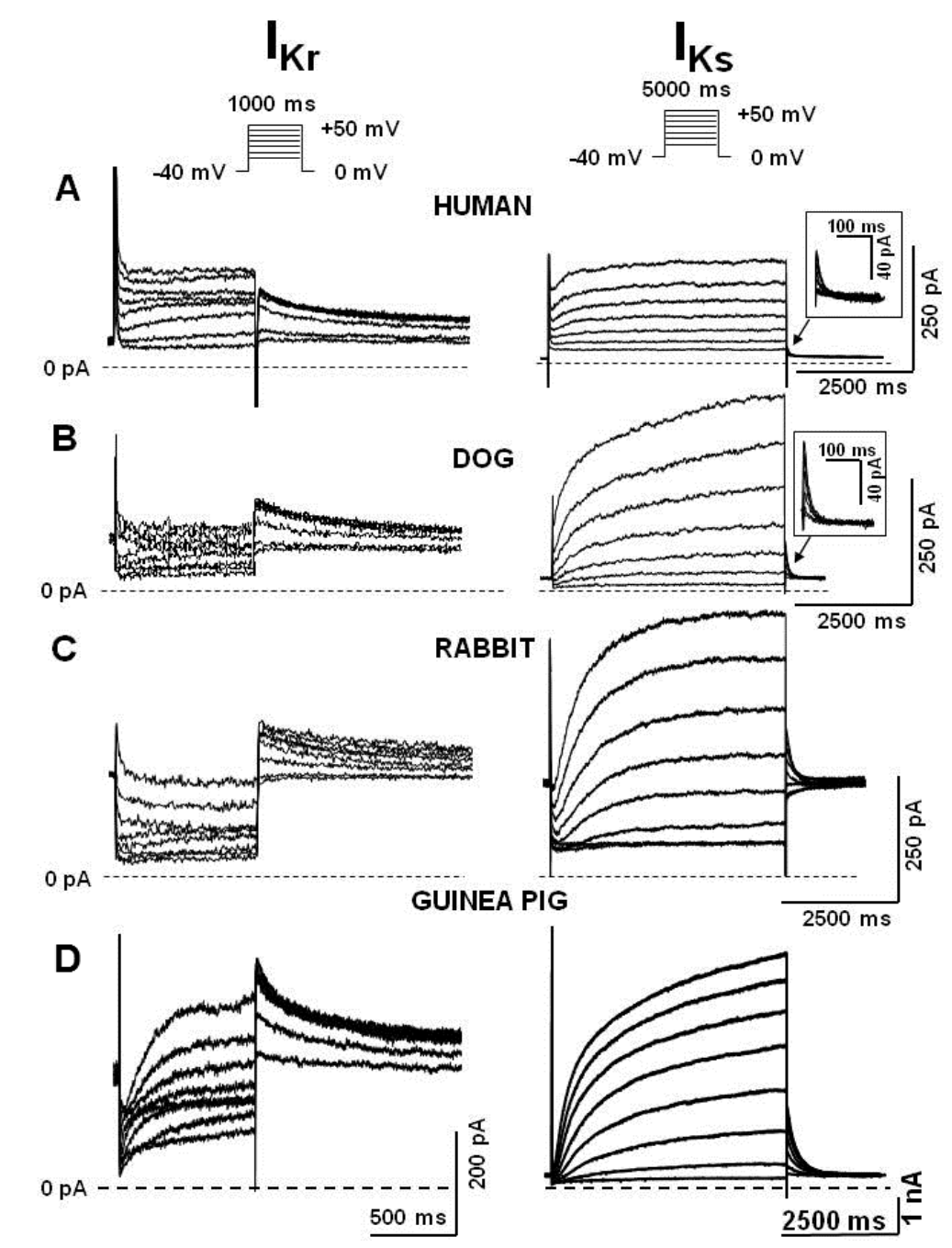

Figure 9. Original recordings of E-4031 sensitive $\left(\mathrm{I}_{\mathrm{Kr}}\right)$ and L-735,821 sensitive $\left(\mathrm{I}_{\mathrm{Ks}}\right)$ currents in undiseased human (Panel A), dog (Panel B), rabbit (Panel C) and guinea pig (Panel D) ventricular myocytes. Nisoldipine $(1 \mu \mathrm{M})$ was used to block inward calcium current $\left(\mathrm{I}_{\mathrm{Ca}}\right)$ Holding potential (HP) was $-40 \mathrm{mV}$ and pulse frequency was $0.05 \mathrm{~Hz}\left(\mathrm{I}_{\mathrm{Kr}}\right)$ or $0.1 \mathrm{~Hz}\left(\mathrm{I}_{\mathrm{Ks}}\right)$.

In Figure 10 we can see that the $\mathrm{I}_{\mathrm{Kr}}$ current started to activate at negative membrane potentials like the $\mathrm{I}_{\mathrm{Ks}}$ current (between -10 and $0 \mathrm{mV}$ ). The amplitude of the $\mathrm{I}_{\mathrm{Kr}}$ current increased rapidly and reached its maximum between 0 and $20 \mathrm{mV}$ and at more positive voltages it was inwardly rectified (Figure 10 left panel). The amplitude of the slow component apparently did not rectify (Figure 10 right panel).

\subsubsection{The activation and deactivation kinetics of the $I_{K r}$ and $I_{K s}$ currents}

The activation kinetics of $\mathrm{I}_{\mathrm{Kr}}$ and $\mathrm{I}_{\mathrm{Ks}}$ tail currents were studied by applying the envelope of tails protocols. Currents were elicited by depolarisation from $-40 \mathrm{mV}$ to 30 $\mathrm{mV}$ with pulses ranging from $10 \mathrm{~ms}$ to $5-7 \mathrm{~s}$ in duration, and tail currents were recorded after repolarisation to $-40 \mathrm{mV}$, with the pulse frequency of $0.05 \mathrm{~Hz}\left(\mathrm{I}_{\mathrm{Kr}}\right)$ or $0.1 \mathrm{~Hz}\left(\mathrm{I}_{\mathrm{Ks}}\right)$. 

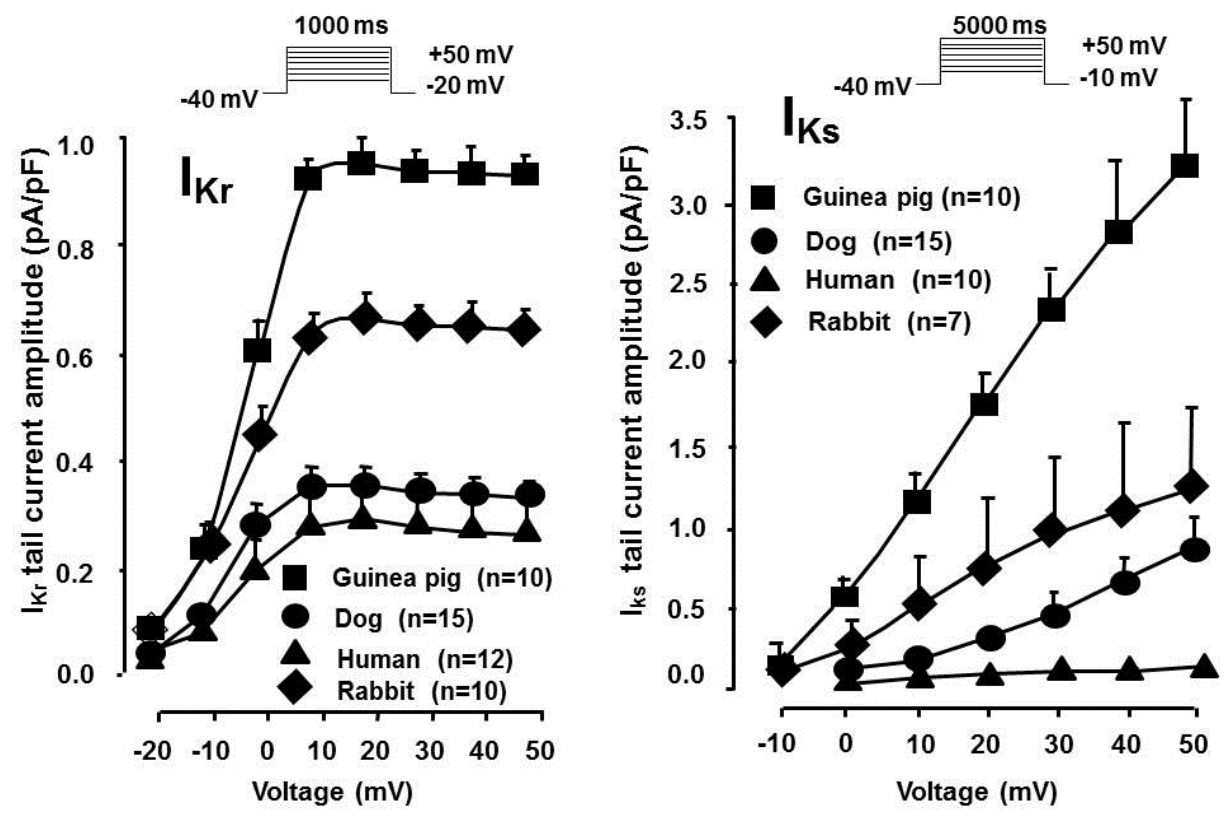

Figure 10. The peak $I_{K r}$ and $I_{K s}$ tail current-voltage relationship in undiseased human (triangle), dog (circle), rabbit (diamond) and guinea pig (rectangle) ventricular myocytes.

$\mathrm{I}_{\mathrm{Kr}}$-tail current presented fast activation kinetics. $\mathrm{I}_{\mathrm{Kr}}$ activated rapidly and monoexponentially in each studied species. The corresponding activation time constants measured at $30 \mathrm{mV}$ were: $36 \pm 3 \mathrm{~ms}$ in $\mathrm{HM}, 53 \pm 6 \mathrm{~ms}$ in DM, $35 \pm 3 \mathrm{~ms}$ in RM and $30 \pm 2 \mathrm{~ms}$ in GM, respectively ( $\mathrm{n}=6-26)$ (Figure 11, top).

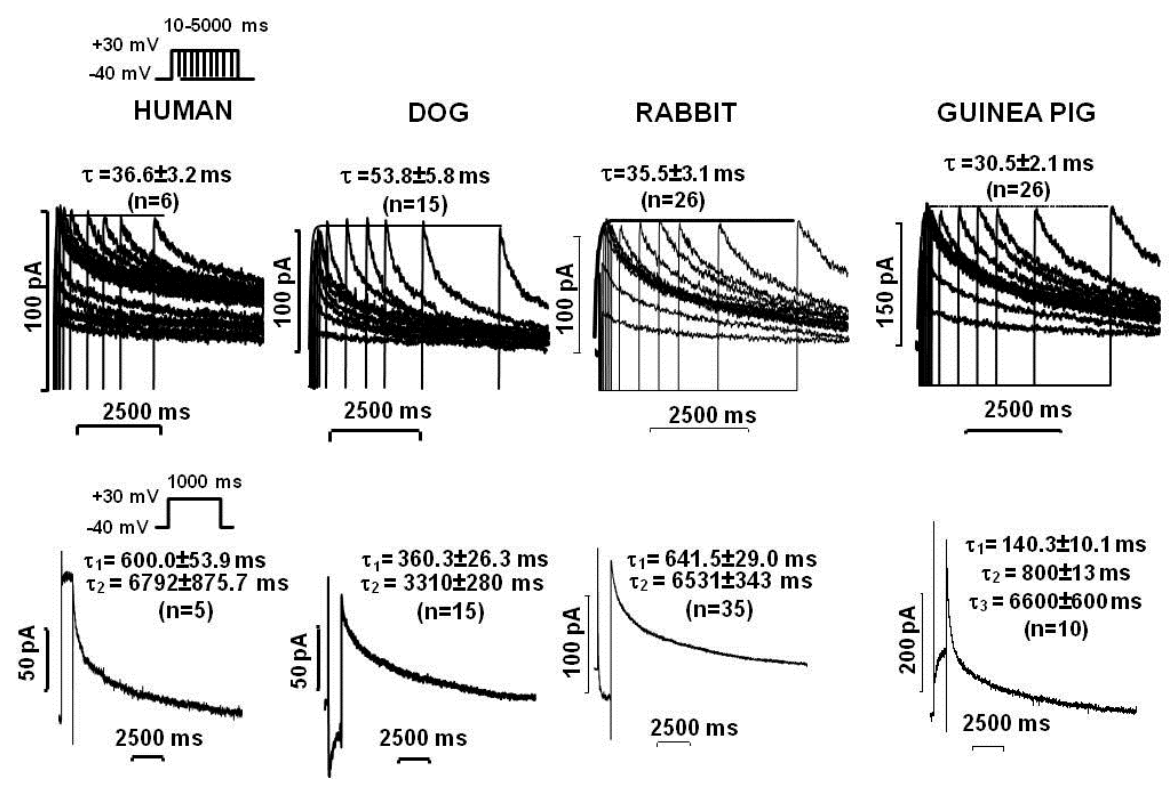

Figure 11. Activation (top) and deactivation (bottom) of $\mathrm{I}_{\mathrm{Kr}}$ current in human, dog, rabbit and guinea pig ventricular myocytes. Top. Activation kinetics was determined with the use of "envelope of tail test" protocol (see inset). $\mathrm{I}_{\mathrm{Kr}}$ current was activated by test pulses with duration from 10 to $5000 \mathrm{~ms}$ to $+30 \mathrm{mV}$, then the cells were clamped back to $-40 \mathrm{mV}$. The amplitude of the tail current as a function of the duration of the depolarizing test pulse was well fitted by a single exponential functions. Bottom. For determining deactivation $\mathrm{I}_{\mathrm{Kr}}$ current was activated by $1000 \mathrm{~ms}$ long test pulse to $30 \mathrm{mV}$ from holding potential of $-40 \mathrm{mV}$, then the cells were clamped back to $40 \mathrm{mV}$. The deactivation time course of the $\mathrm{I}_{\mathrm{Kr}}$ tail currents were fitted by double (HM, DM or $\mathrm{RM}$ ) and triple (GM) exponential functions. 
The deactivation of $\mathrm{I}_{\mathrm{Kr}}$ in $\mathrm{HM}, \mathrm{DM}$ and $\mathrm{RM}$ measured at $-40 \mathrm{mV}$, after a pulse to 30 $\mathrm{mV}$ was slow and biexponential $\left(\tau_{1}=0.6 \pm 0.05 \mathrm{~s}\right.$ and $\tau_{2}=6.7 \pm 0.9 \mathrm{~s}$ in HM; $\tau_{1}=0.4 \pm 0.02 \mathrm{~s}$ and $\tau_{2}=3.3 \pm 0.3 \mathrm{~s}$ in DM; $\tau_{1}=0.6 \pm 0.03 \mathrm{~s}$ and $\tau_{2}=6.5 \pm 0.3 \mathrm{~s}$ in RM, respectively, $\mathrm{n}=8-26$ ), while in GM the $\mathrm{I}_{\mathrm{Kr}}$ tail current was best fitted triexponentially $\left(\tau_{1}=0.14 \pm 0.01 \mathrm{~s}, \tau_{2}=0.8 \pm 0.01 \mathrm{~s}\right.$ and $\left.\tau_{3}=6.6 \pm .06 \mathrm{~s}, \mathrm{n}=10\right)$ (Figure 11, bottom).

$\mathrm{I}_{\mathrm{Ks}}$ measured at $30 \mathrm{mV}$, activated slowly and had apparently a monoxponential time course in HM, DM and RM ( $\tau=0.9 \pm 0.2 \mathrm{~s}$ in HM, $\tau=1 \pm 0.1 \mathrm{~s}$ in DM, and $\tau=0.8 \pm 0.05 \mathrm{~s}$ in RM, respectively, $\mathrm{n}=6-21)$. In contrast, in $\mathrm{GM}$ the activation was clearly biexponential $\left(\tau_{1}=0.5 \pm 0.02 \mathrm{~s}\right.$ and $\tau_{2}=3.2 \pm 0.01 \mathrm{~s}, \mathrm{n}=10$ ) (Figure 12, top). In HM, DM and RM $\mathrm{I}_{\mathrm{Ks}}$ deactivation measured at $-40 \mathrm{mV}$, was fast and monoexponential $(\tau=0.15 \pm 0.02 \mathrm{~s}$, $\tau=0.14 \pm 0.01 \mathrm{~s}$ and $\tau=0.16 \pm 0.05 \mathrm{~s}$, respectively, $\mathrm{n}=6-22$ ), while in $\mathrm{GM}$, in addition to the fast component $\left(\tau_{1}=0.16 \pm 0.01 \mathrm{~s}, \mathrm{~A}_{1}=860 \pm 98 \mathrm{pA}\right)$ an another slower component was also revealed $\left(\tau_{2}=0.6 \pm 0.1 \mathrm{~s}, \mathrm{~A}_{2}=670 \pm 79 \mathrm{pA}, \mathrm{n}=10\right)$ (Figure 12, bottom).

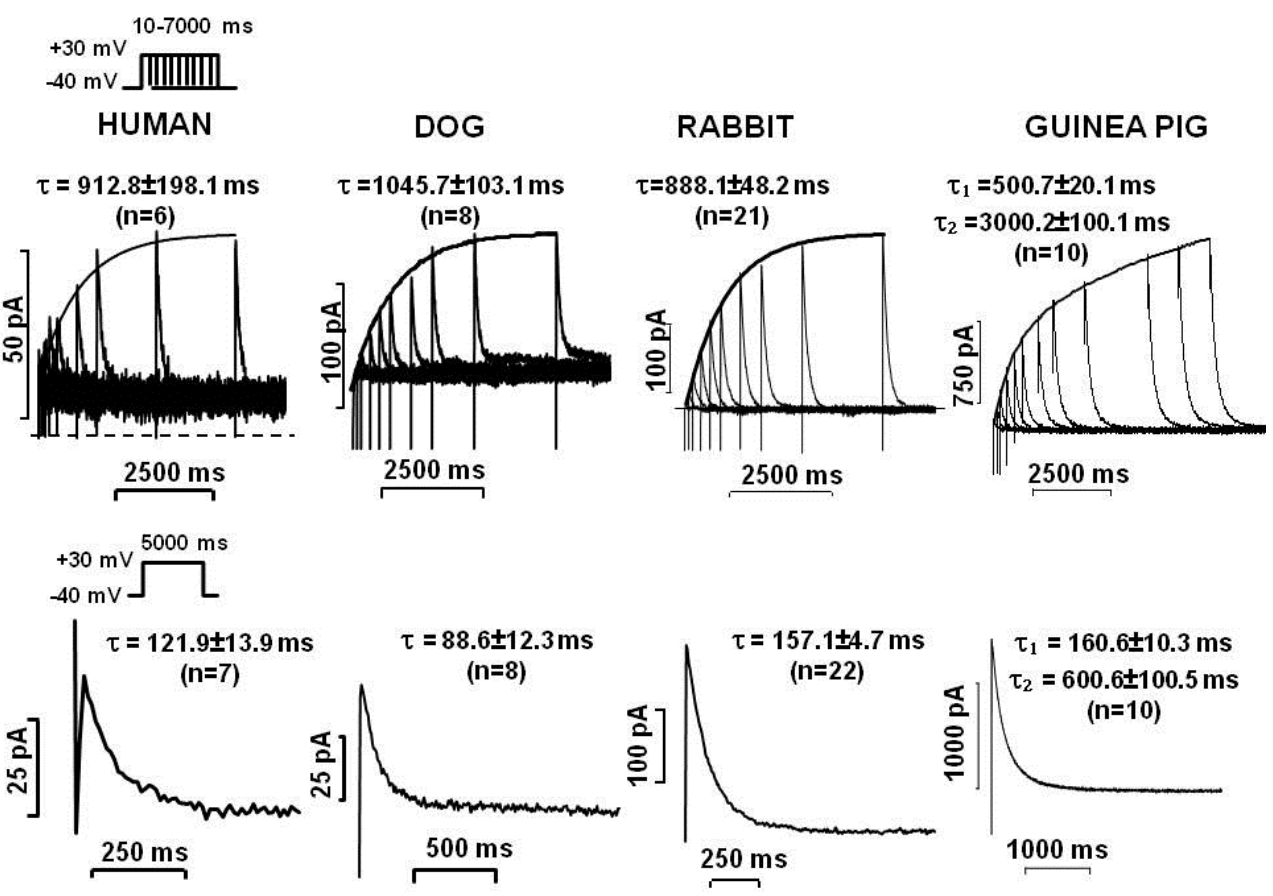

Figure 12. Activation (top) and deactivation (bottom) of $I_{K s}$ current in human, dog rabbit and guinea pig ventricular myocytes. Top. Activation kinetics was determined with the use of "envelope of tail test" protocol (see inset). $\mathrm{I}_{\mathrm{Ks}}$ current was activated by test pulses with duration from 10 to $7000 \mathrm{~ms}$ to $+30 \mathrm{mV}$, and then the cells were clamped back to $-40 \mathrm{mV}$. The amplitude of tail current as a function of the duration of the depolarizing test pulse was well fitted by a single exponential function in the case of HM, DM and RM and by double exponential function for GM. Bottom. For determining deactivation $\mathrm{I}_{\mathrm{Ks}}$ current was activated by $5000-\mathrm{ms}$ long test pulse to +30 $\mathrm{mV}$ from holding potential of $-40 \mathrm{mV}$, and then the cells were clamped back to $-40 \mathrm{mV}$. The deactivation time course of the $\mathrm{I}_{\mathrm{Ks}}$ tail currents were fitted by single (HM, DM and RM) or double (GM) exponential functions. The activation and deactivation kinetics of $\mathrm{I}_{\mathrm{Kr}}$ and $\mathrm{I}_{\mathrm{Ks}}$ measured at the whole range of activating and deactivating membrane potentials (Figure 13) were studied only in human and dog myocytes. 
The voltage dependence of the $\mathrm{I}_{\mathrm{Kr}}$ and $\mathrm{I}_{\mathrm{Ks}}$ kinetics and are in principle similar between dog and human except the deactivation kinetics of $\mathrm{I}_{\mathrm{Kr}}$ in the voltage range of $-50 \mathrm{mV}$ to $10 \mathrm{mV}$. In this range where the $\mathrm{I}_{\mathrm{Kr}}$ deactivation kinetics were clearly biexponential, the deactivation time constant of the slow component was slower in human $(\tau \sim 8000-10000$ $\mathrm{ms}$ in average) than in $\operatorname{dog}(\tau \sim 4000-5000 \mathrm{~ms}$ in average) (Figure 13C).
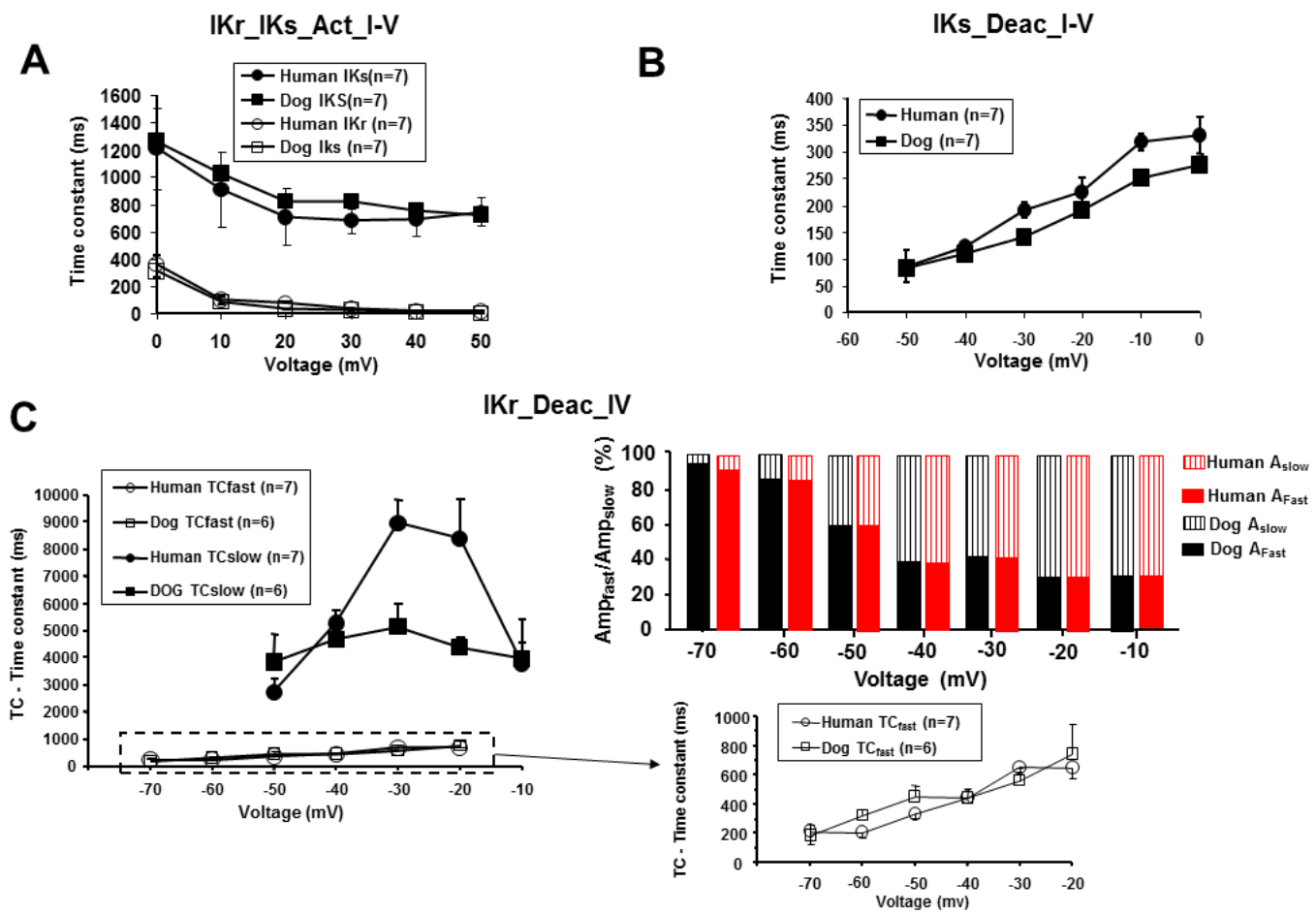

Figure 13. Voltage dependence of the activation (panel A) and deactivation (panels B and C) of $\mathrm{I}_{\mathrm{Kr}}$ and $\mathrm{I}_{\mathrm{Ks}}$ currents in human (open and closed circles) and dog (open and closed rectangles) ventricular myocytes. Panel A. Activation kinetics was determined by applying the use of "envelope of tail test" protocol (see inset). $\mathrm{I}_{\mathrm{Kr}}$ and $\mathrm{I}_{\mathrm{Ks}}$ currents were activated by test pulses with duration from 10 to $5000 \mathrm{~ms}$ to various test potentials ranging from 0 to $50 \mathrm{mV}$, and then the cells were clamped back to $-40 \mathrm{mV}$. The amplitude of the deactivating tail current as a function of the duration of the depolarizing test pulse was well fitted by a single exponential functions. Panel B. The voltage dependence of the $\mathrm{I}_{\mathrm{Ks}}$ deactivation kinetics was determined by using the voltage protocol indicating the inset in panel $\mathrm{B}$. $\mathrm{I}_{\mathrm{Ks}}$ current was activated by 5000-ms long test pulse to 50 $\mathrm{mV}$ from HP of $-40 \mathrm{mV}$. Then the cells were clamped back to different potentials ranging from -50 to $0 \mathrm{mV}$ (this voltage step was $2 \mathrm{~s}$ long and the pulse frequency was $0.1 \mathrm{~Hz}$ ) and the deactivation time course of the tail current was fitted by a single exponential function. Panel $\mathrm{C}$. The voltage dependence of the $\mathrm{I}_{\mathrm{Kr}}$ deactivation kinetics was determined by using a quite similar voltage protocol as for $\mathrm{I}_{\mathrm{Ks}} . \mathrm{I}_{\mathrm{Kr}}$ current was activated by 1000 -ms long test pulse to $30 \mathrm{mV}$ from HP of -40 $\mathrm{mV}$. Then the cells were clamped back to different potentials ranging from -70 to $0 \mathrm{mV}$ (this voltage step was $16 \mathrm{~s}$ long and the pulse frequency was $0.05 \mathrm{~Hz}$ ) and the deactivation time course of the tail current was fitted by a double exponential function. Left panel shows the voltage dependence of slow and fast time constants. In order to better resolution the voltage dependence of the fast time constants are depicted in the right bottom panel. Right top panels show the relative ratio of the fast and slow components of the amplitudes of at different voltages in DM and HM. 


\subsubsection{Effect of selective $I_{K r}$ and $I_{K s}$ blockade on the action potential duration}

We tested the effect of $\mathrm{I}_{\mathrm{Kr}}$ and $\mathrm{I}_{\mathrm{Ks}}$ block on action potential using conventional microelectrode technique. Selective $\mathrm{I}_{\mathrm{Kr}}$ blockade with E-4031 $(1 \mu \mathrm{M})$ using test pulse $1000 \mathrm{~ms}(1 \mathrm{~Hz})$ resulted in substantial and comparable APD lengthening (30-70\%) in all species (Figure 14, top).

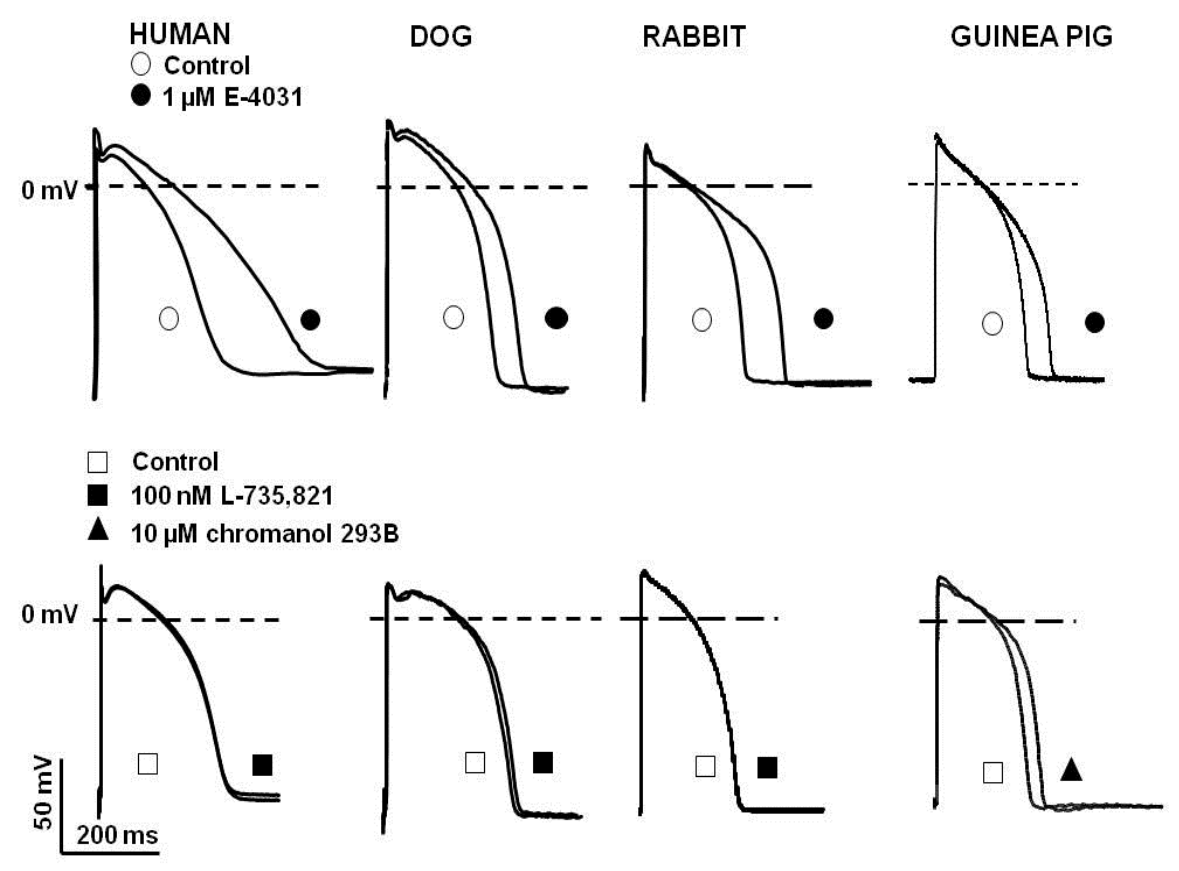

Figure 14. Effect of selective $I_{\mathrm{Kr}}$ (by E-4031) and $\mathrm{I}_{\mathrm{Ks}}$ (by chromanol and L-735,821) blockade on the action potential in undiseased human, dog, rabbit and guinea pig ventricular myocytes with the stimulation frequency of $1 \mathrm{~Hz}$.

$\mathrm{I}_{\mathrm{Ks}}$ blockade with L-735,821 (100 nM) using test pulse $1000 \mathrm{~ms}$ did not lengthen significantly APD in HM, DM and RM (Figure 14, bottom, first three panels). In contrary, in GM, the other selective $\mathrm{I}_{\mathrm{Ks}}$ blocker, chromanol $293 \mathrm{~B}$ (at the concentration of $10 \mu \mathrm{M}$, which blocks $\mathrm{I}_{\mathrm{Ks}}$ to about $\left.60 \%\right)$ significantly lengthened the APD (+12\%). In this last experiment the test pulse was $500 \mathrm{~ms}(0.5 \mathrm{~Hz})$ (Figure 14, Bottom, last panel).

\subsection{Effects of ORM - 10103 on the NCX current, $I_{C a L}, I_{N a}$, and $K^{+}$currents and on the formation of EAD and DAD in the canine hearts}

\subsubsection{Chemical structure of ORM-10103}

ORM-10103 [5-nitro-2-(2-phenylchroman-6-yloxy) pyridine] was put at disposal by Orion Pharma (Espoo, Finland) and its structure is depicted in Figure 15. 
<smiles>O=[N+]([O-])c1ccc(Oc2ccc3c(c2)CCC(c2ccccc2)O3)nc1</smiles>

ORM-10103

Figure 15. The chemical structure of ORM-10103

\subsubsection{Effects of ORM-10103 on the outward and inward NCX current}

Panel A of Figure 16 shows the original recording of the current in the presence of normal Tyrode solution during the voltage ramp pulse illustrated in the top right corner while, panel B illustrates a current recording after blocking $\mathrm{Na}^{+}, \mathrm{Ca}^{2+}, \mathrm{K}^{+}$and $\mathrm{Na}^{+} / \mathrm{K}^{+}$ pump currents. In panel C, $1 \mu \mathrm{M}$ ORM-10103 was applied and the current was recorded with the same voltage pulse. Finally, to obtain a complete block of the NCX current 10 $\mathrm{mM} \mathrm{NiCl} l_{2}$ was added to the tissue bath and the resulting recording (part D) was subtracted from the control recording (to give trace B-D) and from the ORM-10103 recording (to give trace C-D).

A Control (in Tyrode solution)

A

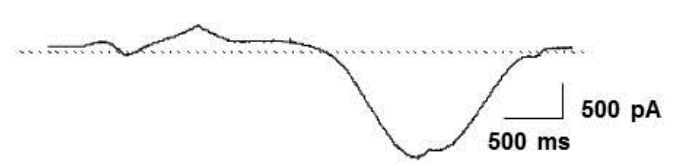

B Control (blocking $I_{N a}, I_{C a}, I_{K}$ and $I_{\text {NaKK }}$ currents)
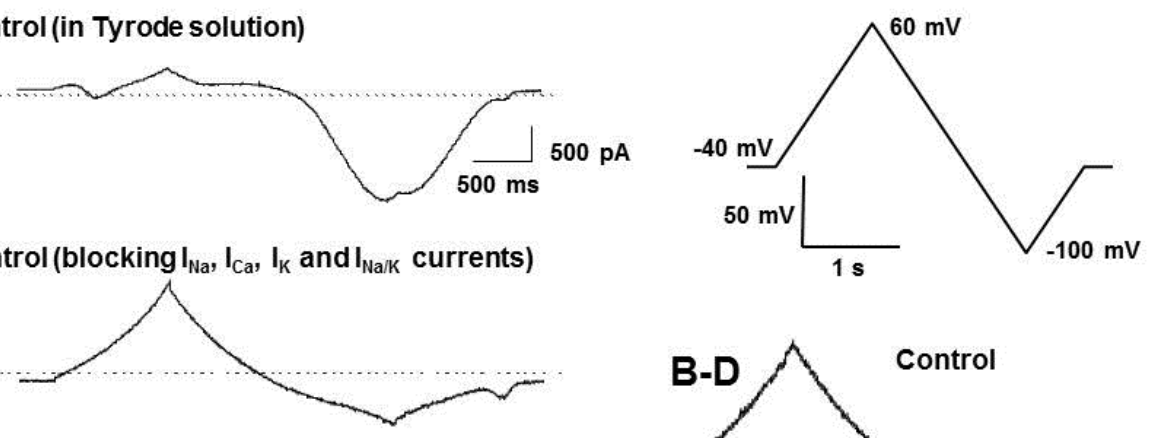

C
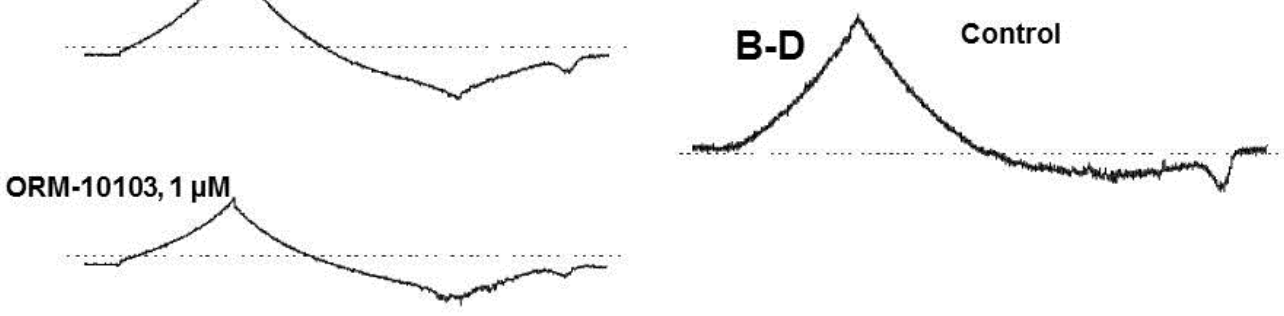

D

$$
\mathrm{NiCl}_{2}, 10 \mathrm{mM}
$$
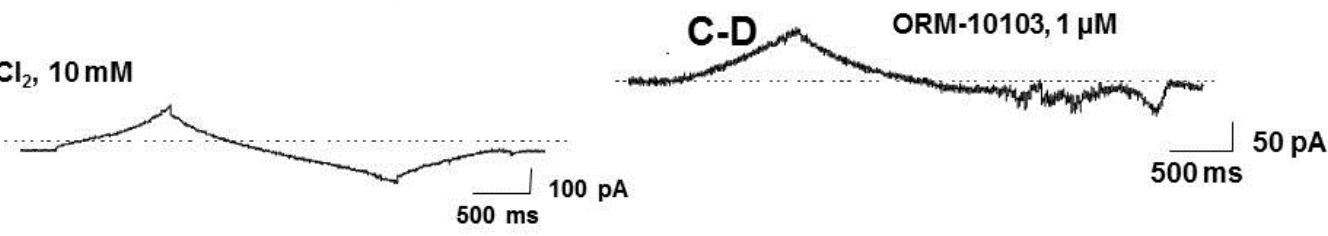

Figure 16. Determination of NCX current in canine ventricular myocytes. A: recording obtained with the voltage protocol shown in the inset with normal Tyrode solution. B: The current trace after blockade of $\mathrm{Na}^{+}, \mathrm{Ca}^{2+}, \mathrm{K}^{+}$and $\mathrm{Na}^{+} / \mathrm{K}^{+}$pump currents. C: The current trace after superfusion with $1 \mu \mathrm{M}$ ORM-10103. D: The current trace at the end of the measurements after the application of $10 \mathrm{mM} \mathrm{NiCl}_{2}$. On the right the control NCX current is shown, which is obtained by subtracting trace D from trace B. The NCX current in the presence of $1 \mu \mathrm{M}$ ORM-10103 is obtained by subtracting trace $\mathbf{D}$ from trace $\mathbf{C}$. Note the difference in the intensity-time calibration in the left and right panels. 
It is clear from Figure 16 that the $\mathrm{Ni}^{2+}$-sensitive current, i.e. the $\mathrm{NCX}$ current was markedly reduced by $1 \mu \mathrm{M}$ ORM-10103. In latter measurements application of $10 \mu \mathrm{M}$ ORM-10103 did not change the $\mathrm{Ni}^{2+}$-insensitive current, after blocking the below mentioned currents, indicate that the current reduced by ORM-10103 was indeed the NCX current and not a $\mathrm{Ni}^{2+}$-insensitive leakage current. Figures 17 and 18 demonstrate that both the outward and the inward NCX currents were considerably reduced by ORM-10103, in a concentration-dependent manner.

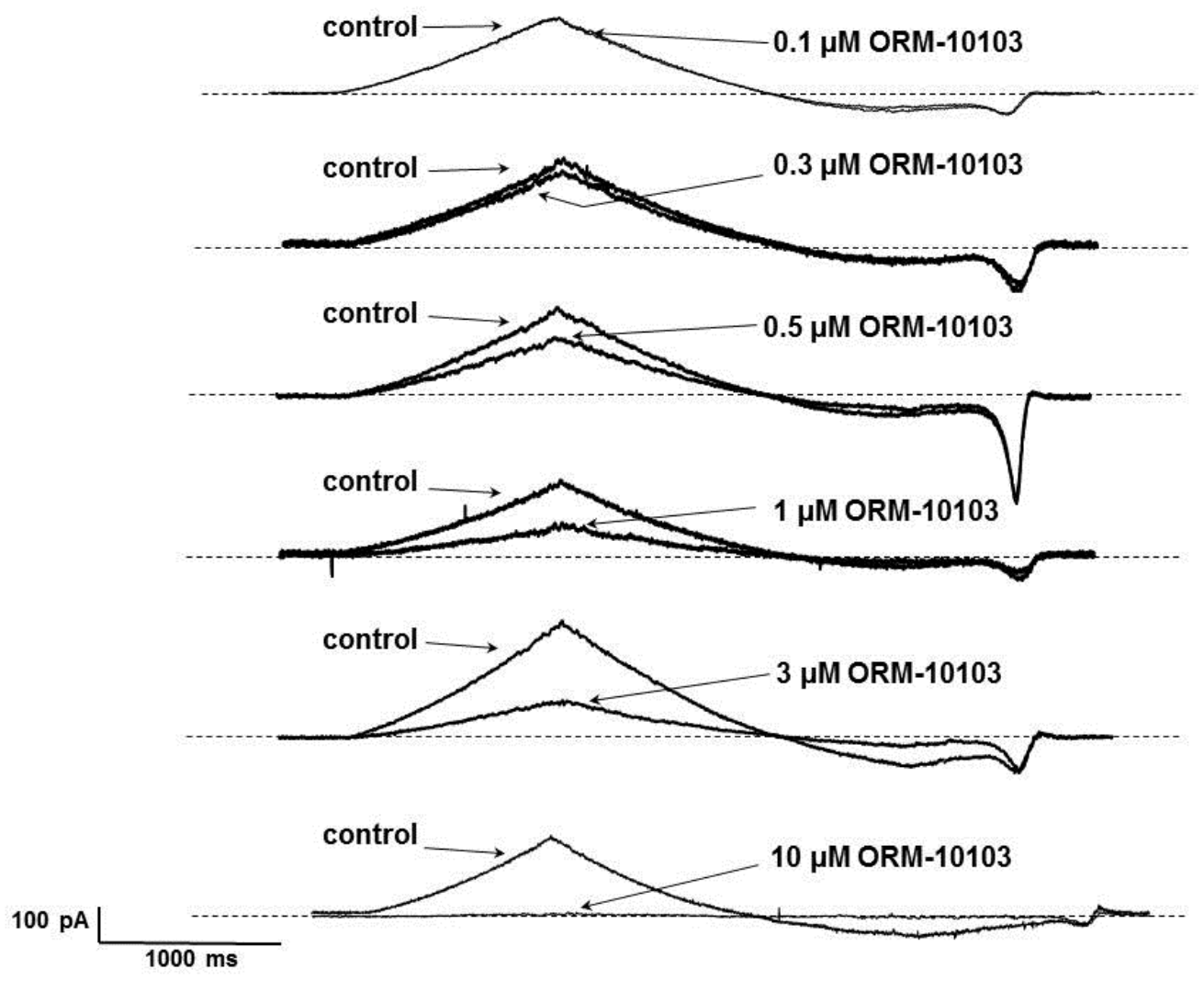

Figure 17. The concentration-dependent effect of ORM-10103 on the NCX current in canine ventricular myocytes. Each panel presents $\mathrm{Ni}^{2+}$-sensitive (NCX) current traces before and after superfusion of the cells with a concentration of ORM-10103 ranging from 0.1 to $10 \mu \mathrm{M}$.

The effect in the outward direction was statistically significant in the potential range between 0 and $60 \mathrm{mV}$ in the presence of ORM-10103 concentrations higher than $0.5 \mu \mathrm{M}$ (Figure 18A, right panel). At the same concentrations the blockade of the inward NCX current by ORM-10103 was also significant (Figure 18A, left panel). The estimated EC $_{50}$ values for the inward and outward NCX currents were $780 \mathrm{nM}$, and $960 \mathrm{nM}$, respectively (Figure 18B). 

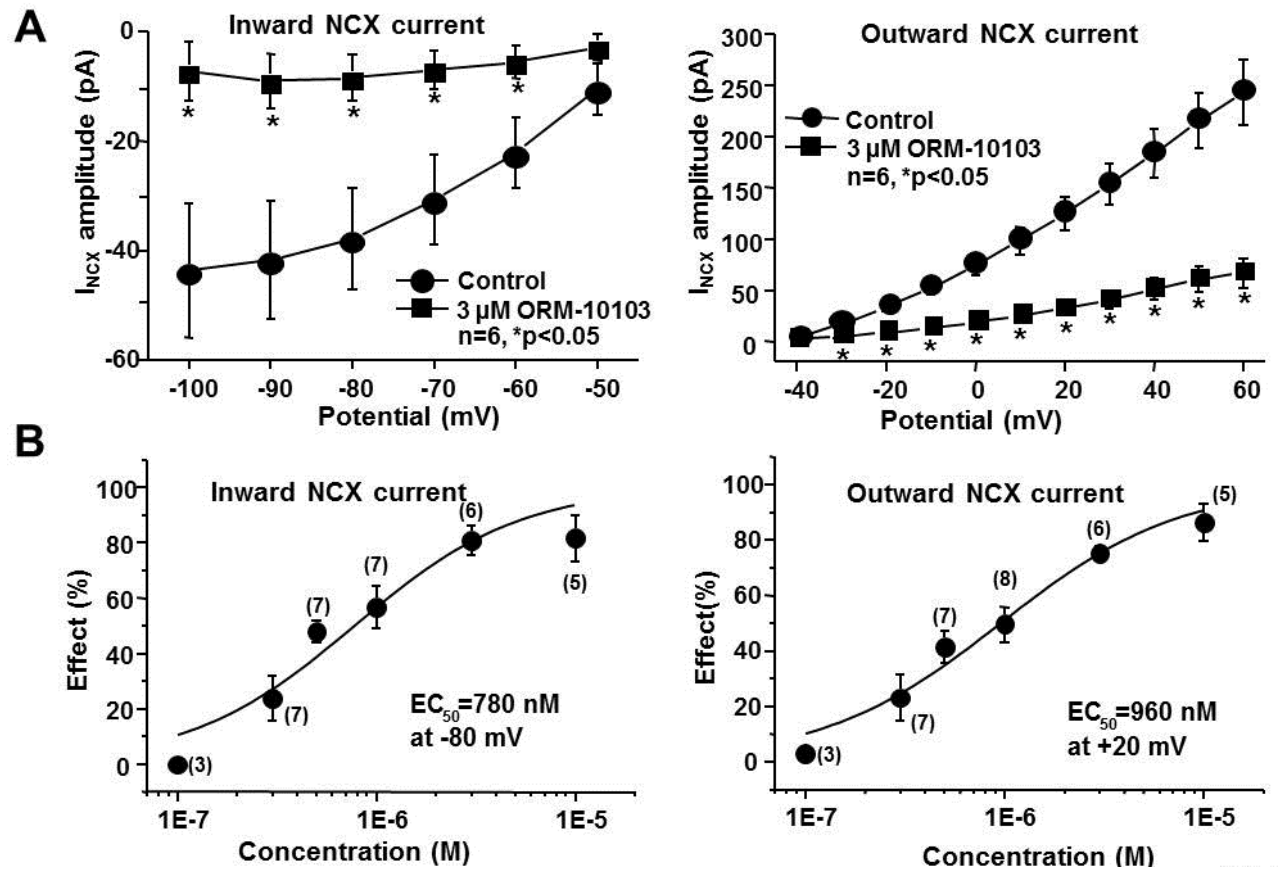

Figure 18. Panel A. The amplitude of the inward (left) and the outward (right) NCX currents in the absence or in the presence of $3 \mu \mathrm{M}$ ORM-10103. Bars indicate \pm standard errors of the means, ${ }^{*} p<0.05$. Panel B. The drug-response curve of ORM-10103 on the inward (left) and outward (right) NCX currents in canine ventricular myocytes at $-80 \mathrm{mV}$ and at $+20 \mathrm{mV}$, respectively. Values are means \pm SEM, $n=3-8$.

\subsubsection{The effect of ORM-10103 on the L-type inward calcium, inward sodium and outward potassium currents}

Further we studied the possible effect of ORM-10103 on the L-type inward calcium current in canine ventricular myocytes. These experiments clearly revealed that even at high $(10 \mu \mathrm{M})$ concentration ORM-10103 did not influence significantly $\mathrm{I}_{\mathrm{CaL}}$ (Figure 18A). We can see that after adding the known selective $\mathrm{I}_{\mathrm{CaL}}$ blocker nifedipine $(10 \mu \mathrm{M})$ we obtained an almost complete block of the current indicating that the recorded current was $\mathrm{I}_{\mathrm{CaL}}$ (Figure 19A). The effect of ORM-10103 on the inactivation kinetics was also investigated. The inactivation time constant was not significantly changed by $10 \mu \mathrm{M}$ ORM-10103 (40.0 $\pm 4.6 \mathrm{~ms}$ vs. $35.0 \pm 5.5 \mathrm{~ms}$ at $0 \mathrm{mV}, \mathrm{n}=8$, n.s.). The effect of ORM-10103 on the inward sodium current was assessed by measuring the $\mathrm{dV} / \mathrm{dt}_{\max }$ in the canine right ventricular papillary muscle with the conventional microelectrode technique. At the high concentration of $10 \mu \mathrm{M}$, ORM-10103 did not change $\mathrm{dV} / \mathrm{dt}_{\max }$ significantly at stimulation cycle lengths in the range 300-5000 ms, suggesting that it had not effect on the inward sodium current (Figure 19B). 
Because the $\mathrm{I}_{\mathrm{CaL}}$ measurements exhibited a slight run down in some voltage clamp experiments, the effect of ORM-10103 was also studied on slow response action potentials recorded from guinea-pig papillary muscles. As Figure 20 shows, ORM-10103 at $10 \mu \mathrm{M}$ did not affect the amplitude (control: $81.2 \pm 5.7 \mathrm{mV}$, ORM-10103: 81.6 $\pm 6.1 \mathrm{mV}, \mathrm{n}=5$, n.s.) or $\mathrm{dV} / \mathrm{dt}_{\max }$ (control: $12.4 \pm 2.3 \mathrm{~V} / \mathrm{s}$, ORM-10103: $11.8 \pm 2.6 \mathrm{~V} / \mathrm{s}, \mathrm{n}=5$, n.s.) of these slow response action potentials, suggesting the lack of effect of ORM-10103 on the L-type calcium current. Using the calcium current blocker nisoldipine at $50 \mathrm{nM}$ markedly reduced both the amplitude and $\mathrm{dV} / \mathrm{dt}_{\max }$ of the slow response action potentials.

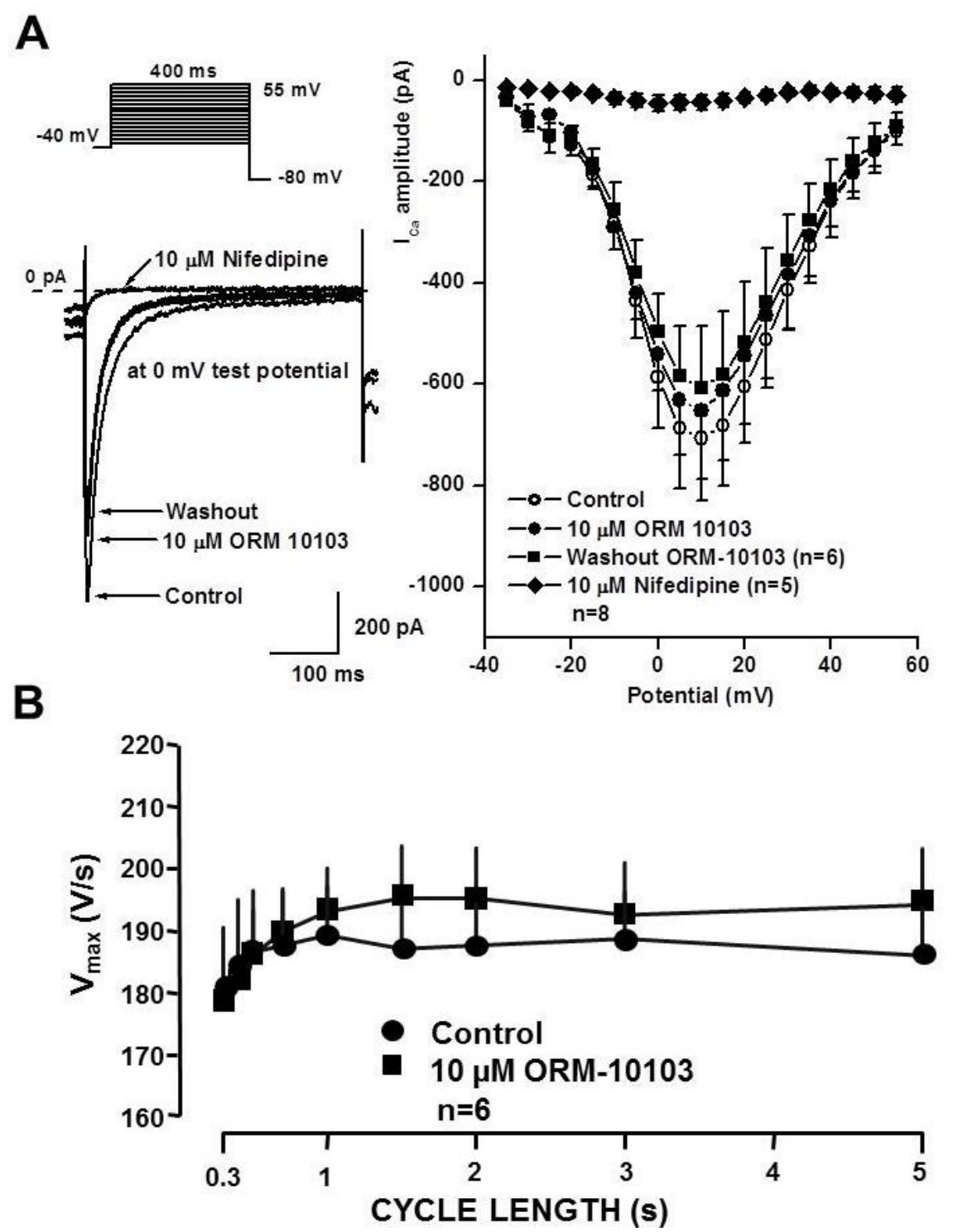

Figure 19. Panel A. Lack of effect of $10 \mu \mathrm{M}$ ORM-10103 on the L-type $\mathrm{I}_{\mathrm{Ca}}$ and $\mathrm{I}_{\mathrm{Na}}$ assessed as $\mathrm{dV} / \mathrm{dt}_{\max }$ in canine ventricular myocytes. In the inset at the top, the voltage protocol is shown. The left panels indicate original current traces recorded in control conditions, in the presence of $10 \mu \mathrm{M}$ ORM-10103, after washout of ORM-10103 and after application of $10 \mu \mathrm{M}$ nifedipine. The right panel illustrates the current-voltage relation of $\mathrm{I}_{\mathrm{CaL}}$ in the absence and presence of $10 \mu \mathrm{M}$ ORM10103, after washout of ORM-10103 and after application of $10 \mu \mathrm{M}$ nifedipine. Values are means \pm standard errors of the means. Panel B. Lack of effect of $10 \mu \mathrm{M}$ ORM-10103 on the $\mathrm{dV} / \mathrm{dt}_{\max }$ indicative of $\mathrm{I}_{\mathrm{Na}}$ in canine right ventricular papillary muscles. Values are means \pm SEM. 
Recording outward potassium currents $(n=8-11)$ we found that $I_{K 1}, I_{t o}$ and $I_{K s}$ were not affected, however, $\mathrm{I}_{\mathrm{Kr}}$ was slightly but significantly diminished (from $58.6 \pm 5.6 \mathrm{pA}$ to $43.1 \pm 5.1 \mathrm{pA}$ at $20 \mathrm{mV}$ test potential, $\mathrm{n}=8, \mathrm{p}<0.05)$ in the presence of $3 \mu \mathrm{M}$ ORM-10103 (Figure 21).

A

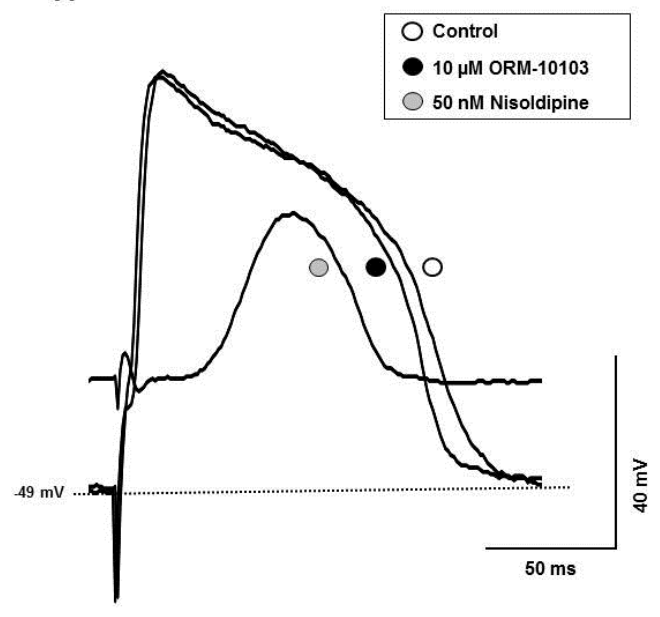

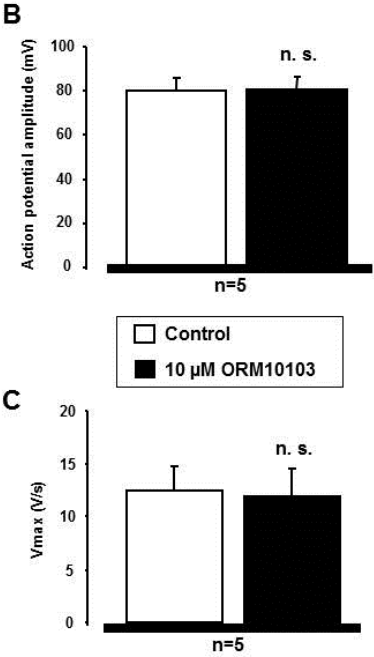

Figure 20. Lack of effect of ORM-10103 on slow response action potentials in guinea-pig ventricular myocytes. Panel A shows original slow action potential records under control conditions, in the presence of $10 \mu \mathrm{M}$ ORM-10103 and after application of $50 \mathrm{nM}$ nisoldipine. $\underline{\text { Panels B }}$ and $\underline{\mathrm{C}}$ reveal the lack of effect of $10 \mu \mathrm{M}$ ORM-10103 on the action potential amplitude and on the maximum rate of depolarization $\left(\mathrm{dV} / \mathrm{dt}_{\max }\right)$, respectively.
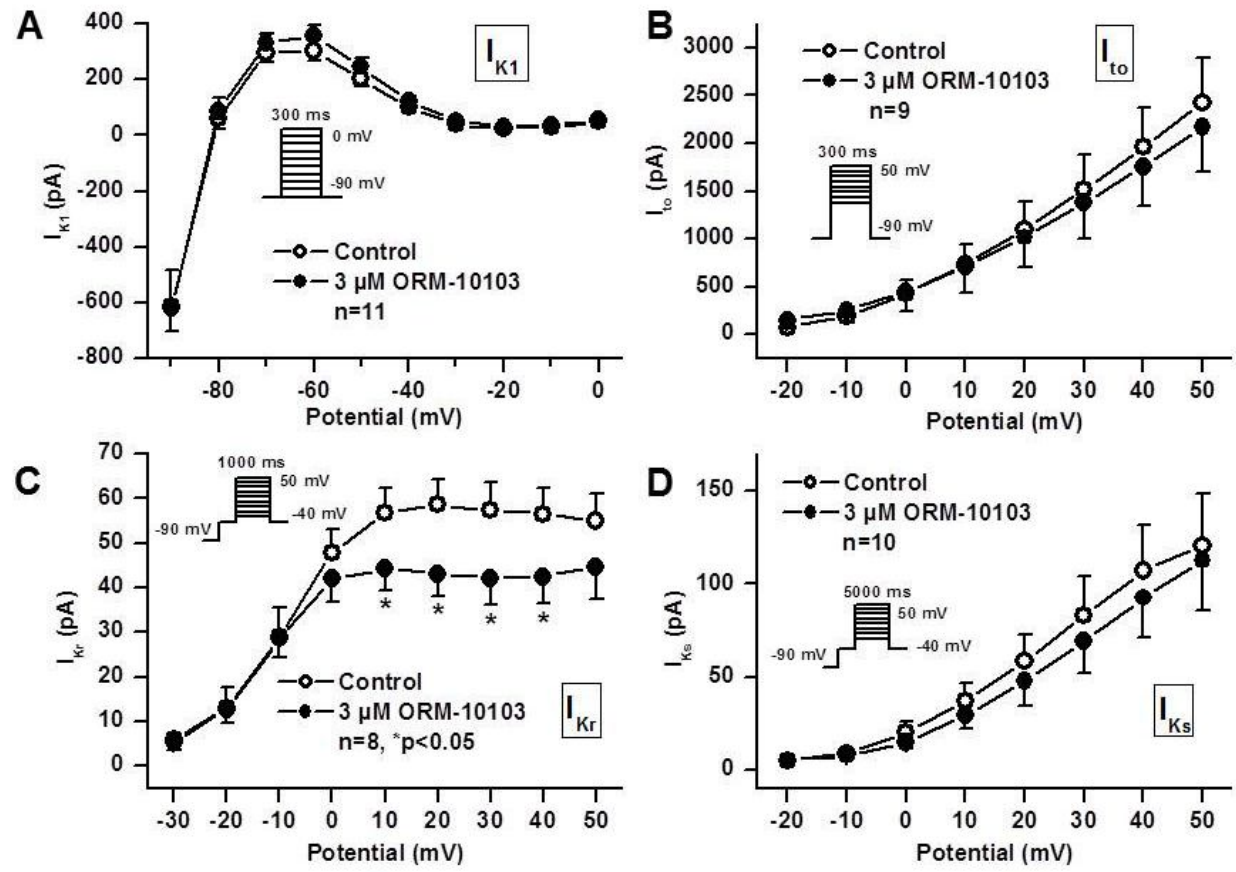

Figure 21. Effect of ORM-10103 on $I_{K 1}\left(\right.$ Panel A), $I_{t o}($ Panel B $), I_{K r}(\underline{P a n e l ~ C})$ and on $I_{K s}(\underline{\text { Panel D }})$ currents. Insets show the applied voltage protocols. Values are means $\pm \mathrm{SEM},{ }^{*} \mathrm{p}<0.05$. 


\subsubsection{Effects of ORM-10103 on the early and delayed afterdepolarizations}

By applying the conventional microelectrode technique the effects of ORM-10103 on early (EAD) and delayed (DAD) afterdepolarizations were studied in canine right ventricular papillary muscles and in canine cardiac Purkinje fibres, respectively.
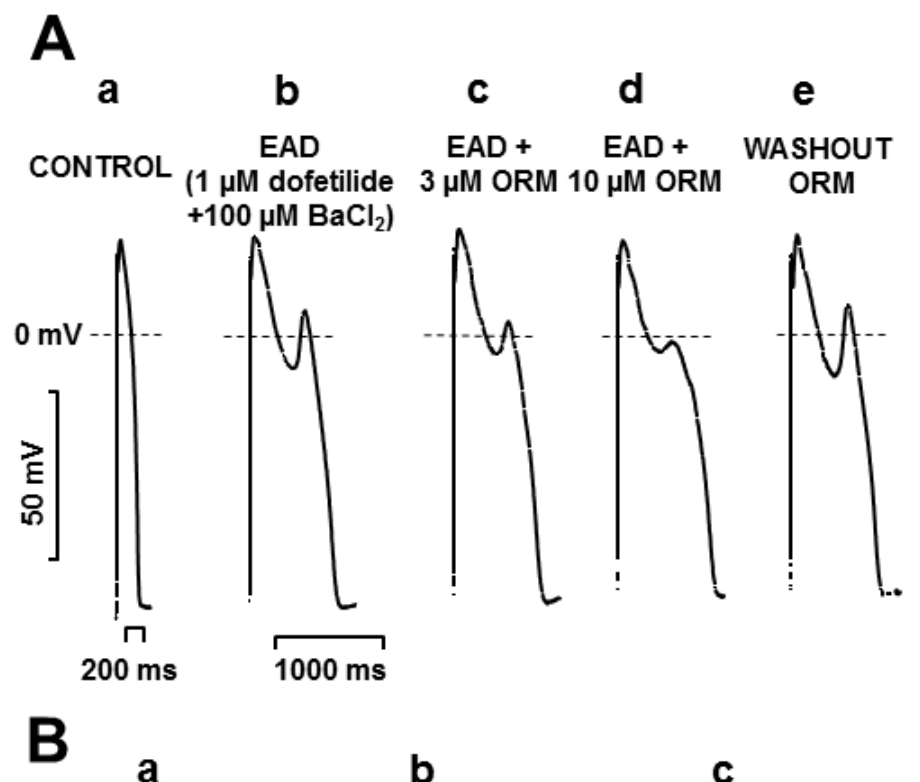

a CONTROL
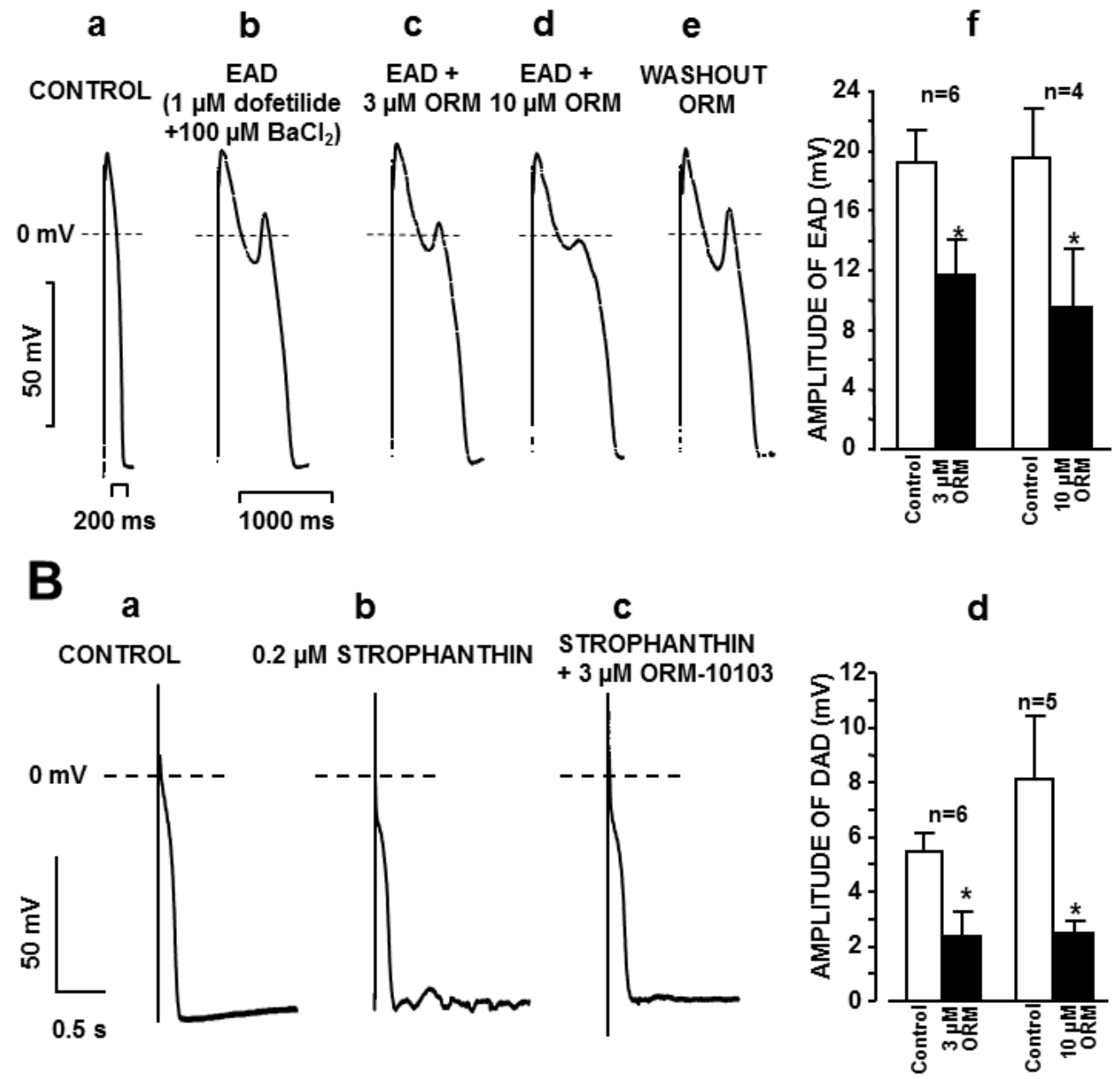

Figure 22. Panel A. Effects of 3 and $10 \mu \mathrm{M}$ ORM-10103 (ORM) on the EAD evoked by $1 \mu \mathrm{M}$ dofetilide $+100 \mu \mathrm{M} \mathrm{BaCl}_{2}$ in canine right ventricular papillary muscle. The stimulation cycle length was $2 \mathrm{~s}$. Trace $\mathbf{a}$ is a control recording. Trace $\mathbf{b}$ reveals that EAD was elicited by $1 \mu \mathrm{M}$ dofetilide $+100 \mu \mathrm{M} \mathrm{BaCl}_{2}$. In traces $\mathbf{c}$ and $\mathbf{d} 3$ and $10 \mu \mathrm{M}$ ORM-10103, respectively were applied in the continuous presence of dofetilide and $\mathrm{BaCl}_{2}$. As shown in trace $\mathbf{e}$, after 30 min washout of ORM-10103 the EAD amplitude was similar to that prior to the application of ORM-10103. In diagram $\mathbf{f}$ the effects of 3 and $10 \mu \mathrm{M}$ ORM-10103 on the EAD amplitude are to be seen. Bars represent means \pm SEM. Panel B. The effect of $3 \mu \mathrm{M}$ ORM-10103 on the DAD amplitude in canine right ventricular Purkinje fibres. DAD was evoked by a 40 stimulus train with a stimulation cycle length of $400 \mathrm{~ms}$ in the presence of $0.2 \mu \mathrm{M}$ strophanthin. Trace $\mathbf{a}$ is a control recording, trace b indicates the induction of DAD by $0.2 \mu \mathrm{M}$ strophanthin, and trace $\mathbf{c}$ demonstrates that $3 \mu \mathrm{M}$ 
ORM-10103 almost completely abolishes DAD in the continuous presence of strophanthin. Diagram d depicts the effects of 3 and $10 \mu \mathrm{M}$ ORM-10103 on the amplitude of DAD. Bars represent means \pm SEM.

EAD was elicited in the papillary muscle preparation, stimulated at slow cycle lengths (1500-3000 ms), with a combination of $1 \mu \mathrm{M}$ dofetilide and $100 \mu \mathrm{M} \mathrm{BaCl}_{2}$ (Figure 22A). Both 3 and $10 \mu \mathrm{M}$ ORM-10103 clearly decreased the amplitude of the EAD. This effect was concentration-dependent and reversible upon washout of the ORM-10103 from the tissue bath containing dofetilide and $\mathrm{BaCl}_{2}$. Similar effects were seen in additional experiments (Figure 22A, right panel). $3 \mu \mathrm{M}$ ORM-10103 decreased the amplitude of the EAD from $19.3 \pm 2.2$ to $11.7 \pm 2.4 \mathrm{mV}(\mathrm{n}=6, \mathrm{p}<0.05)$. At higher concentration $10 \mu \mathrm{M}$, the compound had a more pronounced effect, decreasing EAD from $19.4 \pm 3.3$ to $9.5 \pm 4.0 \mathrm{mV}$ $(\mathrm{n}=4, \mathrm{p}<0.05)$.

DAD was evoked in Purkinje fibre preparations superfused with $0.2 \mu \mathrm{M}$ strophanthin for $40 \mathrm{~min}$ (Figure 22B, right panel). In these experiments, a train of 40 stimuli was applied with a cycle length of $400 \mathrm{~ms}$ in the train. The train was then followed by a stimulation-free period of $20 \mathrm{~s}$ to allow observation of DAD formation.

Following the addition of 3 or $10 \mu \mathrm{M}$ ORM-10103, the DAD amplitude was decreased (Figure 22B). This effect was also concentration-dependent; ORM-10103 at $3 \mu \mathrm{M}$ decreased the DAD amplitude from $5.5 \pm 0.6$ to $2.4 \pm 0.8 \mathrm{mV}(\mathrm{n}=6, \mathrm{p}<0.05)$, while 10 $\mu$ M ORM-10103 did so from $8.1 \pm 2.3$ to $2.5 \pm 0.3 \mathrm{mV}(\mathrm{n}=5, \mathrm{p}<0.05)$. In two experiments, strophanthin evoked a run of extra beats after the termination of the stimulus train, which could be successfully abolished by the application of $10 \mu \mathrm{M}$ ORM-10103 (not shown).

\section{DISCUSSION}

\subsection{The effects of the two optical enatiomers of R-L3}

A previous study (53) which suggested that L-364,373 has two optical enantiomers that might have adverse modulating effect on the slow delayed rectifier potassium current $\left(\mathrm{I}_{\mathrm{Ks}}\right)$ led us to the major finding of our study. We have analyzed the efficacy of ZS_1270B (right) and ZS 1271B (left), the two enantiomers of R-L3 (Figure 5). The right enantiomer ZS_1270B proved to be a successful activator of $\mathrm{I}_{\mathrm{Ks}}$ current, at $1 \mu \mathrm{M}$ it increased by about $26 \%$ (Figure 6), while the left enantiomer ZS_1271B, at $1 \mu \mathrm{M}$ blocked the current by about $47 \%$ (Figure 7). Moreover, it seems that the two enantiomers have these adverse modulating effects at close concentrations. In some previous studies others showed that in 
guinea pig and rabbit myocytes L-364,373 (R-L3) increased $\mathrm{I}_{\mathrm{Ks}}$ markedly and in a concentration dependent manner $(0.1-1 \mu \mathrm{M})$ causing a leftward shift in its activation curve $(\mathbf{4 9 , 5 0 )}$.

In 2006, in another study it was shown that at higher concentrations up to $3 \mu \mathrm{M}$ R-L3 failed to activate the $\mathrm{I}_{\mathrm{Ks}}$ current in dog ventricular myocytes. At that time it was speculated whether this might be a species dependent, different blocking property of the compound (52).

In a latter study performed by a Danish group, it was reported that the pharmacologically induced Long QT type 2 can be rescued by activating the $\mathrm{I}_{\mathrm{Ks}}$ current with the application of the benzodiazepine R-L3 (53). In their paper they hypothesized that the left enantiomer of the R-L3 (S-L3) might be a potent $\mathrm{I}_{\mathrm{Ks}}$ blocker, thereby even at small impurities in the racemic R-L3 used could therefore cause significant reductions in the APD shortening effect of optically pure R-L3 (53). After getting access to the two enatiomers we decided to test the $\mathrm{I}_{\mathrm{Ks}}$ modulator effect on the cardiac repolarization. We have applied the right enantiomer on the action potential repolarization in guinea pig papillary muscle and we showed that $1 \mu \mathrm{M}$ ZS_1270B shortened APD 90 , while conversely the left enantiomer ZS_1271B applied on the same concentration of $1 \mu \mathrm{M}$ significantly lengthened the guinea pig repolarization (Figure 8).

$\mathrm{I}_{\mathrm{Ks}}$ current is composed by co-assembling expression of the KvLQT1 and MinK proteins that can associate to form functional cardiac $I_{K s}$ channels $(\mathbf{1 3 , 7 8 )}$. It has been known for many years that the cardiac current $I_{\mathrm{Ks}}$ is upregulated following sympathetic stimulation (79). It would be an important question to discuss at which pathways activates the ZS_1270B compound the $\mathrm{I}_{\mathrm{Ks}}$ current, ie. whether the $\mathrm{I}_{\mathrm{Ks}}$ activating properties of the enantiomers is or not mediated via sympathetic stimulation. We have checked the chemical structures of isoprenaline and other beta adrenergic agonist compounds, and may say the beta-phenylethylamine structure is an important criteria for beta-adrenergic stimulation on adrenerg receptors. If we looked the structure of the $\mathrm{I}_{\mathrm{Ks}}$ activator enantiomer ZS_1270B, we found that none of the three critical pharmacophoric groups (80) could be found in the structure of ZS_1270B, therefore, in principle we can conclude that the activating effect of this compound is not mediated via beta-adrenergic stimulation pathways.

The observation that a racemic compound have two enantiomers with complete adverse modulating effect on a current, receptor, etc, (ie. one is an activator, while the other is a blocker, moreover with a more or less similar activity), is quite unique and 
unusual, however not unknown at all $(\mathbf{8 1}, \mathbf{8 2}, \mathbf{8 3})$. Similar observation were made in some other studies, for example, the stereoisomers of the new dihydropyridine derivative 202791 [isopropyl 4-(2,1,3-benzoxadiazol-4-yl)-1,4-dihydro-2,6-dimethyl-5-nitro-3 pyridinecarboxylate] were synthesized separately and tested on isolated rabbit aortic rings for effects on depolarization-induced contraction and depolarization-stimulated uptake of $45 \mathrm{Ca}^{2+}$. The result in that investigation showed the right enantiomer inhibited contraction, while by contrast, the left enantiomer of 202-791 compound shifted the concentrationresponse curve for depolarization-induced contraction in an almost parallel fashion to the left, thus enhancing contraction (84).

\subsection{Comparison of the properties of the $I_{K r}$ and $I_{K s}$ in human, dog, rabbit and guinea pig ventricular myocytes}

The available data regarding the $\mathrm{I}_{\mathrm{Kr}}$ and $\mathrm{I}_{\mathrm{Ks}}$ components in various species draws our attention to another important question. The different experimental conditions, whether they are related to the isolation procedures or to the recording methods, resulted in significantly different, moreover, often contradictory conclusions. Therefore, our originally presumption was that our human $\mathrm{I}_{\mathrm{K}}$ data can be discussed only, if we compare them with results obtained from other species and measured also in identical or at least similar experimental setting.

In our experiments we separated the two components through pharmacological methods, choosing selective blockers in specific concentrations, which were used in earlier studies $\left(\mathbf{1 3 , 7 4 )}\right.$. In this study the well expressed presence of $\mathrm{I}_{\mathrm{Kr}}$ and $\mathrm{I}_{\mathrm{Ks}}$ was identified and characterised in undiseased human ventricle. $\mathrm{I}_{\mathrm{Kr}}$ exhibited fast activation $(\tau \approx 40 \mathrm{~ms})$ and slow and biexponential deactivation $\left(\tau_{1} \approx 600 \mathrm{~ms}\right.$ and $\tau_{2} \approx 7000 \mathrm{~ms}$ ) kinetics (Figure 11, left panels). $\mathrm{I}_{\mathrm{Ks}}$ exhibited slow activation $(\tau \approx 900 \mathrm{~ms})$ and fast and monoexponentially deactivation kinetics ( $\tau \approx 120 \mathrm{~ms}$ ) (Figure 12, left panels). Earlier reports regarding the existence of $\mathrm{I}_{\mathrm{Ks}}$ in human ventricular myocytes were controversial, namely in some studies no evidence was found for $\mathrm{I}_{\mathrm{Ks}}$. It is also worth noting that the amplitude of the $\mathrm{I}_{\mathrm{Ks}}$ tail current reported in this thesis is relatively small. But in the present studies the control solution contained neither $\mathrm{CdCl}_{2}$ nor $\mathrm{BaCl}_{2}$ as in the paper of $\mathrm{Li}$ et al $(\mathbf{1 3}, \mathbf{8 5})$.

The kinetic properties of $\mathrm{I}_{\mathrm{Kr}}$ and $\mathrm{I}_{\mathrm{Ks}}$ measured by us in rabbit and dog ventricular myocytes were similar to those determined in human. In both species, $\mathrm{I}_{\mathrm{Kr}}$ exhibited fast activation $(\tau \approx 35 \mathrm{~ms}$, resp. $50 \mathrm{~ms})$ and slow and biexponential deactivation $\left(\tau_{1} \approx 640 \mathrm{~ms}\right.$ 
resp. $360 \mathrm{~ms}$, and $\tau_{2} \approx 6500 \mathrm{~ms}$ resp. $3300 \mathrm{~ms}$ ) kinetics (Figure 11, middle panels), while $\mathrm{I}_{\mathrm{Ks}}$ current exhibited slow activation $(\tau \approx 800$ resp. $1000 \mathrm{~ms})$ and fast monoexponential deactivation ( $\tau \approx 160 \mathrm{~ms}$ resp. $90 \mathrm{~ms}$ ) (Figure 12, middle panels). The kinetic parameters of the $I_{K r}$ and $I_{K s}$ measured in rabbit and dog were similar to those measured in human $\left(\mathbf{2 8 , 2 9 , 8 6 )}\right.$. The amplitude of the $\mathrm{I}_{\mathrm{Kr}}$ current in dog was similar to that measured in human myocytes, while in rabbit myocytes the amplitude was greater (Figure 10, left panel). The amplitude of $\mathrm{I}_{\mathrm{Ks}}$ in human seems to be smaller than that measured in dog and rabbit (Figure 10, right panel). If we compare our results with those published in literature, we can conclude, that the amplitude of the $\mathrm{I}_{\mathrm{Kr}}$ and $\mathrm{I}_{\mathrm{Ks}}$ in rabbit and dog is similar to those measured by other groups $(\mathbf{2 8 , 2 9 , 4 4 )}$.

We observed an important difference in our guinea pig experiments. In guinea pig myocytes $\mathrm{I}_{\mathrm{Kr}}$ exhibited fast activation $(\tau \approx 30 \mathrm{~ms})$ and slow triexponential deactivation $\left(\tau_{1} \approx 140 \mathrm{~ms}, \tau_{2} \approx 800 \mathrm{~ms}\right.$ és $\tau_{2} \approx 6600 \mathrm{~ms}$ ) (Figure 11, right panels). The characteristics of the $\mathrm{I}_{\mathrm{Ks}}$ current obtained in guinea pig were distinct from those of other three species. The $\mathrm{I}_{\mathrm{Ks}}$ current activated slowly, biexponentially $\left(\tau_{1} \approx 500 \mathrm{~ms}\right.$ and $\left.\tau_{2} \approx 3000 \mathrm{~ms}\right)$ and the deactivation had two components: a fast $\left(\tau_{1} \approx 160 \mathrm{~ms}\right)$ and a slow $\left(\tau_{2} \approx 600 \mathrm{~ms}\right)$ one (Figure 12, right panels). These results are different from those obtained by Sanguinetti's group, where they showed that the activation and deactivation of the $I_{\mathrm{Kr}}$ current were fast, while the $\mathrm{I}_{\mathrm{Ks}}$ current had a slow activation and deactivation (13). Based on this, they suggested that $\mathrm{I}_{\mathrm{Ks}}$ blockers are able, in a reverse use dependent way, to lenghten the APD (Sanguinetti's hypothesis) (40). In contradiction with Sanguinetti's group, in our experiments we measured for $\mathrm{I}_{\mathrm{Ks}}$ current slow kinetics, while for $\mathrm{I}_{\mathrm{Kr}}$ slow deactivation kinetics (13). Based on this observation we questioned the "Sanguinetti's hypothesis" by suggesting that $\mathrm{I}_{\mathrm{Ks}}$, due to its fast deactivation, cannot accumulate during diastole, consequently its block cannot attenuate the reverse dependent properties of the Class III antiarrhythmic agents. In our earlier experiments the most selective $\mathrm{I}_{\mathrm{Ks}}$ blocker was L735,821 , which in another study, at a lower concentration than $100 \mathrm{nM}$ totally blocked the $\mathrm{I}_{\mathrm{Ks}}$ (74). This means that we could measure pure $\mathrm{I}_{\mathrm{Kr}}$ current.

We have to note that the amplitude of $\mathrm{I}_{\mathrm{Kr}}$ and $\mathrm{I}_{\mathrm{Ks}}$ recorded in guinea pig were distinct from those of other three species. The amplitude of both currents in guinea pig was three times larger than that in dog and human, but much greater than that in rabbit (Figure 10). Especially we emphasize the extent of the $\mathrm{I}_{\mathrm{Ks}}$ current, namely in guinea pig it proves to be great. This fact played an important role in Sanguinetti's hypothesis (13). In contrast with 
the other species, the $\mathrm{I}_{\mathrm{Ks}}$ in human is smaller and the role in the repolarisation of ventricular tissue must be different than that described earlier.

It is well known that even the partial (30-50\%) blockade of the $\mathrm{I}_{\mathrm{Kr}}$ current resuls in a substantial but reverse use dependent lenghtening of the APD. In our experiments we showed that in all four species the $\mathrm{I}_{\mathrm{Kr}}$ blocker E-4031, while in different proportion, but significantly lenghtened the APD (Figure 14, top panels). In our experiments the selective $\mathrm{I}_{\mathrm{Ks}}$ blocker L-735,821 (100 nM) did not lenghten the APD in human, dog and rabbit ventricular muscle (Figure 14, bottom panels). These results can be best explained by the kinetic parameters of the $\mathrm{I}_{\mathrm{Ks}}$ current, ie. $\mathrm{I}_{\mathrm{Ks}}$ activated slowly and the current amplitude is relatively small. Due to its slow activation kinetics the $\mathrm{I}_{\mathrm{Ks}}$ current under voltages relevant to an action potential plateau phase activated only in a small quantity, thereby its selective inhibiton did not resulted in a measurable APD lenghtening.

In an earlier study we showed, that when the APD was artificially lengthened by pharmacological means (augmenting inward $-\mathrm{I}_{\mathrm{Na}^{-}}$and decreasing outward $-\mathrm{I}_{\mathrm{Kr}}$ - currents), $\mathrm{I}_{\mathrm{Ks}}$ was more fully activated and thereby, the amplitude of $\mathrm{I}_{\mathrm{Ks}}$ sufficiently increased so that its selective blockade produced a significant lengthening of the APD. We concluded that $\mathrm{I}_{\mathrm{Ks}}$ had limited role in the repolarization of a ,normal” healthy heart, but our observation that when the duration of rectangular or "action potential-like" test pulse was increased and $I_{\mathrm{Ks}}$ was more fully activated, suggested that $\mathrm{I}_{\mathrm{Ks}}$ may play an important role when cardiac APD is abnormally lengthened by other means (e.g. by reductions in $\mathrm{I}_{\mathrm{Kr}}$ or $\mathrm{I}_{\mathrm{K} 1}$ or increases in $\mathrm{I}_{\mathrm{Na}}$ or $\mathrm{I}_{\mathrm{Ca}}$ ). Under such conditions pharmacological block of $\mathrm{I}_{\mathrm{Ks}}$ might be expected to have severe detrimental consequences when this protective mechanism is eliminated. For example, if repolarisation is excessively lengthened due to drug induced $\mathrm{I}_{\mathrm{Kr}}$ block, hypokalaemia, genetic abnormality or bradycardia, the subsequent increase in APD would favour $\mathrm{I}_{\mathrm{Ks}}$ activation and provide a negative feedback mechanism to limit further lengthening of APD $(45,48)$.

Based on the results reported in this thesis we need to point that this observation is true in human, dog and rabbit, where the amplitude of the slow activating $\mathrm{I}_{\mathrm{Ks}}$ current is not so significant, thereby its selective blockade did not result in substantial APD lengthening. We have shown that in guinea pig the properties of $\mathrm{I}_{\mathrm{Ks}}$ current (magnitude and kinectics as well) differed from those of other studied species. The current is sigfnificantly activated under voltages relevant to an action potential, thereby even the partial blockade of the current by $10 \mu \mathrm{M}$ chromanol 293B (which inhibits by about $60 \%$ of the $\mathrm{I}_{\mathrm{Ks}}$ in GM) resulted in a significant APD lenghtening ( $\sim 12 \%$, Figure 14, right bottom panel). 


\subsection{Effects of the ORM-10103 on the NCX, delayed rectifier potassium current and on the early and delayed afterdepolarizations}

In our experiments NCX current is defined as $\mathrm{Ni}^{2+}$-sensitive current. ORM-10103 inhibited $\mathrm{I}_{\mathrm{NCX}}$ in canine ventricular myocytes at relatively low concentrations, with an estimated $\mathrm{EC}_{50}$ of $780-960 \mathrm{nM}$. In the same cells, even at the high concentration of 10 $\mu \mathrm{M}$, ORM-10103 did not influence $\mathrm{I}_{\mathrm{CaL}}$ measured by the patch clamp technique, or $\mathrm{I}_{\mathrm{Na}}$ estimated as $\mathrm{dV} / \mathrm{dt}_{\max }$ by the conventional microelectrode measurements. Consequently, decreases of the inward currents and thereby diminution of the $\mathrm{Ca}^{2+}$ load via the $\mathrm{I}_{\mathrm{CaL}}$ and $\mathrm{I}_{\mathrm{Na}}$ can not explain the effects of ORM-10103 on the amplitudes of EAD and DAD.

The main finding of this study was that ORM-10103 effectively inhibited the NCX current without affecting $\mathrm{I}_{\mathrm{CaL}}$, and this effect was associated with decreases in the amplitudes of EAD and DAD evoked in canine ventricular papillary muscle and cardiac Purkinje fibres, respectively.

ORM-10103 did not change considerably $\mathrm{I}_{\mathrm{to}}, \mathrm{I}_{\mathrm{K} 1}$ and $\mathrm{I}_{\mathrm{Ks}}$, and regarding $\mathrm{I}_{\mathrm{Kr}}$ a slight but significant decrease of the current was found in the presence of ORM-10103. The reduction in outward potassium currents resulting in prolongation of repolarization would rather increase than decrease the liability to afterdepolarizations (87). Therefore, participation of the rapid delayed rectifier $\mathrm{K}^{+}$current in the mechanism whereby ORM10103 decreases EAD and DAD is unlikely.

In the literature two compounds, KB-R7943 and SEA0400 have been reported as potent inhibitors of the NCX current even in submicromolar concentrations. KB-R7943 additionally abolishes experimental arrhythmias (88), while SEA-0400 significantly decreases the pharmacologically induced EAD and DAD in canine ventricular preparations in concentrations at which it does not interfere with $\mathrm{I}_{\mathrm{CaL}}$ (66). In other studies, it was demonstrated that KB-R7943 and SEA-0400 in micromolar concentrations do inhibit the L-type calcium current $(\mathbf{8 9 , 9 0 )}$, which makes the interpretation of their antiarrhythmic effect somewhat uncertain. Our present investigation has provided further evidence that specific NCX inhibition results in suppression of triggered arrhythmias in in vitro cardiac preparations.

The possible therapeutic implications of our study appear to be rather complex. Suppression of EAD and DAD may be antiarrhythmic in both ventricles and atria (91) during a $\mathrm{Ca}^{2+}$ overload, as in heart failure, digitalis intoxication, and at the beginning of atrial flutter and fibrillation, especially when $\mathrm{K}^{+}$currents have been downregulated $(\mathbf{9 2 , 9 3 )}$ and the NCX current upregulated (94). It has been considered that, on reperfusion after 
myocardial ischaemia, $\mathrm{Ca}^{2+}$ influx occurs via $\mathrm{NCX}$ in the reverse mode contributing to $\mathrm{Ca}^{2+}$ overload and the release of $\mathrm{Ca}^{2+}$ from the sarcoplasmic reticulum and thereby causing cardiac arrhythmias (95). Accordingly, blockade of the reverse mode of the NCX current may be beneficial.

Further research is clearly needed with both in vitro and in vivo methods in order to elucidate the potential therapeutic targets and, in a wider sense, the possible beneficial effect of specific NCX inhibition.

\section{CONCLUSIONS AND POTENTIAL SIGNIFICANCE}

(1) We have shown that the two optical enantiomers of the benzodiazepine R-L3 (ZS_1270B and ZS_1271B) have adverse modulating effects on $\mathrm{I}_{\mathrm{Ks}}$ in the same concentration range. ZS_1270B is a potent activator of $\mathrm{I}_{\mathrm{Ks}}$, therefore, this substance is adequate to test whether $\mathrm{I}_{\mathrm{Ks}}$ activators are indeed ideal tools to suppress ventricular arrhythmias originating from prolongation of action potentials.

(2) The rapid $\left(\mathrm{I}_{\mathrm{Kr}}\right)$ and the slow $\left(\mathrm{I}_{\mathrm{Ks}}\right)$ components of the delayed rectifier potassium current are both expressed in the undiseased human cardiac ventricle. $\mathrm{I}_{\mathrm{Kr}}$ activates fast (within $50 \mathrm{~ms}$ ) and deactivates slowly (several seconds) and biexponentially, while, conversely $\mathrm{I}_{\mathrm{Ks}}$ activates slowly $(800-1000 \mathrm{~ms})$ and deactivates rapidly $(\approx 150 \mathrm{~ms})$. Considering these kinetic properties it is concluded that the human cardiac delayed rectifier potassium currents best resemble those measured in the dog ventricle and rabbit heart, but are dissimilar to the kinetic properties of $\mathrm{I}_{\mathrm{Kr}}$ and $\mathrm{I}_{\mathrm{Ks}}$ found in guinea pig. Based also on our studies the $\mathrm{I}_{\mathrm{Kr}}$ current plays the most important role in cardiac repolarization, and our new findings suggest that the dog and the rabbit are suitable species for preclinical evaluation of new drugs believed to affect cardiac repolarisation.

(3) ORM-10103, a newly synthetised NCX selective blocker significantly reduced both the inward and outward NCX currents at submicromolar range. Even at a high concentration $(10 \mu \mathrm{M})$, ORM-10103 did not significantly change the L-type $\mathrm{Ca}^{2+}$ current or the fast inward $\mathrm{Na}^{+}$current. ORM-10103 did not influence $\mathrm{Na}^{+} / \mathrm{K}^{+}$pump and the main $\mathrm{K}^{+}$currents of canine ventricular myocytes except the rapid delayed rectifier $\mathrm{K}^{+}$current, which is slightly diminished by the drug at $3 \mu \mathrm{M}$ concentration. The amplitude of pharmacologically induced early and delayed afterdepolarizations (EAD and DAD) were significantly decreased by ORM-10103 (3 and $10 \mu \mathrm{M})$ in a concentration-dependent manner. In conclusion, our study has furnished evidence of the strong NCX-inhibitory 
activity of ORM-10103 and its potential to suppress elementary arrhythmogenic phenomena, such as EAD and DAD.

\section{REFERENCES}

1 Thireau J, Pasquié JL, Martel E, Le Guennec JY, Richard S (2011). New drugs vs. old concepts A fresh look at antiarrhythmics. Pharmacology \& Therapeutics, 13, 125-145.

2 Vaughan William EM (1984). A classification of antiarrhythmic actions reasessed after a decade of new drugs. J Clin Pharmacol., 24, 129-147.

3 The Sicilian Gambit (1991). A new approach to the classification of antiarrrhythmic drugs based on their actions on arrhytmogenic mechanisms. Task Force of the Working Group on Arrhythmias of the European Society of Cardiology. Circulation, 84, 1831-1851.

4 Singh BN, Vaughan Williams EM (1970). A third class of anti-arrhythmic action. Effects on atrial and ventricular intracellular potentials, and other pharmacological actions on cardiac muscle, of MJ-1999 and AH-3474. Br J Pharmacol., 39, 675-687.

5 Singh BN (1999). Current antiarrhythmic drugs. An overwiew of mechanisms of action and potential clinical utility. J Cardiovasc. Electrophysiol., 10, 283-301.

6 Nattel S, Carlsson L (2006). Innovative approaches to anti-arrhythmic drug therapy. Nat Rev Drug Discov., 5(12), 1034-1049.

7 Nattel S, Duker G, Carlsson L (2008). Model systems for the discovery and development of antiarrhythmic drugs. Prog Biophys Mol Biol., 98(2-3), 328-339.

8 The CAST Investigators (1989): Preliminary report: effect of encainide and flecainide on mortality in randomized trial arrhythmia supression after myocardial infarction. $N$ Engl J Med., 321, 406-412.

9 The CAST II Investigators (1992): Effect of the antiarrhythmic agent moricizine on survival after myocardial infarction. $N$ Engl J Med., 327, 227-233.

10 Waldo AL, Camm AJ, de Ruyter H, et al. for the SWORD Investigators (1996): Effect of dsotalol on mortality in patients with left ventricular dysfunction after recent and remote myocardial infarction. Lancet, 348, 7-12.

11 Litovsky SH, Antzelevitch C (1988). Transient outward current prominent in canine ventricular epicardium but not endocardium. Circ Res., 62, 116-126.

12 Li GR, Dong MQ (2010). Pharmacology of cardiac potassium channels. Adv Pharmacol., 59, 93-134.

13 Sanguinetti MC, Jurkiewicz NK (1990). Two components of cardiac delayed rectifier $\mathrm{K}^{+}$ current. Differential sensitivity to block by class III antiarrhythmic agents. J Gen Physiol., 96, 195-215.

14 Bers DM (2002). Sarcolemmal Na/Ca exchange and Ca-pump. In: Bers DM (ed). Excitationcontraction coupling and cardiac contractile force. Boston: Kluwer Academic Publishers, pp 133-160.

15 Lopatin AN, Makhina EN, Nichols CG (1994). Potassium channel block by cytoplasmic poly amines as the mechanism of intrinsic rectification. Nature, 372: 366-369.

16 Ishihara K, Mitsuiye $\mathrm{T}$, Noma A, Takano M (1989). The $\mathrm{Mg}^{2+}$ block and intrinsic gating underlying inward rectification of the $\mathrm{K}^{+}$current in guinea-pig cardiac myocytes. $J$ Physiol., 419: 297-320.

17 Smith PL, Baukrowitz T, Yellen G (1996). The inward rectification mechanism of the HERG cardiac potassium channel. Nature, 37, 833-836.

18 Rocchetti M, Besana A, Gurrola GB, Possani LD, Zaza A (2001). Ratedependency of delayed rectifier currents during the guinea-pig ventricular action potential. J Physio., 534: 721-732.

19 Shimoni Y, Clark RB, Giles WR (1992). Role of inwardly rectifying potassium current in rabbit ventricular action potential. $J$ Physiol., 448: 709-727. 
20 Maltsev VA, Sabbah HN, Higgins RS, Silverman N, Lesch M, Undrovinas AI (1998). Novel, ultraslow inactivating sodium current in human ventricular cardiomyocytes. Circulation., 98(23): 2545-52.

21 Kim J, Ghosh S, Liu H, Tateyama M, Kass RS, Pitt GS (2004). Calmodulin mediates $\mathrm{Ca}^{2+}$ sensitivity of sodium channels. $J$ Biol Chem., 279(43): 45004-12.

22 Wagner S, Maier LS. Modulation of cardiac $\mathrm{Na}\left({ }^{+}\right)$and $\left.\mathrm{Ca}^{(2+}\right)$ currents by $\mathrm{CaM}$ and CaMKII (2006). J Cardiovasc Electrophysiol., 17 Suppl 1: S26-S33.

23 Whalley DW, Wendt DJ, Grant AO (1995). Basic concepts in cellular cardiac electrophysio logy: part I: ion channels, membrane currents and action potential. PACE, 18, 1556-1574.

24 Varró A, Papp JGy (1992). The impact of single cell voltage clamp on the understanding of the cardiac ventricular action potential. Cardioscience, 3, 131-144.

25 Barry DM, Nerbonne JM (1996). Myocardial potassium channels: electrophysiological and molecular diversity. Annu Rev Physiol., 58, 363-394.

26 Noble D, Tsien RW (1969). Outward membrane currents activated in the plateau range of potentials in cardiac Purkinje fibres. $J$ Physiol., 200, 205-231.

27 Varró A, Lathrop DA, Hester SB, Nánási PP, Papp JG (1993). Ionic currents and action potentials in rabbit, rat and guinea pig ventricular myocytes. Basic Res Cardiol, 88, 93-102.

28 Gintant GA (1995). Regional differences in $I_{K}$ density in canine left ventricle: role of $I_{K, s}$ in electrical heterogeneity. Am J Physiol., 268, H605-H613.

29 Liu DW, Antzelevitch C (1995). Characteristics of the delayed rectifier current $\left(\mathrm{I}_{\mathrm{Kr}}\right.$ and $\left.\mathrm{I}_{\mathrm{Ks}}\right)$ in canine ventricular epicardial, midmyocardial and endocardial myocytes. A weaker $\mathrm{I}_{\mathrm{Ks}}$ contributes to the longer action potential of the M cell. Circ Res., 76, 351-365.

30 Sanguinetti MC, Jurkiewicz NK (1990). Two components of cardiac delayed rectifier $\mathrm{K}^{+}$ current. Differential sensitivity to block by class III antiarrhythmic agents. J Gen Physiol., 96, 195-215.

31 Gintant GA (1996). Two components of delayed rectifier current in canine atrium and ventricle. Does $\mathrm{I}_{\mathrm{Ks}}$ play a role in the reverse rate dependence of Class III agents? Circ Res., 78,26-37.

32 Carmeliet E (1992). Voltage and time-dependent block of the delayed $\mathrm{K}^{+}$current in cardiac myocytes by dofetilide. J Pharmacol Exp Ther., 262, 809-817.

33 Follmer CH, Lodge NJ, Cullinan CA, Colatsky TJ (1992). Modulation of the delayed rectifier $\mathrm{I}_{\mathrm{K}}$ by cadmium in cat ventricular myocytes. Am J Physiol., 262, C75-C83.

34 Bennett PB, McKinney LC, Kass RS, Begenisich T (1985). Delayed rectification in the calf Purkinje fiber. Evidence for multiple state kinetics. Biophys J., 48, 553-567.

35 Apkon J, Nerbonne JM (1991). Characterization of two distinct depolarization-acvtivated K ${ }^{+}$ currents in isolated adult rat ventricular myocytes. J Gen Physiol., 97, 973-1011.

36 Sanguinetti MC, Keating MT (1997). Role of delayed rectifier potassium channels in cardiac repolarisation and arrhythmias. News Phys Sci., 12, 152-158.

37 Singh BN (1998). Antiarrhythmic drugs: a reorientation in light of recent developments in the control of disorders of rhythm. Am J Cardiol., 81, 3D-13D.

38 Hohnloser SH, Woosley RL (1994). Sotalol. N Engl J Med., 331, 31-38.

39 Singh BN, Vaughan Williams EM (1970). A third class of anti-arrhythmic action. Effects on atrial and ventricular intracellular potentials, and other pharmacological actions on cardiac muscle, of MJ-1999 and AH-3474. Br J Pharmacol., 39, 675-687.

40 Jurkiewicz NK, Sanguinetti MC (1993). Rate-dependent prolongation of cardiac action poten tials by a methanesulfonanilide class III antiarrhythmic agent. Specific block of rapidly activating delayed rectifier $\mathrm{K}^{+}$current by dofetilide. Circ Res., 71, 75-83.

41 Surawicz B (1989). Electrophysiologic substrate of Torsade de Pointes: Dispersion of repola risation or early afterdepolarisation? J Am Coll Cardiol., 14, 172-184.

42 El-Sherif N (1992). The proarrhythmic mechanism of drugs that prolong repolarisation. Role of early afterdepolarisation. New Trends in Arrhythmias, 8, 617-626.

43 Hondeghem LM, Snyders DJ (1990). Class III antiarrhythmic agents have a lot of potential but a long way to go. Reduced effectiveness and dangers of reverse use dependence. Circulation, $81,686-690$. 
44 Salata JJ, Jurkiewicz NK, Jow B, Folander K, Guinosso PJ, Raynor B, Swanson R, Fermini B (1996). $\mathrm{I}_{\mathrm{K}}$ of rabbit ventricle is composed of two currents: evidence for $\mathrm{I}_{\mathrm{Ks}}$. Am J Physiol., 271, H2477-H2489.

45 Varró A, B. Baláti, N. Iost, J. Takács, L. Virág, D. A. Lathrop, C. Lengyel, L. Tálosi, J. Gy. Papp (2000). The role of the delayed rectifier component $\mathrm{I}_{\mathrm{Ks}}$ in dog ventricular muscle and Purkinje fibre repolarization. Journal of Physiology (London), 523, 67-81.

46 Virág L, N Iost, M Opincariu, J Szolnoky, J Szécsi, G Bogáts, P Szenohradszky, A Varró, JGy Papp (2001). The slow component of the delayed rectifier potassium current in undiseased human ventricular myocytes. Cardiovasc. Res., 49, 790-797.

47 Roden DM, Lazzara R, Rosen M, Schwartz PJ, Towbin J, Vincent GM (1996), for the SADS Foundation Task Force on LQTS. Multiple mechanisms in the long QT syndrome: current knowledge, gaps, and future directions. Circulation, 94, $1996-2012$.

48 Jost N, Virág L, Bitay M, Takács J, Lengyel Cs, Biliczki P, Nagy ZA, Bogáts G, Lathrop DA, Papp JGy, Varró A (2005). Restricting excessive cardiac action potential and QT prolongation: a vital role for $\mathrm{I}_{\mathrm{Ks}}$ in human ventricular muscle. Circulation, 112, 1392-1399.

49 Salata JJ, Jurkiewicz NK, Wang J, Evans BE, Orme HT, Sanguinetti MC (1998). A novel benzodiazepine that activates cardiac slow delayed rectifier $\mathrm{K}^{+}$currents. Mol Pharmacol., 54, 220-230.

50 Xu X, Salata JJ, Wang J, Wu Y, Yan GX, Liu T, Marinchak RA, Kowey PR (2002). Increasing $\mathrm{I}_{\mathrm{Ks}}$ corrects abnormal repolarization in rabbit models of acquired LQT2 and ventricular hypertrophy. Am J Physiol., 283, H664-H670.

51 Seebohm G, Pusch M, Chen J, Sanguinetti MC (2003). Pharmacological activation of normal and arrhythmia-associated mutant KCNQ1 potassium channels. Circ Res., 93, 941-947.

52 Magyar J, Horváth B, Bányász T, Szentandrássy N, Birinyi P, Varró A, Szakonyi Z, Fülöp F, Nánási PP (2006). L-364,373 fails to activate the slow delayed rectifier $\mathrm{K}\left({ }^{+}\right)$current in canine ventricular cardiomyocytes. Naunyn Schmiedebergs Arch Pharmacol., 373, 85-90.

53 Nissen JD, Diness JG, Diness TG, Hansen RS, Grunnet M, Jespersen T (2009). Pharmacolo gically induced long QT type 2 can be rescued by activation of $\mathrm{I}_{\mathrm{Ks}}$ with benzodiazepine R-L3 in isolated guinea pig cardiomyocytes. J Cardiovasc Pharmacol., 54, 169-777.

54 Dibb KM, Graham HK, Venetucci LA, Eisner DA, Trafford AW (2007). Analysis of cellular calcium fluxes in cardiac muscle to understand calcium homeostasis in the heart. Cell Calcium, 42(4-5), 503-512.

55 Dibb KM, Eisner DA, Trafford AW (2007). Regulation of systolic $\left[\mathrm{Ca}^{2+}\right]$ i and cellular $\mathrm{Ca}^{2+}$ flux balance in rat ventricular myocytes by SR $\mathrm{Ca}^{2+}$, L-type $\mathrm{Ca}^{2+}$ current and diastolic $\left[\mathrm{Ca}^{2+}\right]_{\mathrm{i}} . J$ Physiol., 585(Pt 2), 579-92.

56 Alexander SPH, Mathie A, Peters JA (2011). Guide to Receptors and Channels (GRAC), 5th Edition. Br J Pharmacol., 164 (Suppl. 1), S1-S324.

57 Bers DM (2000). Calcium fluxes involved in control of cardiac myocyte contraction. Circ Res., 87: $275-281$.

58 Bers DM (2002). Cardiac excitation-contraction coupling. Nature, 415: 198-205.

59 Venetucci LA, Trafford AW, O'Neill SC, Eisner DA (2007). Na/Ca exchange: regulator of intra cellular calcium and source of arrhythmias in the heart. Ann N Y Acad Sci., 1099:315-325.

60 Hardman JG, Limbird LE, Molinoff PB, Ruddon RW (1996). In Goodman \& Gilman's The Pharmacological Basis of Therapeutics, Roden DM: Antiarrhythmic drugs, Chapter 35, 839871.

61 Volders PGA, Vos MA, Szabo B, Sipido KR, Marieke DE, Groot SH, Gorgels APM, Wellens HJJ, Lazzara R (2000). Progress in the understanding of cardiac early afterdepolarizations and torsades de pointes: time to revise current concepts. Cardiovasc Res., 46, 376-392.

62 Pogwizd SM, Schlotthauer K, Li L, Yuan W, Bers DM (2001). Arrhythmogenesis and con tractile dysfunction in heart failure. Roles of sodium-calcium exchange, inward rectifier potassium current, and residual-adrenergic responsiveness. Circ Res., 88, 1159-1167.

63 Pogwizd SM, Bers DM (2002). Calcium cycling in heart failure: the arrhythmia connection. $J$ Cardiovasc Electrophysiol., 13, 88-91. 
64 Pogwizd SM (2003). Clinical potential of sodium-calcium exchanger inhibitors as antiarrhyth mic agents. Drugs, 63, 439-452.

65 Elias CL, Lukas A, Shurraw S, Scott J, Omelchenko A, Gross GJ, Hnatowich M, Hryshko LV (2001). Inhibition of $\mathrm{Na}^{+} / \mathrm{Ca}^{2+}$ exchange by KB-R7943: transport mode selectivity and antiarrhythmic consequences. Am J Physiol., Heart Circ Physiol., 281, H1334-H1345.

66 Nagy A, Virág L, Tóth A, Biliczki P, Acsai K, Bányász T, Nánási PP, Papp JGy, Varró A (2004). Selective inhibition of sodium-calcium exchanger by SEA-0400 decreases early and delayed afterdepolarization in canine heart. Br J Pharmacol., 143, 827-831.

67 Roden DM (1998). Taking the "idio" out of "idiosyncratic": predicting torsades de pointes. Pacing Clin Electrophysiol., 21(5), 1029-34.

68 Biliczki P, Virag L, Iost N, Papp JG, Varro A (2002). Interaction of different potassium channels in cardiac repolarization in dog ventricular preparations: role of repolarization reserve. Br J Pharmacol., 137(3), 361-368.

69 Banyasz T, Magyar J, Szentandrassy N, Horvath B, Birinyi P, Szentmiklosi J, et al (2007). Action potential clamp fingerprints of $\mathrm{K}+$ currents in canine cardiomyocytes: their role in ventricular repolarization. Acta Physiol (Oxf)., 190(3), 189-198.

70 Mazzanti M, DiFrancesco D (1989). Intracellular Ca modulates K-inward rectification in car diac myocytes. Pflugers Arch., 413, 322-324.

71 Nagy N, Acsai K, Kormos A, Sebők Z, Farkas AS, Jost N, Nánási PP, Papp JGy, Varró A, Tóth A. (2013). [Ca2+]i-induced augmentation of the inward rectifier potassium current (IK1) in canine and human ventricular myocardium. Pflügers Archiv Eur J Physiol, epub.

72 Lengyel C, Iost N, Virág L, Lathrop AD, Varró A, Papp JG (2001). Pharmacological block of the slow component of the outward delayed rectifier current $(\mathrm{I}(\mathrm{Ks})$ ) fails to lengthen rabbit ventricular muscle QT(c) and action potential duration. Br J Pharmacol., 132(1), 101-110.

73 Bosch RF, Gaspo R, Busch AE, Lang HJ, Li GR, Nattel S (1998). Effects of the chromanol $293 \mathrm{~B}$, a selective blocker of the slow component of the delayed rectifier $\mathrm{K}^{+}$current on repolarisation in human and guinea pig ventricular myocytes. Cardiovasc Res., 38:441-450.

74 Gerlach U: $\mathrm{I}_{\mathrm{Ks}}$ channel blockers: potential antiarrhythmic agents (2001). Drug Future, 26, 473 484.

75 Hobai IA, Khananshvili D, Levi AJ (1997). The peptide "FRCRCFa", dialysed intracellularly, inhibits the $\mathrm{Na} / \mathrm{Ca}$ exchange in rabbit ventricular myocytes with high affinity. Pflugers Arch 433: 455-463.

76 Evans BE, Rittle KE, Bock MG, DiPardo RM, Freidinger RM, Whitter WL, Gould NP, Lundell GF, Homnick CF, Veber DF, Anderson PS, Chang RSL, Lotti VJ, Cerino DJ, Chen TJ, King PJ, Kunkel KA, Springer JP, Hirshfieldt J (1987). Design of nonpeptidal ligands for a peptide receptor: cholecystokinin antagonists. J Med Chem., 30, 1229-1239.

77 Jost N, Virág L, Hála O, Varró A, Thormählen D, Papp JGy (2004). Effect of the antifibrillatory compound tedisamil (KC-8857) on transmembrane currents in mammalian ventricular myocytes. Current Medicinal Chemistry, 11, 3219-3228.

78 Barhanin J, Lesage F, Guillemare E, Fink M, Lazdunski M, Romey G (1996). K(V)LQT1 and IsK (minK) proteins associate to form the $\mathrm{I}_{\mathrm{Ks}}$ ) cardiac potassium current. Nature, 384:78-80.

79 Volders PG, Stengl M, van Opstal JM, Gerlach U, Spatjens RL, Beekman JD, Sipido KR, Vos MA (2003). Probing the contribution of $\mathrm{I}_{\mathrm{Ks}}$ to canine ventricular repolarization: key role for beta-adrenergic receptor stimulation. Circulation, 107, 2753-2760.

80 Easson LH, Stedman E (1933). CLXX. Studies on the relationship between chemical consti tution and physiological action. V. Molecular dissymmetry and physiological activity. Biochem. J., 27, 1257-1266.

81 González E, Ledesma de Paolo MI, Celener D, Celener FP, Rosembeck G, Panzitta MT, Bustos Fernández L (1993). The effect of different lactic acid isomers in the colon of rats. Acta Gastroenterol Latinoam., 23, 203-210.

82 Zittoun J, Marquet J, Pilorget JJ, Tonetti C, De Gialluly E (1991). Comparative effect of 6S, 6R and 6RS leucovorin on methotrexate rescue and on modulation of 5-fluorouracil. $\mathrm{Br} J$ Cancer., $63,885-888$. 
83 Caillet C, Chauvelot-Moachon L, Montastruc JL, Bagheri H; French Association of Regional Pharmacovigilance Centers (2012). Safety profile of enantiomers vs. racemic mixtures: it's the same? Br J Clin Pharmacol., 74, 886-889.

84 Hof RP, Rüegg UT, Hof A, Vogel A (1985). Stereoselectivity at the calcium channel: opposite action of the enantiomers of a 1,4-dihydropyridine. J Cardiovasc Pharmacol., 7, 689-693.

85 Beuckelmann DJ, Näbauer M, Erdmann E (1993). Alteration of $\mathrm{K}^{+}$currents in isolated human ventricular myocytes from patients with terminal heart failure. Circ Res., 73, 379-385.

86 Varró A, Lathrop DA, Papp JG (2001). Role of the delayed rectifier component $\mathrm{I}_{\mathrm{Ks}}$ in cardiac repolarization. J Cardiovasc Electrophysiol., 12, 1204-1205,

87 Morissette P, Hreiche R, Turgeon J (2005). Drug-induced long QT syndrome and torsade de pointes. Can J Cardiol., 21(10): 857-864.

88 Elias CL, Lukas A, Shurraw S, Scott J, Omelchenko A, Gross GJ, Hnatowich M, Hryshko LV (2001). Inhibition of $\mathrm{Na}^{+} / \mathrm{Ca}^{2+}$ exchange by KB-R7943: transport mode selectivity and antiarrhythmic consequences. Am J Physiol, Heart Circ Physiol., 281: H1334-H1345.

89 Tanaka H, Nishimaru K, Aikawa T, Hirayama W, Tanaka Y, Shigenobu K (2002). Effect of SEA0400, a novel inhibitor of sodium-calcium exchanger, on myocardial ionic currents. $\mathrm{Br} J$ Pharmacol., 135: 1096-1100.

90 Birinyi P, Acsai K, Banyasz T, Toth A, Horvath B, Virag L, Szentandrassy N, Magyar J, Varro A, Fulop F, Nanasi PP (2005). Effects of SEA-0400 and KB-R7943 on $\mathrm{Na}^{+} / \mathrm{Ca}^{2+}$ exchange current and L-type $\mathrm{Ca}^{2+}$ current in canine ventricular cardiomyocytes. Naunyn Schmiedebergs Arch Pharmacol., 372: 63-70.

91 Chen YJ, Chen SA, Chang MS, Lin CI (2000). Arrhythmogenic activity of cardiac muscle in pulmonary veins of the dog: implication for the genesis of atrial fibrillation. Cardiovasc Res., 48: 265-273.

92 Van Wagoner DR, Nerbonne JM (2000). Molecular basis of electrical remodeling in atrial fibrillation. J Mol Cell Cardiol., 32: 1101-1117.

93 Yue L, Feng J, Gaspo R, Li GR, Wang Z, Nattel S (1997). Ionic remodeling underlying action potential changes in a canine model of atrial fibrillation. Circ Res., 81: 512-525.

94 Studer R, Reinecke H, Bilger J, Eschenhangen T, Bohm M, Hasenfuss G, Just H, Holtz J, Drexler H (1994). Gene expression of the cardiac $\mathrm{Na}^{+}-\mathrm{Ca}^{2+}$ exchanger in end-stage human heart failure. Circ Res., 75: 443-453.

95 Levi A, Brooksby P, Hancox JC (1993). One hump or two? The triggering of calcium release from the sarcoplasmic reticulum and the voltage dependence of contraction in mammalian cardiac muscle. Cardiovasc Res., 27: 1743-1757. 


\section{ACKNOWLEDGEMENTS}

I am very grateful to Professor Julius Gy. Papp MD, DSc, academian, for his continuous support, his kindness and critical reading of my manuscripts, his inspirational comments and constructive criticism were always of help and are greatly appreciated, and to Professor András Varró MD, DSc for providing me the opportunity for research as $\mathrm{PhD}$ student at the Department of Pharmacology and Pharmacotherapy, University of Szeged and the helpful discussions were exceptionally useful during my work.

I am especially thankful to my $\mathrm{PhD}$ supervisor Dr. Norbert Jost, for personal guidance and for introducing me to the fascinating world of cardiac cellular electrophysiology. I always enjoyed his optimistic attitude to the scientific problems. Without his continuous support, never-failing interest and eagerness to discuss new ideas, plans and findings throughout these years, this $\mathrm{PhD}$ study could have hardly come to an end.

I am indebted to Professor Ferenc Fülöp and his colleagues for the synthesis of the R-L3 enantiomers.

Zsófia Kohajda is sincerely thanked for excellent collaboration during the years, for the many hours of splendid discussions and helpful scientific lessons.

I wish to thank my senior colleague, Dr. László Virág and my $\mathrm{PhD}$ student colleagues Attila Kristóf, András Horváth and Amir Geramipour for their continuous support and help in my work, for creating a cheerful and social milieu in the laboratory, and to Mrs. Zsuzsanna Molnár and Mr. Gábor Girst for their helpful technical assistance. Dr. Károly Acsai is also gratefully acknowledged for inspiring discussions and lots of excellent advices.

I also wish to thank Dr. Attila Kun, my grandfather (Ferenc Mayer) and to my parents (Rita and Toma), to Whom I want to dedicate this thesis, for their endless love, trust and support.

I am also thankful to my dear friends for their support and encouragement.

This work was supported by grants from the Hungarian Scientific Research Fund (OTKA K-82079 and NK-104331), the National Innovation Office - Baross Programmes (REG-DA-09-2-2009-0115-NCXINHIB), the National Development Agency and cofinanced by the European Regional Fund (TÁMOP-4.2.2/B-10/1-2010-0012; TÁMOP4.2.2A-11/1/KONV-2012-0073), HU-RO Cross-Border Cooperation Programmes (HURO/1001/086/2.2.1_HURO-TWIN) and the Hungarian Academy of Sciences. 
8. ANNEX

Publications related to the subject of the Thesis 